\title{
Differentiated Integration in the European Union
}

\section{Doctoral Thesis}

Author(s):

Schäubli, Thomas

Publication date:

2016

Permanent link:

https://doi.org/10.3929/ethz-a-010654132

Rights / license:

In Copyright - Non-Commercial Use Permitted 


\title{
Differentiated Integration in the European Union
}

\author{
A thesis submitted to attain the degree of \\ DOCTOR OF SCIENCES of ETH ZURICH \\ (Dr. sc. ETH Zurich)
}

\author{
presented by \\ THOMAS SCHÄUBLI \\ lic. phil. University of Zurich \\ born on 16.09.1983 \\ citizen of Bassersdorf / ZH
}

accepted on the recommendation of

Prof. Dr. Frank Schimmelfennig (ETH Zurich), examiner Prof. Dr. Katharina Holzinger (University of Konstanz), co-examiner

Prof. Dr. Berthold Rittberger (LMU Munich), co-examiner 
To my parents

and to Dheden,

for their unconditional support. 


\section{Summary}

The European Union (EU) is usually conceptualized in terms of unity, which suggests that its Member States and non-Member States can clearly be distinguished by their adoption of the EU's acquis communautaire. And yet, some of the EU's rules and policies only apply to a subset of Member States; some apply beyond the EU; while others do not apply to some Member States, but to some non-Member States. All of these cases are cases of differentiated integration (DI). In the existing literature, DI is said to be increasing over time due to the increasing width and depth of the EU and not to be explained with the existing theoretical toolset on European integration. And yet, we have little empirical knowledge about the extent and development of DI in EU primary and secondary law and face a literature that is ripe with conceptualizations, but contains little cumulative theorizing and even less positive hypothesis testing. In this thesis, I introduce the first comprehensive dataset on the topic, support the transfer of theorizing on DI into the realms of the grand theories of European integration and conduct a number of empirical analyses on the topic. I find that although the common narrative on the development of DI is not unequivocally wrong, it is certainly an oversimplification, and that liberal intergovernmentalism does a good job in capturing the phenomenon.

\section{Zusammenfassung}

Die Europäische Union (EU) wird üblicherweise als Einheit verstanden, deren Mitgliedsländer sich von Nicht-Mitgliedsländern dadurch unterscheiden, dass sie den acquis communautaire der EU übernommen haben. Doch viele EU-Regeln gelten nicht für alle Mitgliedsländer, während einige auch über die EU hinaus gelten. Diese Beispiele können als differenzierte Integration bezeichnet werden. Das Ausmass und die Entwicklung dieser differenzierten Integration ist weitestgehend unbekannt. Die entsprechende Literatur setzt sich aus einer Vielzahl von Konzepten, nur wenigen theoretischen Ansätzen und noch weniger empirischen Hypothesentests zusammen. Trotzdem suggeriert die bestehende Literatur, dass die differenzierte Integration aufgrund der zunehmenden Tiefe und Weite der EU über die Jahre zugenommen habe und dass nur ein synthetischer Theorierahmen dem Phänomen gerecht werden könne. In dieser Arbeit präsentiere ich den ersten umfassenden Datensatz zum Thema, bringe die Argumente zum Thema differenzierte Integration mit den wichtigsten Theorien der europäischen Integration in Verbindung und nehme eine Reihe von empirischen Analysen vor. Dabei komme ich zum Schluss, dass das Argument eines generellen Anstiegs der Differenzierung zwar nicht grundsätzlich falsch, aber doch stark verkürzt ist. Ich komme ausserdem zum Schluss, dass der Liberale Intergouvernementalismus zwar nicht das gesamte Phänomen der differenzierten Integration zu erklären vermag, aber doch einen ausgezeichneten Startpunkt dazu liefert. 


\section{Contents}

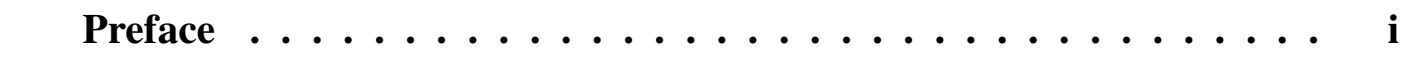

1 Differentiated Integration in the European Union $\ldots \ldots \ldots \ldots$

$1.1 \quad$ Extent and Development of DI . . . . . . . . . . . . . 3

1.2 Concepts of DI $\ldots \ldots \ldots \ldots \ldots$

1.3 Theories and Hypotheses . . . . . . . . . . . . . . . . . 21

1.4 Outlook . . . . . . . . . . . . . . . . . . . 32

2 Preference Heterogeneity and EU Primary Law Differentiation . . . . 37

$2.1 \quad$ DI in EU Primary Law $\ldots \ldots \ldots$

2.2 Preferences and Heterogeneity $\ldots \ldots \ldots$

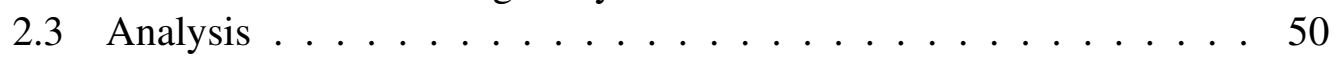

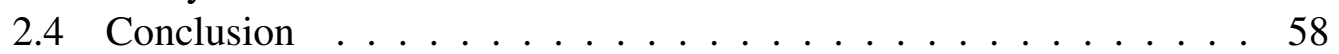

3 Delegation and EU Secondary Law Differentiation . . . . . . . 63

3.1 DI in EU Secondary Law $\ldots \ldots \ldots$

3.2 Theories and Hypotheses $\quad \ldots \ldots \ldots$

3.3 Analysis $\ldots \ldots \ldots \ldots \ldots \ldots \ldots \ldots$

3.4 Conclusion $\ldots \ldots \ldots \ldots \ldots \ldots \ldots \ldots \ldots \ldots$

4 Differentiation in EU Monetary Policy . . . . . . . . . . . . . 85

4.1 DI in EU Monetary Policy $\ldots \ldots \ldots \ldots$

4.2 Explaining DI in EU Monetary Policy . . . . . . . . . . . . . 93

4.3 Analysis . . . . . . . . . . . . . . . . . . . . . . . . 97

4.4 Conclusion $\ldots \ldots \ldots \ldots \ldots$

Conclusion $\ldots \ldots \ldots \ldots \ldots \ldots \ldots$

Bibliography $\ldots \ldots \ldots \ldots \ldots \ldots \ldots \ldots \ldots$ 


\section{List of Tables}

1.1 Sources of EU primary law . . . . . . . . . . . . . 5

1.2 Schematic representation of the EUDIFF dataset . . . . . . . . . 8

2.1 Differentiation opportunities in EU primary law . . . . . . . . . . 51

2.2 Logit models of probability that country realizes DI . . . . . . . . . 55

2.3 Logit models of probability that country realizes DI . . . . . . . . 59

3.1 Coding of policy areas $\ldots \ldots \ldots 6$

3.2 Development of DI over policy areas . . . . . . . . . . . . . . 69

3.3 Coding of legislative procedures . . . . . . . . . . . . 76

3.4 Descriptive statistics . . . . . . . . . . . . . . . . . . 76

3.5 Development of supranationality over policy areas and decades . . . 77

$3.6 \quad$ Development of saliency over policy areas and decades . . . . . . . 78

3.7 Results of linear regression analysis $\ldots \ldots$. . . . . . . . . . 80

3.8 Results of linear regression analysis, individual policy areas . . . . . 81

$4.1 \quad$ Logit models of probability that country realizes DI . . . . . . . . 103 


\section{List of Figures}

$1.1 \quad$ Extent and development of DI . . . . . . . . . . . . . . 10

1.2 DI in EU primary law . . . . . . . . . . . . . . . . . . . . . . . . 11

1.3 DI in EU secondary law . . . . . . . . . . . . . . . . . 13

2.1 Development of DI in EU primary law . . . . . . . . . . . . . . 42

2.2 Descriptive bivariate relationships, identity and wealth . . . . . . 54

2.3 Effects of national identity and wealth on DI . . . . . . . . . . . 56

$2.4 \quad$ Descriptive bivariate relationships, EU membership . . . . . . . . . 57

$3.1 \quad$ Development of DI in EU secondary law . . . . . . . . . . . . . . 68

3.2 Descriptive bivariate relationships $\ldots . . \ldots 79$

4.1 Development of DI in EU monetary policy . . . . . . . . . . . . . . 92

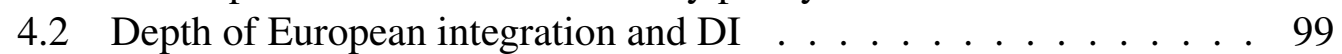

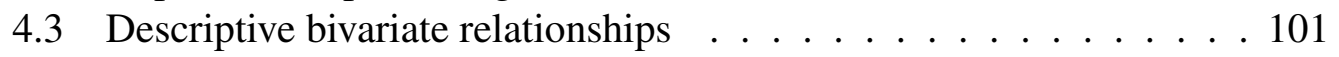

4.4 Effects of inflation rates and euroscepticism on DI . . . . . . . . . . 105 



\section{Preface}

I am grateful to have had the opportunity to write this dissertation. I would like to thank the amazing people at ETH, especially my colleagues at the European Politics Research Group, whose collegiality has carried me through the experience and whose savviness has challenged me throughout. I am particularly thankful to Frank Schimmelfennig, my supervisor, who has always been responsive, insightful and supportive. I also enjoyed working with my co-supervisor, Katharina Holzinger, from the University of Konstanz, whose understanding of the European Union is unsurpassed to my knowledge. I am thankful to Berthold Rittberger, from the LMU Munich, that he agreed to act as an external examiner. Not least, my project was funded by the Swiss National Science Foundation as well as the German Research Foundation, to which I am grateful.

I hope that anyone who commented on one of my conference contributions or research papers finds his or her insightfulness reflected in this document. I also hope that he or she may forgive me all remaining errors, for they are entirely my own. Finally, I would like to thank my friends and family. Without their helpful comments and warm support, this thesis would not have been possible.

This thesis contains material from the following sources:

- Chapter 1 is based on the PhD proposal that I presented to the CIS staff in spring 2011 and that was reviewed by Prof. Dr. Frank Schimmelfennig (ETH Zurich), Prof. Dr. Lars-Erik Cederman (ETH Zurich) and Prof. Dr. Dieter Ruloff (University of Zurich).

- Chapter 2 is based on a conference paper that I wrote with Thomas Winzen (ETH Zurich), Heterogeneity and Differentiated Integration in the European Union, that we presented at the Conference on Differentiated Integration at the Europa Universität Viadrina (Frankfurt/Oder) in December 2011. 
- Chapter 3 is based on a paper that I co-authored with Thomas Duttle, Katharina Holzinger, Frank Schimmelfennig and Thomas Winzen, The Dynamics of Secondary-Law Differentiation in the European Union, that we presented at the EPSA Annual General Conference in June 2013.

- Chapter 4 is based on a paper titled Monetary Policy Autonomy in Europe that I presented at the UACES Conference on Contemporary European Studies in September 2012; the Annual Meeting of the European Political Science Association in June 2012; and the Annual Meeting of the Swiss Political Science Association in February 2012. 


\section{Chapter 1}

\section{Differentiated Integration in the European Union}

The European Union (EU) is usually conceptualized in terms of unity. In this perspective, the acquis communautaire defines the substantive scope of the EU, whereas the adoption of this body of law allows to distinguish between EU Member States and non-Member States. And yet, some rules and policies of the EU apply to only a subset of Member States; some rules and policies have been adopted by non-Member States; while others again do not apply in some Member States, but in some non-Member States. All of these cases, in which the territorial extension of EU membership and EU rule validity are incongruent, are cases of differentiated integration (Holzinger/Schimmelfennig 2012, 292).

Differentiated integration (DI) has been the subject of political debate already. In the 1970s, then-Belgian Prime Minister Leo Tindemans (1975) brought forward the idea that DI might be a means to advance the European project in that it would allow the EU to reconcile the increasing tensions from both the enlargement of the EU (widening) as well as the extension of its scope (deepening). The topic got further attention no later than with the Treaty of Maastricht (1992), where Denmark and the UK decided to opt-out from the third stage of the Economic and Monetary Union (EMU) and were later joined by Sweden in their abstention from the common currency. A number of further differentiations held the debate alive, such as the opt-outs acquired by some acceding Member States from obligations with the free movement of persons or the acquis on competition. And not least, both the Treaty of Amsterdam (1997) and the Treaty of Nice (2002) introduced articles for 
closer cooperation (Amsterdam) or enhanced cooperation (Nice), respectively, thus further anchoring the concept of DI in the political debate surrounding European integration.

More recently, DI has even made it into the tabloids. In July 2015, David Cameron, the Prime Minister of the United Kingdom (UK), threatened that the UK would opt-out from a number of EU labor law rules in an effort to appease conservative Members of Parliament that demanded the role of the UK in Europe be changed or the country would leave the EU altogether. ${ }^{1}$ In a similar vein, the discussion about a potential exit of Greece from the eurozone first led to a legalistic debate according to which the idea of a grexit was considered dubious not just for the reason that the EU treaties do not allow for a procedure to exit the eurozone, but also because the euro was considered an obligation for each and every EU Member State. As the abstention of the UK, Denmark and Sweden from the common currency got more prominent, the idea of EU membership without adoption of the euro and thus DI in EU monetary policy became increasingly widespread. With that, DI again made it into the newspapers.

The academic debate on DI lags far behind the political debate on the topic. The existing literature on DI is defined by an abundance of conceptual work, but a scarcity of positive theorizing (Holzinger/Schimmelfennig 2012). It rather uniformly proposes that the traditional approaches to European integration need to be revisited to come up with a more satisfactory analysis of differentiated integration (e.g. de Neve 2007, 515; Stubb 2002, 165; Kölliker 2006, 19). Some scholars even suggest that we ultimately need to come up with a synthetic theoretical framework to fully cope with the phenomenon (e.g. Leuffen et al. 2013, 259-267). And yet, as we will see, only few attempts have been made at systematically testing our existing theoretical toolset. I find that the main approaches to European integration can be convincingly extended to include explanations of DI, especially liberal intergovernmentalism, whose explanatory power is one of the key topics in the remainder of this thesis. Liberal intergovernmentalism, I conjecture, offers a convincing starting point for an explanation of DI.

The empirical literature on DI concentrates on a few case studies in EU primary law such as EMU, Schengen and defense policy (e.g. Risse et al. 1999; McNamara

\footnotetext{
${ }^{1}$ http://www.theguardian.com/politics/2015/jul/11/david-cameron-employment-law-opt-out-eumembership-renegotiation.
} 
1999; König-Archibugi 2004). While this highlights a general lack of systematic empirical analysis in EU primary law differentiation, we must concede an almost complete lack of empirical knowledge about DI in EU secondary law (for an exception, see de Búrca 2000). This is all the more problematic as the actors and procedures in EU primary law and secondary law are very different, allowing for the investigation of not just the role of national preferences and bargaining power, but also the effects of institutionalization and socialization. Interestingly, despite the fact that the extent and development of DI is largely unknown, a common narrative on the topic suggests that the extent of DI has steadily increased over time and in response to the increasing width and depth of European integration (e.g. Schimmelfennig/Winzen 2014, 360).

In the following, I investigate whether or not DI really is constantly on the rise and whether or not the existing approaches to European integration really are unable to cope with the phenomenon. I do so in the substantive parts of my thesis, but also in this introductory chapter. In the next section, I present the first comprehensive dataset on DI, the EUDIFF dataset. I introduce its coding process and offer first descriptive insights into the de-facto development of DI in EU primary and secondary law. I show that the development of DI is, perhaps unsurprisingly, much more complicated than the common narrative suggests. Afterwards, I present the most important normative and descriptive concepts of DI and discuss why it makes sense to understand the EU as a system of differentiation integration. I then present the main theoretical approaches to DI and link them to the grand theories of European integration, namely liberal intergovernmentalism, supranationalism and post-functionalism. I conclude this chapter with an outlook on the substantive chapters of my thesis, in which I investigate the role of preference heterogeneity for DI in EU primary law (chapter 2), the role of delegation for DI in EU secondary law (chapter 3) as well as the extent and development of DI in EU monetary policy (chapter 4).

\subsection{Extent and Development of DI}

Despite the fact that the extent and development of DI is largely unknown, the literature on European integration suggests that DI in EU primary and secondary law is constantly on the rise due to the increasing width and depth of European 
integration (e.g. Schimmelfennig/Winzen 2014, 360). The thesis at hand is situated in a project on DI collaboratively conducted at the ETH Zurich and the University of Konstanz. The project itself started with the idea of creating the first comprehensive dataset on DI in European integration ${ }^{2}$ As this EUDIFF dataset is at the very core of my thesis, I here introduce its coding process and present some first descriptive insights. As we will see, while the common narrative on DI cannot be unequivocally rejected, it must at least be seriously contested.

\section{Definition and sources of DI}

In this thesis, DI is defined as the differential validity of EU legal rules across territories. This definition is broad enough to include differentiation in both EU primary and EU secondary law, but specific enough to exclude a number of further potential meanings of the term. It most importantly neglects any informal cooperation, cooperation on the basis of rules other than EU primary and EU secondary law as well as questions of compliance. Neither does it capture non-total harmonization such as minimum, partial or optional harmonization. Minimum harmonization, for instance, requires all Member States to comply with a minimum standard, but more stringent standards are allowed. This could, of course, result in actual differences across Member States since some might adopt more or less strict domestic rules. It does not result in the differential validity of EU legal rules, however, because the positively stated minimum standards apply to all. Comes to it that the dataset only captures differentiation between EU Member States. These restrictions include no claim about the validity or importance of different perspectives. They rather stem from necessary trade-offs one faces when deciding to study a topic on the basis of a new and comprehensive dataset as well as a genuine interest in DI as implied in the definition in the above.

The aim of the EUDIFF dataset is to assess the degree of differentiation of EU legal rules across EU Member States since the beginning of European integration.

\footnotetext{
${ }^{2}$ When I started working on my thesis, data collection had already started. Ultimately, it would take us from the year 2010 to the early 2015 to finish the EUDIFF dataset. We often found ourselves faced with an intense and sometimes overwhelming effort. Coding involved many coding assistants, to whom I here offer my warmest sympathies. The quality of the dataset was assured through partial double coding and the later double checking of certain parts of the dataset, which involved the work of two distinguished colleagues, Christian Frommelt (Liechtenstein Institute) and Sabine Jenni (ETH Zurich), whom I would like to thank sincerely.
} 


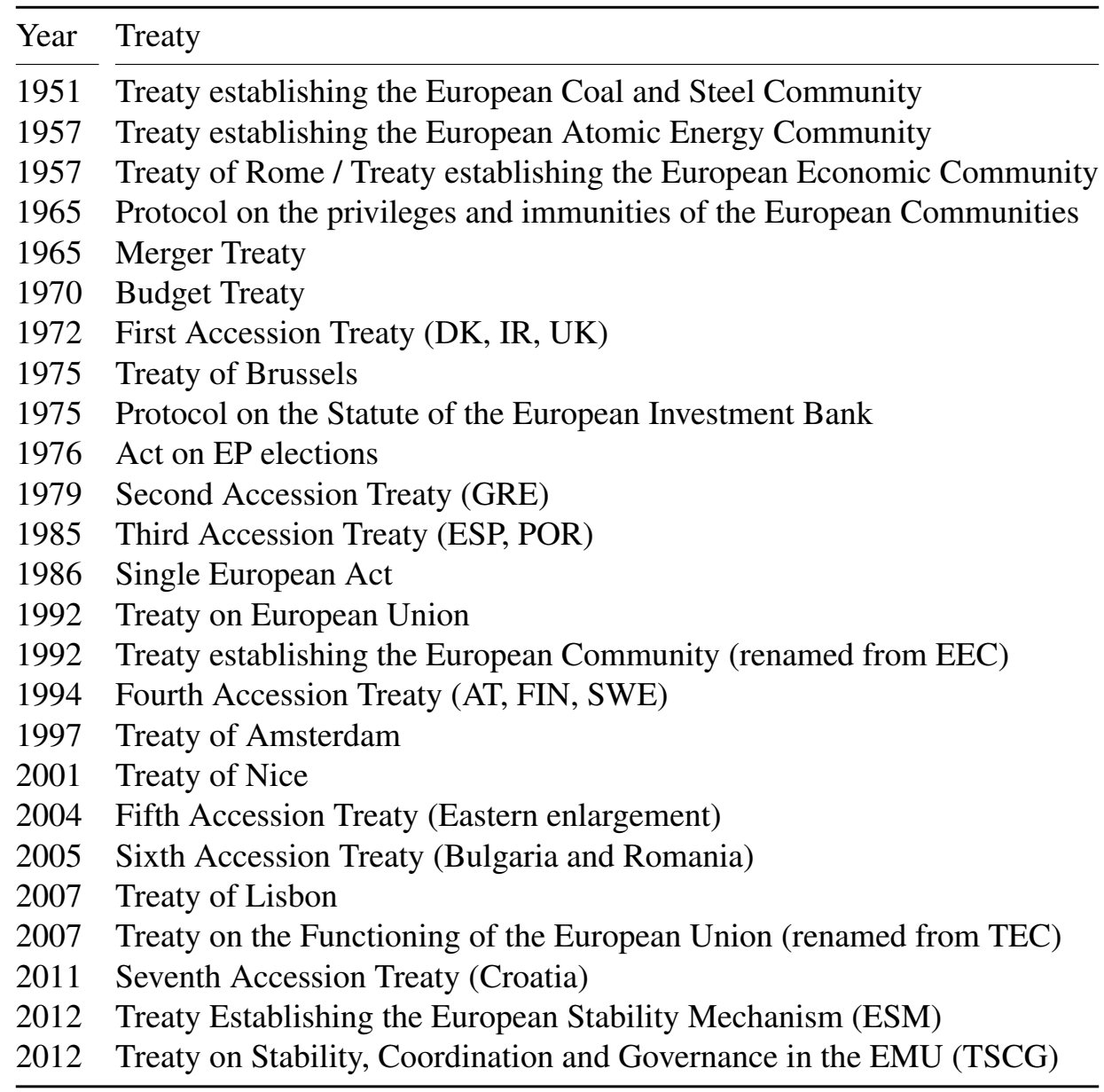

Table 1.1: Sources of EU primary law

Therefore, it identifies for each legal rule whether it is valid for all states (no differentiation) or whether it is valid for some states, but not for others (differentiation). This necessitates, in the very first place, a clear understanding about the definition of such legal rules. A legal rule is thus here defined as a behavioral prescription contained in a legally binding act applicable to the addressee of the act. That said, in legal texts, a rule is difficult to identify reliably because even an individual treaty article can contain many rules with unclear boundaries. The EUDIFF dataset still investigates the individual treaty article in EU primary law, in full knowledge of the fact that legal rules are not necessarily congruent with subdivisions in legal texts, based on the assumption that most treaty articles deal with only one substantive issue and because doing so allows to identify legal rules consistently and (rather) efficiently. In EU secondary law, the legal act is the unit of analysis of the EUDIFF 
dataset. The individual legal act can be considered a relatively coherent unit from which a Member State can either acquire a differentiation or not.

The sources of DI thus differ between EU primary law and secondary law. EU primary law consists of those provisions which are adopted directly by the Member States in their capacity as constituent authority in intergovernmental conferences, meaning in the first place the Community Treaties and the Treaties amending or supplementing them. Together with the general principles of law, these Treaty provisions constitute the constitutional provisions of Community law (Lenaerts/van Nuffel 2005, 705). The general principles of law, however, are by definition nondifferentiating. The relevant population thus consists of all formal sources of EU primary law (the treaties) including the original Community Treaties, amending Treaties, Protocols included in the Treaties, and accession Treaties. Two treaties that deal with particularities regarding the validity of EU rules on territories affiliated to particular Member States but outside the Community, namely Greenland and the Netherlands Antilles, are excluded from the dataset. All said, the sources of DI in EU primary law under consideration in the EUDIFF dataset are reflected in table 1.1

EU secondary law comprises of those acts adopted by the European institutions within the competencies conferred on them by the Treaties. Again the interesting legal acts are only those that are legally binding and, in principle, supposed to be applicable to all Member States. This leaves the following legal acts to be taken into consideration:

- Directives, regulations and decisions by the EU legislators: Directives and regulations are the two standard instruments of legal harmonization in the EU. They are mainly distinguished by the extent to which they require subsequent implementation at the national level in order to become effective. Decisions used to be the standard instrument of legal harmonization in the Third Pillar, i.e. in Justice and Home Affairs (JHA) / Police and Judicial Co-operation in Criminal Matters (PJC), between 1993 and 2009.

- Relevant decisions by the European Commission and the Council: In some cases, directives may allow for differentiation subject to a positive decision by the European Commission. In addition, derogations can be requested by Member States based on Article 95 of the EC Treaty. In the latter case, the 
Commission or, in rare cases, the Council decides on such a request (Hristova 2008). These types of decisions are not coded themselves, but are drawn on to refine the coding of affected legal acts and treaty articles.

\section{Temporal evolution and characteristics of DI}

In order to capture the temporal evolution of DI in EU primary and secondary law, the validity of every relevant legal rule must be assessed in each individual year. Regarding the coding process, this means the following: For point in time 1, a list of all valid legal rules must be created. For each rule, it must then be coded whether it applies to all Member States or is of differential validity. The entire data can then be extended into point in time 2 (the next year), where the necessary additions to and changes of this body of law can now be coded. Additions to the body of law consist of new legal rules, say, new treaty articles or new secondary law legal acts. Various types of changes can occur to the body of law. A number of changes stem from the legal rules themselves. Most commonly, a differentiation may be temporal and thus disappear in a certain year. It is also possible that third legal rules change an original one. Most importantly, a new rule may enter into force that amends an existing rule, potentially altering its characteristics. Then, a new rule may repeal another one, thus leading to its termination. In some instances, legal rules prolong legal acts that previously had a date of termination. Also, legal acts may specify the content of previous rules, thus potentially altering its characteristics. Data must thus be coded chronologically. Table 1.2 shows a schematic representation of the structure of the EUDIFF dataset.

The EUDIFF dataset also contains a number of key characteristics of DI for each legal rule in question (see Tuytschaever 1999). To begin with, the EUDIFF dataset captures to which countries a legal rule applies and to which it does not apply. The dataset also captures the legal basis of a legislative act in both EU primary law and EU secondary law, which allows to ascribe legal acts to policy areas. Further characteristics include the distinction between actual and potential differentiation. Whereas actual differentiation means an article is not valid for certain Member States, potential differentiation means that further action is required to realize the possibility for differentiation. Then, one must distinguish general from specific differentiation. General differentiation applies to all Member States, whereas specific differentiation clearly defines a sub-set of Member States which derogate from 


\begin{tabular}{|c|c|c|c|c|c|}
\hline Year & Rule & DI & Country & Policy Area & Characteristics \\
\hline 1958 & 1 & 0 & & & \\
\hline 1958 & 2 & 1 & & & \\
\hline 1958 & 3 & 0 & & & \\
\hline 1959 & 1 & 0 & & & \\
\hline 1959 & 2 & 1 & & & \\
\hline 1959 & 3 & 0 & & & \\
\hline 1960 & 1 & 0 & & & \\
\hline 1960 & 2 & 1 & & & \\
\hline 1961 & 1 & 0 & & & \\
\hline 1961 & 2 & 0 & & & \\
\hline 1961 & 4 & 1 & & & \\
\hline$\ldots$ & $\ldots$ & $\ldots$ & & & \\
\hline
\end{tabular}

Table 1.2: Schematic representation of the EUDIFF dataset

a given rule. Furthermore, it is worthwhile to look at temporal versus permanent differentiation. Some forms of differentiation may only apply for a fixed period of time, while others are permanent. Permanent forms of differentiation need not last forever, however, for they may be repealed or amended by other legislation. What distinguishes them from temporal differentiations is just that they do not cease to apply automatically. Not least, it is important to capture the procedure a legislative act has been legislated in.

\section{Extent and development of DI}

The common narrative on the development of DI in EU primary and secondary law was formulated despite the fact that the actual extent of DI is largely unknown. The empirical literature on DI in EU primary law usually cites a number of case studies on EMU, Schengen and defense policy (e.g. Risse et al. 1999; McNamara 1999; König-Archibugi 2004), but no systematic, long-term empirical analysis. In EU secondary law, we must concede an almost complete lack of empirical knowledge (for an exception, see de Búrca 2000). To put it differently, the common narrative on the extent and development of DI derives from selective insights and general expectations rather than empirical observation. Here the argument as summarized by Schimmelfennig and Winzen $(2014,360)$ : 
The more countries the EU integrates, the more likely it is to have a membership with heterogeneous preferences and capabilities. The more policy sectors it integrates, the more likely they will include valueladen or redistributive policies that provoke conflict and are difficult to manage or settle. Finally, the more supranationally centralized European integration becomes, the more it reduces state autonomy and the more likely it provokes nationalist backlash. Increased heterogeneity and conflict, in turn, threaten to create deadlock in an organization based to a large extent on intergovernmental consensus - particularly in the case of treaty negotiations that require unanimous agreement. DI then helps to overcome deadlock by allowing the Member States to co-operate at different levels of integration that fit their preferences and capabilities.

Figure 1.1 shows that the common narrative possesses some explanatory power with regard to the extent of DI in EU primary law, but not in EU secondary law. In EU primary law, I here measure the number of actually differentiated (AD) treaty articles as a share of all treaty articles in force in any given year. In EU secondary law, I measure the number of actually differentiated legal acts as a share of all legal acts in force in any given year. As figure 1.1 shows, while the extent of DI in EU secondary law largely eludes the common narrative, the extent of DI in EU primary law indeed increases with the increasing width and depth of the EU. Prior to 1992 , between $1 \%$ to $2 \%$ of all treaty articles have an actual differentiation. As the scope and depth of the EU increases, however, the share of DI does so, too. The relationship between DI, the number of integrated policy areas and the number of EU Member States is certainly far from perfect. Also, we cannot yet tell whether that relationship is systematic and whether it is driven by the extension of the EU's scope or by the extension of its membership. A good case in point is the year 1995, in which the increase in DI might stem from the Schengen Treaty, but could also derive from the 1995 enlargement round. Still, figure 1.1 largely validates the common narrative on the topic with regard to EU primary law.

However, measuring DI at the level of the treaty article is highly problematic, as it is insensitive to the number of countries and policy areas in which differentiations can be acquired and is prone to inflate the extent of DI resulting from a single decision if this decision affects many treaty articles. In the top part of figure 1.2, I thus refer to the definition of DI in EU primary law as refined by Schimmelfennig 

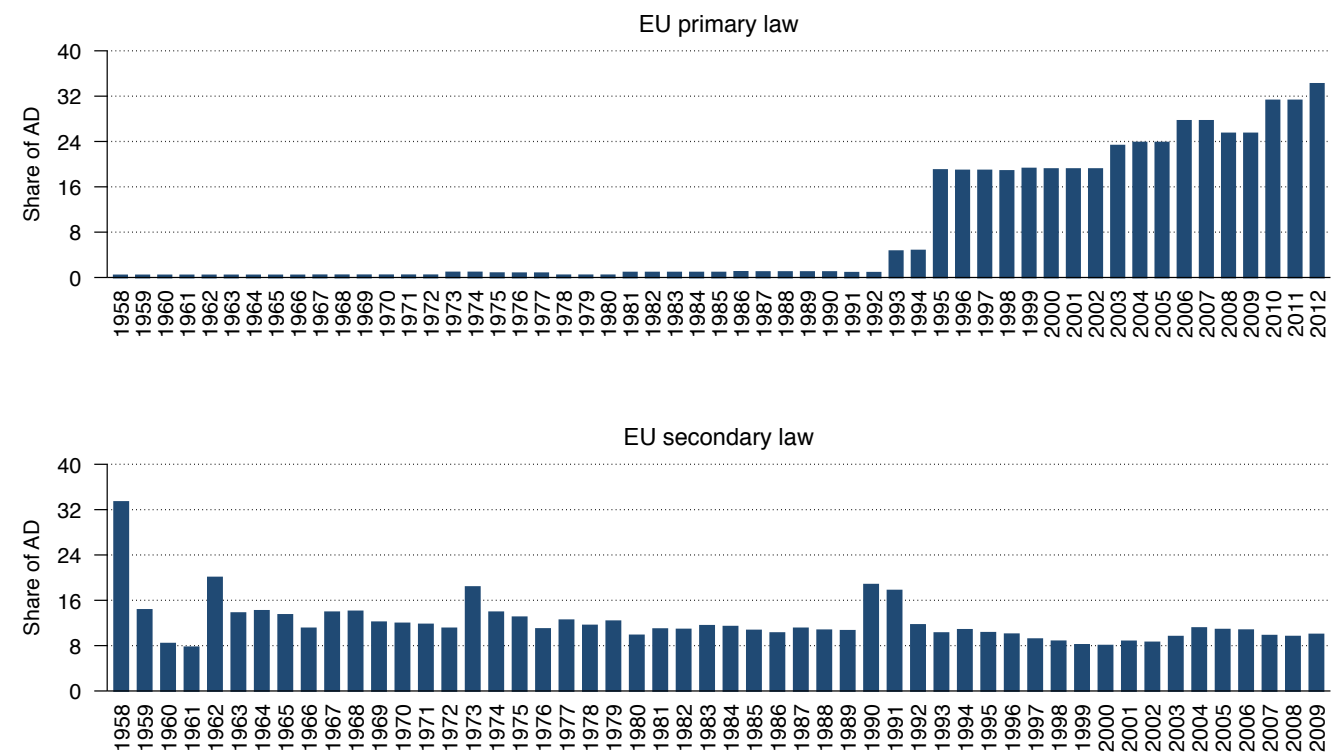

Figure 1.1: Extent and development of DI

and Winzen (2014). I here measure differentiations instead of differentiated treaty articles, whereas a differentiation is constituted by the legal exemption of a Member State from a treaty article and lasts for as long as this exemption is valid uninterruptedly. I furthermore count differentiations that belong to the same policy area, affect the same country and start in the same year as only one single differentiation $]^{3}$ Finally, I calculate the number of realized differentiations as a share of the number of differentiation opportunities, which I calculate as the product of the number of Member States and the number of integrated policy areas.

Figure 1.2 shows that when calculated as individual differentiations and in relation to the number of differentiation opportunities, the extent and development of DI in EU primary law no longer aligns with the common narrative. Now, while DI in general increases with each enlargement round, with new treaties and with treaty revisions, we also find a number of developments that contradict the common narrative. To begin with, enlargement rounds have only temporary and largely uneven effects on DI. For instance, DI sees its highest numbers not after the Eastern Enlargement, where 10 new Member States join the EU, but after the 1973 enlarge-

\footnotetext{
${ }^{3}$ I thank Frank Schimmelfennig and Thomas Winzen for sharing their dataset on EU primary law differentiations.
} 

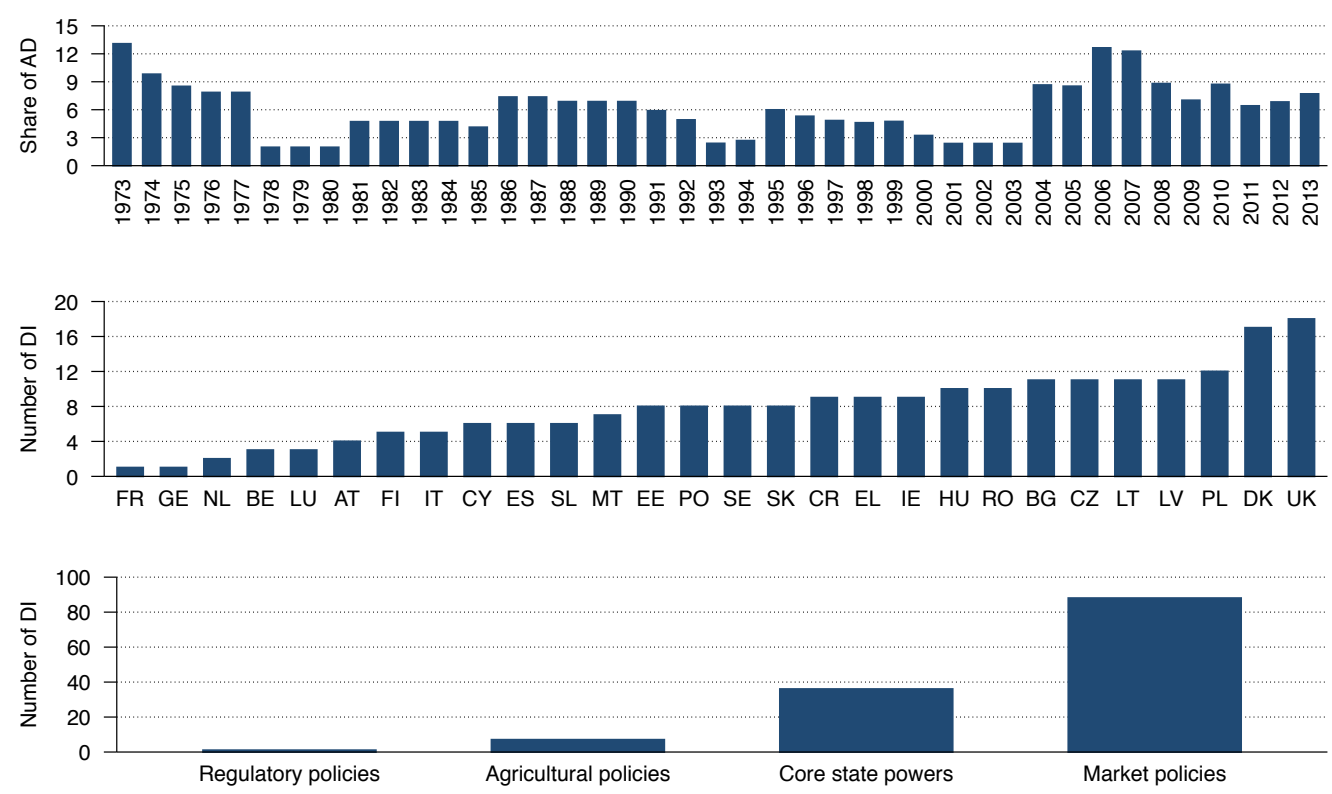

Figure 1.2: DI in EU primary law

ment round, where only 3 countries join the EU. In the same vein, DI stemming from the integration of new policy areas is not necessarily extraordinary in number or permanent in applicability. Although differentiation increases with the Schengen Treaty and the Treaty of Maastricht, for instance, it leads to an only modest and largely temporary rise of DI. This suggests that it is not just the number of policy areas or Member States integrated into the EU that explains its degree of differentiation, but rather that DI varies with the specific characteristics of these policy areas and the respective Member States. Overall, looking again at figure 1.2, we can still conclude that DI is on the rise. But the story behind this development is much less intuitive than the common argument might suggest.

In the middle part of figure 1.2, I show the number of realized differentiation opportunities per country. The common narrative can be read to indicate that each country that joins the EU contributes similarly to DI. As we can see, however, there is substantial variation in differentiation across countries. The UK and Denmark are the absolute champions of DI in EU primary law. The 2004 enlargement round follows suit, while Sweden and Ireland also rank among those countries with a comparatively high number of realized differentiation opportunities. Austria and Finland as well as the EU-6 show rather low levels of DI. To give some perspective, 
the UK counts 18 realized differentiation opportunities, while Germany and France each realized only one of them. The main issue with figure 1.2 is obviously that it does not distinguish between differentiation that was acquired in the course of treaty revisions (constitutional DI) and DI that was acquired during rounds of enlargement (instrumental DI). Also, as it only shows absolute numbers, we might miss some crucial insights in terms of the share of realized differentiation opportunities. In chapter 2, I conduct an analysis on the use of differentiation opportunities that takes note of both of these points. For now, however, figure 1.2 neatly illustrates that DI is not just about the number of Member States, but also about the attributes of the states that join the EU.

With regard to the distribution of DI in EU primary law across policy areas, figure 1.2 shows that in EU primary law, market policies show the most realized differentiations, followed by DI in core state powers. This again highlights the importance of a data-driven analysis of DI. The existing research on DI largely concentrates on a few case studies in core state powers, especially EMU. Indeed, DI in EMU accounts for 28 of the 36 differentiation in core state powers. All of these differentiations were acquired with or after the Maastricht Treaty. As such, a focus on EMU might indeed give rise to the notion that DI is substantially on the rise. And yet, this narrative misses some important facts. Market policies, for instance, account for 88 differentiations, almost half which have been realized prior to the Maastricht Treaty. This serves to illustrate how the existing research on DI distorts our narratives on the phenomenon and highlights the importance of further, more granular research on the topic. It also serves to illustrate that the incorporation of policy areas cannot be expected to have constant effects, but that DI varies with their characteristics.

The above also broadly applies to DI in EU secondary law. Here, however, even in a cumulative understanding, DI develops more or less sideways (figure 1.1). This suggests that temporal dynamics, such as the expiration or amendment of legal acts, play a greater role in EU secondary law than in EU primary law. To get a better understanding of these temporal dynamics, I measure the number of actually differentiated legal acts as a share of all legislative acts adopted in any individual year in figure 1.3. As we now can see, the role of enlargement in DI in EU secondary law is not straightforward. In some enlargement rounds, especially in 1973, I find a substantial increase in DI. In other cases, especially in the 2004 enlargement round, 

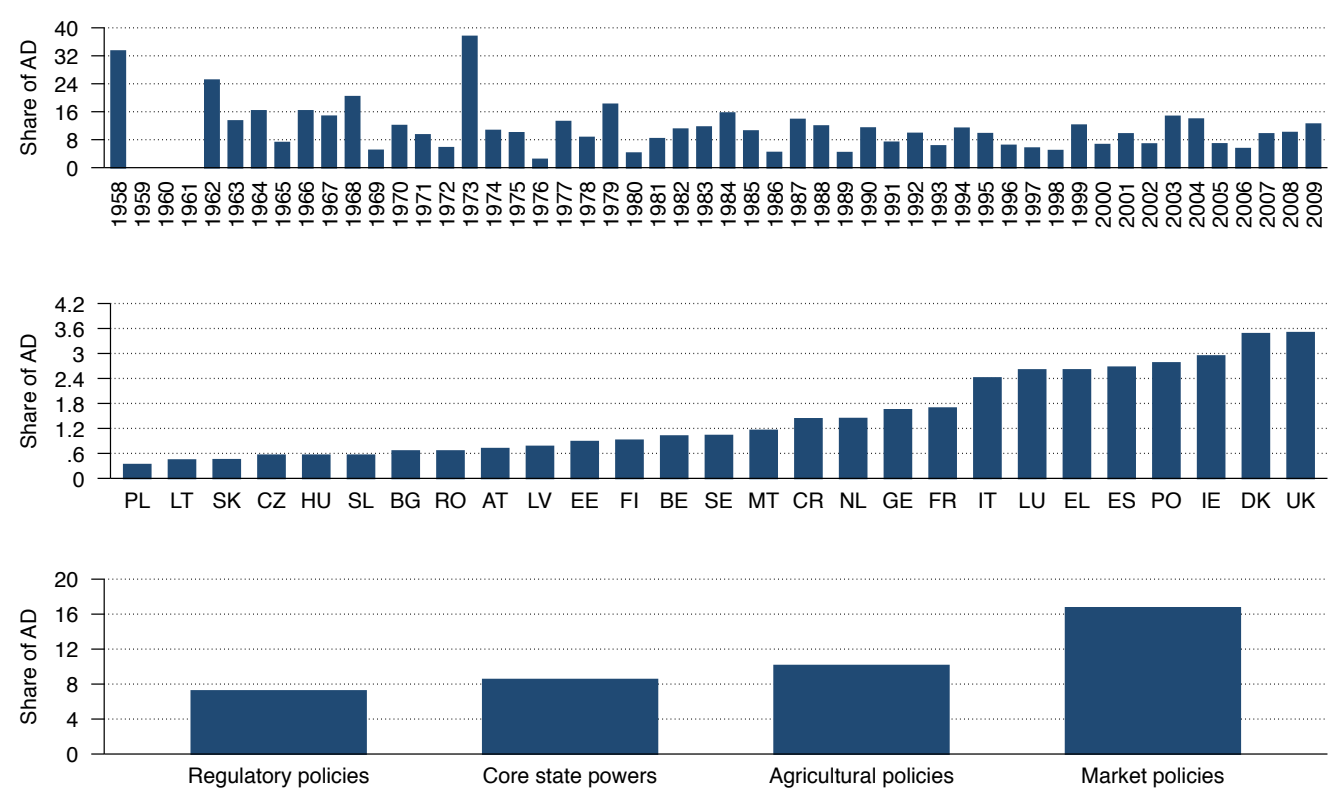

Figure 1.3: DI in EU secondary law

I find very little effect on DI in EU secondary law. To investigate the extent of DI across EU Member States, I measure how many differentiations a country has realized, on average, as a share of all legislative acts adopted in any given year of its EU membership. The one group of states that realized the highest share of differentiation opportunities is the 1973 enlargement round, this time followed by the 1982 and 1986 enlargement rounds. Over time, the number of EU Member States does not appear to influence DI in EU secondary law. The same is essentially true for the integration of new policy areas. Here, I show the average share of actually differentiated legal acts in a given policy area. As we can see, policy areas contribute rather unevenly to DI and if anything, DI in EU secondary law is driven by the integration of market policies, not by the integration of core state powers. Again, this makes clear that the de-facto extent and development of DI does not align with the common narrative on the topic.

The above covers only a small sample of potentially interesting descriptive insights into the EUDIFF dataset. But it suffices to make clear that the idea that DI simply increases due to the widening and deepening of European integration must be seriously contested. The key takeaway at this point is that according to most measurements, DI develops more or less sideways and that Member States 
and policy areas contribute unequally to it. Additionally, DI even fluctuates in years in which no states join the EU and no new policy areas are integrated into the acquis communautaire. The existing narrative on DI must thus be reconsidered. To do so, I present a number of more nuanced approaches to the extent and development of DI in the remainder of this thesis, focusing on preference heterogeneity (chapter 2), the delegation of competencies to the European level (chapter 3) as well as the role of interdependence and politicization (chapter 4).

\subsection{Concepts of DI}

In marked contrast to the scarce availability of data and the limited theoretical literature on DI, there is an abundance of conceptual work on the topic (Holzinger/ Schimmelfennig 2012, also see Leruth/Lord 2015). In the following, I present this literature and distinguish between normative concepts of DI, descriptive concepts of DI and the concept that the whole EU must be understood as a system of differentiated integration. I conclude that it is indeed crucial to understand the EU as a system of differentiated integration, for doing so allows us to shed light on new and important aspects of European integration. I also caution against understanding DI as simply good or bad, for while some forms of DI further the European project, others compromise it.

\section{The EU as a system of differentiated integration}

The EUDIFF dataset shows that differentiation is a crucial element of European integration. This gives meaning to those approaches that suggest that we can only understand the EU's real character by looking at it as a system of differentiated integration. To begin with, Walker (1998) proposes to understand the EU as a number of many Europes whose width and depth is subject to the arrangements in specific policy areas. He finds the analytical tools to adequately understand this multidimensional EU in the concept of sovereignty. In this vein, Walker concludes that the EU must be increasingly understood as a system of differentiated integration. Walker claims that a differentiated EU faces many difficulties concerning its capacity to manage boundaries between legal orders, its political efficacy, its democratic credentials and its social legitimacy. And yet, he proposes, this does not doom the 
European Union. In his understanding, DI is not the subject of an explicit design, but the outgrowth of the preferences of political actors.

Zielonka (2006) also suggests that the EU must be understood as a system of differentiated integration. With his metaphor of the EU as an empire, Zielonka essentially refers to the EU's non-hierarchical structure, in which differentiation is a key element. With this, Zielonka is close to the arguments of Ruggie (1993), who proposes that the EU is reminiscent of medieval rule with its overlapping forms of authority and non-exclusive forms of territoriality. For Zielonka, however, this is only the starting point, for he conceives of two possible future developments, namely that the EU can either develop towards a Westphalian model or a form of neomedievalism. In the former case, the EU would develop towards a concentration of power, hierarchy and sovereignty and foster the development of clear-cut identities. In the latter case, the EU would develop towards overlapping authorities, divided sovereignty, diverse institutional arrangements as well as multiple identities (Zielonka 2001). In any case, however, Zielonka suggests that by today, the EU best resembles a system of differentiated integration (this paragraph is based on Adler-Nissen 2014, 32-35).

De Neve (2007) proposes that differentiated integration has already had such an influence on the EU that it should be visualized as an onion, that is, a system of governance segmented not only by policy areas and levels of government, but also by subgroups of European states. He asks, in other words, for the shape of the European project and the opportunities - and dangers, we might add - that this process entails. There are no substantive key take-aways from his study. The paper rather adds to the debate on European integration in that it presents an up-to-date overview of the concept and practice of differentiated integration; notes the disparity between the factual importance of DI and the public perception of it; highlights the role of centripetal effects of DI; and offers an alternative understanding of the EU by way of the onion metaphor. With this, de Neve's study largely re-iterates the idea that the EU must be understood as a system of differentiated integration.

Warleigh-Lack (2015) extends the idea of the EU as a system of differentiated integration even beyond the study of the EU. He proposes that global macro-regions other than the EU also experience forms of DI and that DI is a inherently neutral feature of regional integration. If anything, it is the absence of DI, not its existence, that would be noteworthy. With that, Warleigh-Lack also proposes that by under- 
standing the EU as just one case of regional integration among many, we can get a more sophisticated understanding of European integration and come to understand that DI is an enduring and perhaps even permanent feature of the EU.

The most sophisticated interpretation of the idea of the EU as a system of differentiated integration comes from Leuffen et al. (2013; also see Schimmelfennig et al. 2015). In their seminal contribution, the authors understand European integration as a multidimensional process that they propose to conceptualize along a three-dimensional understanding of authority, namely the level of centralization, the functional scope and the territorial extension of European integration. In this vein, the authors first distinguish unitary states from international organizations. Here, unitary states are defined by high centralization, high functional scope and limited territorial extension, whereas international organizations are defined by low centralization, low functional scope and large territorial extension.

Leuffen et al. also identify three more complex configurations of authority. They demarcate the federation by the fact that whereas some policies are fully centralized, others are governed at the regional level, while yet further policy areas are co-governed by regional and national authorities. The territorial extension and functional scope of the federation, however, is equal to that of the unitary state. In systems of competing and overlapping institutions (also see Frey/Eichenberger 1996), each jurisdiction focuses on a single policy or function, each policy is provided for or offered by several jurisdictions that compete with each other, and the membership of jurisdiction varies in size. However, Leuffen et al. conclude that the EU corresponds to neither of these types. In contrast to the federation, the territorial extension of the EU varies by policy area or task. In contrast to the idea of a system of competing and overlapping institutions, the EU has developed an institutional centre and a membership core that reaches across the EU's policies. The EU is thus not many Europes, as Walker (1998) suggests, but one Europe with an organizational and membership core but with a level of centralization and territorial extension that vary by function (Leuffen et al. 2013, 10).

I find the contribution of Leuffen et al. (2013) to offer a sophisticated and convincing understanding of the EU as a system of differentiated integration. Most importantly, Leuffen et al. do not just describe the fact that the EU is a system of differentiated integration, but offer an insightful framework of DI by referring it to a three-dimensional understanding of authority. With that, they deliver an independ- 
ent conceptualization of the EU, not just a negative demarcation of a differentiated EU from the oversimplified idea of a unitary Union. In this perspective, DI is not the deviation from a normal case, but is itself the normal case. In turn, conceptualizing the EU as a system of differentiated integration allows us to re-consider some key theoretical debates and core narratives on European integration and thus to advance the study of not just differentiated integration, but European integration in general. It is in this vein that I seek to shed light on a few aspects of DI in the remainder of this thesis.

\section{Normative and descriptive concepts of DI}

Having established that DI is a crucial element of European integration, we must also discuss its normative value. In normative terms, differentiated integration is best discussed against the background of whether it fosters or compromises European integration (for an alternative approach, see Lord 2015). In its preamble, the Treaty of Rome refers to the integration process as a process of ever closer union. In this vein, in the perspective of the contra-differentiation camp, claims to sovereignty in the form of opt-outs threaten the authority of the EU's political order and ultimately endanger the very idea of European integration. To the pro-differentiation camp, on the other hand, opt-outs do not pose a threat to the EU, but are an inevitable and often promising avenue for its further development (Adler-Nissen 2014, 26). Where the contra-differentiation group sees DI as an expression of national sovereignty and thus a danger to European integration, in other words, the pro-differentiation camp sees DI as an opportunity to allow integration-friendly states to move ahead; of overcoming gridlock in bargaining situations; and of enabling secondary effects from integration.

The idea of flexible integration was already evident in the thoughts of Jean Monnet, the first President of the High Authority of the European Coal and Steel Community. Monnet consistently promoted a sort of domino theory of European integration. He essentially proposed that European integration had to be tackled gradually, from policy area to policy area, depending on where the problem-solving incentives were sufficient. Monnet expected this gradual approach to make sure that integration would always be accepted, but he was also convinced that integration, once set in motion, would exert self-reinforcing effects. For Monnet, the finality of European integration lay in the supranationalization of EU politics and the ex- 
tension of the authority of the EU's political order. DI compromises this idea in that it represents the protection of national sovereignty against ongoing European integration. No wonder, then, that Monnet is said to have equated differentiated integration to a failure of the integration process (Monnet 1978, cit. in de Neve 2007, 505; Warleigh-Lack 2015, 872-874).

Quite contrary to the ideas of Jean Monnet, Belgian Prime Minister Leo Tindemans defended the advantages of a differentiated character of the EU when he proposed an EU in which states were free to choose if they want to progress or stay behind. His positive interpretation of DI came from his judgement that ultimately, the laggards would be forced to catch up to those who moved ahead and that insisting that all integration steps should be adopted fully by all Member States at the same time would make progress impossible and Europe would in fact start to deteriorate. To be sure, the Belgian Prime Minister did not imply a Europe in which governments were free to pick and choose their areas of cooperation. Instead, he proposed that each country would be bound by the idea of full integration and that only the timescale of that achievement would vary (Tindemans 1975). With that, Tindemans also delivered one of the first distinctions of à la carte- und multi-speed Europe.

Tindemans' arguments were supported in the year 2000 by then-German foreign minister Joschka Fischer, who argued that the key challenge to European integration was in fact the twin challenge of organizing enlargement, on the one hand, and managing the deepening of the EU, on the other hand. The EU's institutions were created for six Member States, Fischer argued, and thus any reform of the EU needs to tackle some important institutional questions. The key to ensure Europe's capacity thus lies in a reform to the existing method of integration. The Monnet method, according to Fischer, increasingly reaches its limits. While it was successful in the (economic) integration of a small group of countries in the 1950s, it had proven to be of only limited use thereafter. Ultimately, where it is not possible for all EU Member States to move ahead, smaller groups of states should take the lead, as was the case with the Schengen Treaty. In essence, given the increasing politicization of European integration in an enlarged and more heterogeneous EU, further differentiation might be a necessary part of further integration (Fischer 2000).

The academic literature, although not initially concerned with normative arguments, offers support for both of the above interpretations of differentiated integ- 
ration. For instance, Tindemans' (1975) argument that DI increases the likelihood of integration in that it allows states preferring more integration to cooperate first and other states to join them later is reflected in the arguments of Kölliker (2001; 2006; also see Downs et al. 1998) about the centripetal effects of DI. This notion was taken up, in turn, in the literature on enlargement, where some scholars propose that differentiation allows to overcome cooperation gridlock in the sense that Fischer (2000) conjectured (e.g. Moravcsik 1998, 48; Plümper/Schneider 2007). At the same time, however, Kölliker (2001, 140-142) concedes that mass politics might compromise his arguments and thus implies that centripetal effects cannot be assumed to be universal. If they are not, however, DI might in fact compromise the European project.

The academic literature is also undecided on the role of secondary effects from integration. According to Ruggie $(1993,172)$ any participation in the emerging system of European governance, regardless of its precise manifestation, changes the identities of the respective countries and hence is itself a (post-functional) driver of European integration. In a similar vein, Stubb $(2002,163)$ interprets a differentiated EU as a post-modern international political form designed to find common solutions to common problems on all levels of governance. In both cases, it is more important that European integration moves ahead than that it remains unitary in character, for ultimately, the latter will be the result of the former. And yet, other authors have argued that opt-outs deteriorate transparency in that they further complicate the relationship between the national and the European level; that they threaten democratic principles; and that they challenge the principles of solidarity and equality between Member States (e.g. Adler-Nissen 2014, 29-31; Fossum 2015). For these authors, DI thus compromises rather than advances the European project.

In the remainder of this thesis, we will come across instances of DI that further European integration, but also learn about instances of DI that compromise the European idea. This is especially the case in chapter 2, where I explicitly address the difference between constitutional DI, which refers to opting-out in the understanding of Jean Monnet, and instrumental DI, which allows to overcome cooperation gridlock in the understanding of Leo Tindemans and Joschka Fischer. That the normative case for DI is not black and white, but a grey-area at best, becomes even more apparent by the effort of Alexander Stubb (1996) to systematize the existing 
conceptual literature on DI.

Stubb (1996) orders his concepts along the lines of time, space and matter. To begin with, Stubb (1996; also see Grabitz 1984) identifies the existence of a multispeed EU, a mode of differentiation in which the acquis communautaire is ultimately preserved and developed, but in which a core group of Member States willing and able to pursue an integration objective of its choosing moves ahead, while the idea is that the laggards will follow later. This is a positive vision of differentiated integration in the understanding of Tindemans (1975), as we already touched upon it. It is so in the sense that the Member States, although admitting to a certain degree of heterogeneity in both preferences and capabilities, identify with the same objectives, although not with the timing in which they shall be realized. The main example of multi-speed integration is the integration in EMU, in which (most) EU Member States subscribe to a timetable to overtake the common currency, but are only allowed to do so once they reach certain convergence criteria.

With relation to the matter of European integration, Stubb (1996) identifies a Europe à la carte. Here, countries maintain only a minimum number of common objectives of European integration and, as the analogy suggests, pick and choose from a menu of matters in which they wish to cooperate. This mode of DI is at the opposite extreme of the multiple-speed Europe. The latter assumes a common objective of European integration at which all EU Member States ultimately strive. The former maintains a darker view of integration in which common objectives are sacrificed on the altar of national interests. With that, Europe à la carte offers a pessimistic understanding of DI in the tradition of Jean Monnet. Examples of à la carte differentiation again include EMU, where opt-out clauses in the framework of the Maastricht Treaty allow countries to permanently reject the process altogether, as Denmark and the UK have in fact done.

Finally, Stubb (1996) proposes the mode of variable geometry differentiation, which refers to an EU differentiated in space rather than time or matter. Here, DI admits to unattainable differences between states by allowing permanent or irreversible separation between a core and a periphery of countries. The idea is thus not that the laggards catch up over time, but rather that the preferences and capabilities of the EU Member States are so diverse that they make a unitary EU impossible. At the same time, the concept of variable geometry DI differs from the concept of Europe à la carte in that it assumes that states do not just pick and choose to their liking, 
but institutionalize their deviant preferences. Variable geometry DI thus refers to functional regimes with sector-specific differentiation (Holzinger/Schimmelfennig 2012, 294). In its ambiguity, variable geometry DI can be understood as occupying a middle ground between the ideas of a multi-speed Europe and a Europe à la carte. In that sense, it also offers a more optimistic understanding of DI than the à la carte perspective, but a less optimistic understanding of DI than the idea of a multi-speed Europe. A main example of variable geometry DI is the Schengen agreement.

DI is a crucial element of European integration, which is why it is important to discuss its normative value. However, the pro- and contra-camps on DI do not just differ in their interpretation of DI, but also refer to different manifestations of the phenomenon. The normative value of DI can thus not be discussed abstractly. Defined against the background of whether it fosters or compromises European integration, DI is not just good or bad, but can be all of the above.

\subsection{Theories and Hypotheses}

The theoretical literature on DI not just suffers from a lack of depth, but is also plagued by the fact that the few existing approaches to the topic are isolated from one another and do not explicitly relate to what may be called the grand theories of European integration. In the following, I survey the current state of the theoretical literature on DI; sketch out the grand theories of European integration; and show how these theories relate to DI. I then lay out the liberal intergovernmentalist approach to DI that is at the heart of the remainder of this thesis and conjecture that despite claims to the opposite, liberal intergovernmentalism offers a promising starting point to the study of DI.

\section{Main existing approaches to DI}

The most comprehensive theoretical account of DI has so far been given by Kölliker (2001; 2006). In his theory of differentiated integration, Kölliker stresses the role of the initial willingness of actors, the flexibility of institutions and the character of policy areas in terms of public goods theory. The first two factors, he proposes, determine why some Member States may move ahead of others, while the public goods theory helps to explain why initially reluctant outsiders end up joining some 
of these arrangements, but not others. Whereas excludable goods generate strong incentives for the initially unwilling to join, Kölliker argues, non-excludable goods allow the outsiders to free-ride and hence to remain outside. This is influenced also by the rivalry in consumption, however, which further reduces or increases outsiders' incentives to join. In sum, excludable goods with complimentary consumption create the strongest incentives for states to join flexible arrangements, while non-excludable goods with rival consumption create the weakest effects to do so. From his elegant theory, Kölliker derives three main hypotheses $(2001,137)$ : that DI is defined by the initial willingness of states; that the likelihood of the eventual integration of initially unwilling states is defined by the character of the policy area in terms of public goods theory; and that unity within the EU tends to be preserved at a low level of integration if differentiation is not applicable, tends to be destroyed at a mixed level of integration if differentiation involves policy areas with weak centripetal effects, and tends to be eventually re-established at a high level of integration if differentiation involves issue areas with strong centripetal effects. Kölliker substantiates his hypotheses in a number of comparative case studies.

Jensen and Slapin (2012) propose an approach to DI based on Member State preferences, agenda-setting power and qualified majority voting and enhance the methodological sophistication of the literature by including these variables into a spatial model of decision-making in the EU. They find that Member States compare policy outcomes that would occur following opt-outs with those that would have occurred if all states had remained part of the decision-making process and that they weigh the benefits of these policy outcomes against the costs of exiting. As such, they propose that while it may sometimes be the laggards who desire DI, it may in other cases be those who want to move ahead who do so, while in some final cases, cascading opt-outs are a possibility. Most interestingly, they conclude that the opt-out of one Member State affects the identity and relative preferences of other Member States, thus affecting both policy outcomes and Member State positioning in future rounds of decision-making.

A special case of differentiation can be found in the transitional differentiation that is often acquired with rounds of enlargement. I will come back to this topic in more detail in chapter 2 of this thesis, where I distinguish between instrumental differentiation, which stems from rounds of enlargement, and constitutional differentiation, which stems from new treaties or treaty revisions (see Schimmelfen- 
nig/Winzen 2014). This concept is based on Schneider (2009) as well as Plümper and Schneider (2007), who in essence propose that instrumental differentiation is used as an instrument to overcome gridlock in accession negotiations deriving from conflict about the distribution of gains and losses from the accession of new Member States. The EU's Eastern enlargement, in this perspective, was accomplished only because most of the accession countries agreed to be temporarily excluded from agricultural subsidies, structural aid and the free movement of labor and thus from those rights and entitlements that produce net losses for the old Member States.

\section{Grand theories of European Integration}

The above approaches relate to important aspects of European integration, including the role of Member State preferences and bargaining power. They also refer to institutional and ideational factors - albeit only in passing. To name just two examples, Schneider $(2009,69)$ accepts in her framework about the discrimination of new EU Member States that norms of legal unity may affect the duration of such arrangements, whereas Kölliker (2006, 106-107) argues that party politics and mass identities may influence the ultimately intergovernmental and functional logic of his approach. With this, the existing approaches to DI loosely refer to a vast number of explanatory factors that are already closely integrated into the main theories of European integration, namely liberal intergovernmentalism, supranationalism and post-functionalism. This reiterates the fragmentation and isolation of the research on differentiated integration. To avoid this pitfall, I relate my research to the grand theories of European integration in the remainder of this thesis. With that, I hope to contribute to an advancement of the study of DI by moving it into the realms of cumulative, theory-oriented research. In the following, I present the three grand theories of European integration and show how they translate into propositions about European integration in general and, most importantly, into conjectures about differentiated integration. These conjectures remain on a rather general level at this point, but will be treated in more detail in later chapters where necessary.

\section{Liberal intergovernmentalism}

Liberal Intergovernmentalism is the most prominent and most fiercely debated theory of European integration. It proposes a three-step model to European integration, 
combining a liberal theory of national preference formation, an intergovernmental model of bargaining on the EU-level and a functional model of institutional choice (Moravcsik 1993; 1998). Liberal intergovernmentalism makes three broad claims about European integration, each of them connected to the three-step model: First, that demand for integration is likely to be strong when issue areas or interstate relations are characterized by high degrees of interdependence (Moravcsik 1998, 2450). Second, that supply of integration is defined by the outcome of international bargaining, which is subject to state preferences and bargaining power (Moravcsik 1998, 50-67). And third, that cooperation in the European Union is then allowed to constrain Member States' sovereignty when it solves collective action problems related to incomplete contracting (Moravcsik 1998, 67-77). Liberal intergovernmentalism regards national governments to be the main actors of European integration, whereas integration is their instrument to realize benefits from economic interdependence (Moravcsik 1993, 482-495). Thereby, the process of integration remains firmly in the hands of the governments, so that the capacities of supranational institutions as well as the effects of social interaction can, with some exceptions, be neglected (Garret/Weingast 1991). With regard to differentiated integration, intergovernmentalism explains differentiation with differences in national preferences, bargaining power and the characteristics of the policy areas to be integrated (Leuffen et al. 2013, 40-61). For the purposes of this introduction, I thus simply conjecture the following:

- The extent of DI varies with (i) the heterogeneity of national preferences, the (ii) distribution of bargaining power and the (iii) characteristics of policy areas in terms of incomplete contracting.

\section{Supranationalism}

Supranationalism claims to be liberal intergovernmentalism's main competitor when it comes to rationalist theories of European integration. It proposes that European integration can be explained through the expansion of transnational exchange, the capacities of supranational institutions to respond to the needs of those who exchange, and the importance of supranational actors in shaping interaction (Stone Sweet/Sandholtz 1997; Sandholtz/Stone Sweet 1998). Supranationalism thus brings forward a two-step idea of European integration: First, demand for integration in- 
creases with increasing levels of cross-border transaction and communication by societal actors (Stone Sweet/Sandholtz 1997, 302-309). Second, once in place, European institutions constrain and influence Member States' behavior and generate an integration dynamic of their own, known as institutionalization. This institutionalization, in turn, is self-reinforcing in that it increases in importance with the respective institutions' degree of capacity (Stone Sweet/Sandholtz 1997, 310311). Supranationalism thus regards transnational society to be the main actor of European integration. Although integration steps are conducted by national governments at intergovernmental conferences, governments are merely reacting to the societal developments around them (Stone Sweet/Sandholtz 1997, 306). Furthermore, supranational institutions use their formal as well as informal resources to influence integration. Integration thus has a transformative impact on European integration and the Member States, making integration preferences become increasingly endogenous (Stone Sweet/Sandholtz 1997, 312-313). With regard to DI, supranationalism expects the extent of DI to vary with the heterogeneity of national preferences as well as, and this is where the theory most substantially departs from liberal intergovernmentalism, the capacities of supranational actors (Leuffen et al. 2013, 62-83). For the purposes of this introduction, I thus conjecture:

- The extent of DI varies with (i) the heterogeneity of national preferences as well as the (ii) capacity of supranational actors.

\section{Post-functionalism}

Post-functionalism, finally, proposes a theory of European integration that is fundamentally different from both liberal intergovernmentalism and supranationalism in that it emphasizes ideas and identities where the former two theories emphasize an essentially similar, functional logic. Different from supranationalism and liberal intergovernmentalism, post-functionalism is a less homogeneous research project. Yet, bringing together the most relevant concepts, it can be understood as being based on two ideas. First, as post-functionalism perceives European integration as a process of community-building, the dissemination and distribution of shared ideas and identities determines the strength of community and hence the extent, speed and direction of European integration (Leuffen et al. 2013, 39). Second, in the post-functionalist framework, similar to supranationalist ideas, European institu- 
tions have independent effects on their own. Here, however, these effects do not stem from the formal and informal capacities of institutions, but from the socialization of agents through intense interaction, leading them to internalize new norms and roles (e.g. Checkel 2005). Thus, post-functionalism proposes a two-step model of European integration: First, it proposes that demand for European integration increases with the degree to which Member States' elites and electorates identify with the EU and share its social values. Second, it proposes that European institutions become, once established, part of a process of socialization, constraining Member States' behavior and shifting their preferences over time. With regard to DI, postfunctionalism thus conjectures that, first, differentiated integration can be explained with the differences in the degree to which Member States' elites and electorates identify with the EU and share its social values and, second, that we must expect effects on DI through the processes of socialization. This most importantly includes, as one can expect the forces of socialization to work towards a homogenization of identities and values, that DI decreases over time (for the entire argument, see Leuffen et al. 2013, 84-104). I thus propose the following:

- The extent of DI varies with (i) the degree of shared identities and social values and the (ii) exposure to European integration.

\section{A liberal intergovernmentalist framework}

The study of DI is a challenge to the existing theories of European integration. Leuffen et al. suggest that no single theory is able to explain all instances of DI and that only a synthetic theoretical framework is able to shed light on DI in the European Union (Leuffen et al. 2013, 259-267). De Neve (2007, 515) even concedes that the existing approaches to European integration are converging towards a single rationalist model to contrast with constructivist approaches as their prime challenger and that the inability of existing approaches to explain DI would serve to intensify this development (also see Pollack 2001; Jachtenfuchs 2001; Glaser 2010). However, given the fact that little systematic inquiry into DI has been conducted, and in the absence of a comprehensive dataset on the topic, I find such claims to be premature and overstated. This is especially true for the idea that liberal intergovernmentalism, in the same vein as it is considered the key theory of European integration, is the one theory most challenged by DI. Adler-Nissen (2014, 36-37), 
for instance, proposes that DI is like a blind alley for liberal intergovernmentalism. And yet, with its emphasis on national preferences, bargaining situations and the characteristics of policy areas in terms of incomplete contracting, liberal intergovernmentalism seems well suited to the study of DI. In fact, as the thesis at hand shows, liberal intergovernmentalism offers convincing explanations to many of the puzzles of DI. I introduce a general liberal intergovernmentalist framework in the following, which I will then use throughout the subsequent chapters of this study.

My framework starts with one of the key arguments of liberal intergovernmentalism, namely that governments are the key actors of European integration. 4 The idea about the centrality of state actors is commonplace in liberal theories of international relations (e.g. Milner 1997), but given the importance of governmental decision-making in the European integration process, it is especially prominent in liberal theories of European integration. In liberal intergovernmentalism, governments are embedded in domestic and transnational civil society, which decisively influences their identities and purposes. In this perspective, groups articulate preferences, while governments aggregate them. Society and government stand in a principal-agent relationship. As the primary objective of governments is to remain in office, they need the support of a coalition of domestic voters, parties, interest groups and bureaucracies. Their views are transmitted through domestic institutions and practices of political representation, a process through which national preferences are ultimately formed (for the entire argument, see Moravcsik 1993, 482-485).

The second key ingredient of liberal intergovernmentalism is its emphasis on the role of interdependence. The idea of the increasing importance of increasing transborder flows of goods, services, factors or pollutants lies at the very heart of liberal theories of interdependence. Scholars of liberalism ascribe a number of policy outcomes to the powers of interdependence, from security policy (e.g. Keohane/Nye 1977) to international regimes and institutions (e.g. Keohane 1984). At the core of these propositions always lies the idea that transborder flows of factors create international policy externalities that in turn create incentives for cooperation among states. In the approach of Andrew Moravcsik, national governments have an incentive to cooperate when economic interdependence increases; the policies of two

\footnotetext{
${ }^{4} \mathrm{My}$ framework largely corresponds to the one by Schimmelfennig et al. (2015) as well as Leuffen et al. (2013) but goes beyond them in that it also encompasses an explicit theory of institutional choice.
} 
or more governments, due to these increases in economic interdependence, create ever more negative policy externalities for one another; and unilateral adjustment strategies become increasingly ineffective, inadequate or expensive (Moravcsik 1993, 485). This proposition entails essentially two arguments, namely first an argument about the role of divergent policies and the vulnerability of states to the costs from this policy divergence and second an argument about a convergence of preferences over time due to states' increasing inability to deal with such negative externalities. With regard to DI, I thus later argue that when interdependence forces divergent preferences to become congruent, we move from differentiation to integration.

The third key ingredient to my liberal intergovernmentalist framework is given by the role of politicization. In short, whereas the convergence of preferences facilitates integration, politicization creates obstacles. Interdependence thus not only promotes integration conditional on preference convergence, but also conditional on low politicization (Leuffen et al. 2013, 261). There are two points to note at this point: To begin with, politicization is perfectly applicable to a liberal intergovernmentalist framework. Earlier, I argued that governments are embedded in domestic and transnational civil society and that its views are transmitted to governments through domestic institutions and practices of political representation. Politicization plays a key part in which topics get mobilized and hence transmitted to governments. Second, it is notable that politics needs to become ever more interdependent to reconcile the effects of politicization. For instance, as we will see, despite the fact that monetary policymaking becomes increasingly interdependent during the 1980s and thereafter, Sweden, the single most eurosceptical country under consideration, still acquires an opt-out from EMU. Interdependence thus not simply overrides the effects of politicization, but constantly struggles with it.

To proceed, we must distinguish between the demand-side arguments and supplyside arguments of European integration. On the supply side, Moravcsik (1993, 496507) suggests the importance of bargaining. One way to understand this point is to come back to the importance of the distribution of costs and benefits among Member States. Consider that these costs and benefits are not just defined by the issue of integration in question as well as the respective preference structure of the states, but also by states' ability to actively distribute these costs and benefits among them. This includes, most importantly, the role of unilateral alternatives and threats of 
non-agreement; alternative coalitions and threats of exclusion; as well as compromises, side-payments and linkages at the margin. Until we also take account of this supply-side of integration, we cannot fully understand the extent and development of DI.

Finally, we must ask for why states would establish international institutions in a liberal intergovernmentalist perspective in the first place. Moravcsik proposes that strong supranational institutions are wrongly seen as the antithesis of intergovernmentalism (Moravcsik 1993, 507). His functional theory of institutions starts from the assumption that states establish international institutions to efficiently deal with problems of international cooperation. In this understanding, institutions allow for cooperation by providing information and reducing uncertainty where transaction costs are high. Institutions thus serve as passive structures to identify issues, negotiate bargains as well as as to codify, monitor and enforce agreements (Moravcsik 1993, 508). And yet, states have at times delegated powers to the EU-level and pooled decision-making. For these cases, liberal intergovernmentalism essentially proposes that states do so to respond to the problem of incomplete contracting (e.g. Garrett/Weingast 1991). Where Member States have shared goals, but are unable or unwilling to foresee all future contingencies involved in the realization of these goals, they may have an incentive to establish decision-making procedures or to empower neutral agents to propose, mediate, implement, interpret and enforce agreements (Moravcsik 1993, 509). Thereby, states only delegate competencies when the potential gains from cooperation are substantial, the level of uncertainty regarding the details of specific delegated decisions is high and the level of political risk for individual governments is low (Moravcsik 1993, 510-511).

The substantive chapters of my thesis are set up to investigate different aspects of this general framework. In chapter 2, I investigate the role of preference heterogeneity for DI in EU primary law. In line with the above framework, I find differentiation to be realized in line with the heterogeneity of preferences among EU Member States. In chapter 3, I inquire the role of secondary effects from European integration. To do so, I inquire the influence of the supranationality of decision making and the age of policy areas on DI in EU secondary law. I find my liberal intergovernmentalist hypotheses supported, for while I find no general effects from institutionalization and socialization, I find effects from institutionalization in market policies, where Member States have the most to gain from incomplete con- 
tracting. Finally, in chapter 4, I research the role of interdependence, preference convergence and politicization in EU monetary policy. I find that the convergence of macroeconomic policies, combined with the increasing depth and politicization of European integration, rather convincingly explains DI in EU monetary policy. Liberal intergovernmentalism thus offers a convincing starting point to an understanding of the extent and development of DI.

\section{Further dimensions of DI}

There are at least three debates in the study of DI that I do not address in my thesis, namely the consequences of DI, the relationship between compliance and DI as well as the differentiated dissemination of EU rules beyond EU Member States. First, with regard to the consequences of DI, Thomas Gehring's (1998) analysis of the Schengen regime is a case in point. Gehring proposes that the establishment of the Schengen regime was an attempt at overcoming a deadlocked bargaining situation. He also concludes, however, that the Schengen regime, once established, altered the cost-benefit analysis of the outsiders and deprived them of free-riding opportunities. This latter point refers to the Schengen regime as an excludable good and thus relates to the common goods arguments, with which Gehring's analysis is largely compatible with Köllikers $(2001 ; 2006)$ and sheds light on the qualities of Köllikers work not just as an explanation of DI, but also as an inquiry into its consequences.

Another account of the consequences of DI is reflected in a series of articles and an encompassing book by Rebecca Adler-Nissen (2008; 2009; 2011; 2014). In her studies, Adler-Nissen draws our attention to the formal and informal practices of opting-out and hence the management of differentiated integration. Her interest is specifically with the literature that claims that opt-outs lead to the exclusion of countries and them being perceived as awkward partners, as in the case of the UK (e.g. George 1998), or as hesitant, as in the case of Denmark (e.g. Miles 2005). Contrary to these arguments, however, Adler-Nissen finds that representatives of opt-out countries are indeed able to participate in the shaping of new EU legislation even in politically sensitive policy areas. She also argues that opt-out countries are not perceived as bad Europeans and that informal norms do not contribute to the exclusion of Member States with opt-outs. On the contrary, Adler-Nissen finds that pragmatic, consensus-oriented norms enable the inclusion of these countries. In 
this way, she argues, the management of opt-outs quite paradoxically conveys the strength of the EU in its movement towards an ever closer union.

In the same vein, Naurin and Lindahl (2010) reject what they call the free-rider hypothesis, that is, the idea that the decisions by Denmark, Sweden and the UK not to join the Euro are considered to be free-riding and hence lead to a bad reputation and the exclusion from informal networks (also see Hobolt/Lebland 2009, 210). As their findings show, the three countries in question are doing well in terms of network capital. Consequently, Naurin and Lindahl conclude that flexible or differentiated integration may be a more feasible solution for dealing with preference heterogeneity than usually acknowledged. Dyson and Marcussen (2010) deliver yet another iteration of essentially the same argument. They suggest that we should relate to DI as transverse integration to indicate that the values, cultures, perceptions, routines, and performance in European (economic and monetary) integration do not neatly correspond with the formal lines of governance. Most specifically, Dyson and Marcussen propose that European integration is best described as a set of fuzzy governance structures. With that, they suggest that there is no clear distinction to be made between outsiders and insiders and hence again downplay the consequences of differentiated integration.

Second, the literature on compliance lacks of theoretical and empirical work regarding the relationship between differentiated integration and Member States' substantive conformity with EU legislative output. As Zhelyazkova (2014) notes, a substantial amount of research has been devoted to uncovering the mechanisms that drive Member States' implementation performance, but this literature remains disconnected from discourses about differentiated integration and often uses rather indirect proxies for Member State conformity to EU norms, such as transposition delays (see Toshkov 2010, Hartlapp/Falkner 2009). In this context, Zhelyazkova (2014) asks for the extent to which selective participation decreases differences between non-participants and fully integrated EU Member States regarding national responses to EU policy. Her research finds that non-participating countries that agree to opt-in to common policies are more likely to comply with EU decisions than those that decide to stay outside, but also that opting-in countries still lag behind fully integrated Member States during the implementation stage because they face higher conformity costs and perceive lower losses from non-compliance.

Third, one may conceptualize DI not just with regard to EU Member States, 
but also with regard to the spread of EU rules beyond EU borders. Along with its internal development, the EU exerts increasing influence on third countries and international affairs more generally (e.g. Holzinger/Schimmelfennig 2012, 301). The most obvious case of this influence lies with the projection of the EU acquis on accession countries, but it reaches even beyond, a notion that is labelled the EU external governance (e.g. Lavenex/Schimmelfennig 2009). There is, in other words, not just internal DI among EU Member States, but also an external DI with third countries. The literature on this topic is rather extensive. Lavenex and Schimmelfennig (2009) make clear that EU external governance takes different forms, including hierarchical models, network constellations and market modes, where the mechanisms of rule expansion shift from harmonization to co-ordination and competition. Lavenex (2015) shows that external DI follows different logics, namely a rather political logic of foreign policy, in which the active promotion of the acquis communautaire is part of EU foreign policy, as well as a more functional logic, in which EU transgovernmental bodies have developed external ties to deal with functional interdependence. Not least, Gstöhl (2015) researches the more narrow phenomenon of the EU's differentiated expansion of its economic community, namely the differences between the European Economic Area (EEA), the EU-Swiss bilateral treaties, the customs union with, most importantly, Turkey and the European Neighborhood Policy (ENP).

\subsection{Outlook}

The substantive part of my thesis consists of chapters 2 to 4 . In the following, I present the individual chapters' research questions and main findings and try to make clear where they expand on the existing literature.

\section{Heterogeneity and EU primary law differentiation}

In chapter 2, I study the role of preference heterogeneity for EU primary law differentiation and use this opportunity to present the current state of the art of the respective literature. First, I present the development of DI in EU primary law. Following the existing literature (Schimmelfennig/Winzen 2014), I aggregate the EUDIFF dataset to represent individual differentiations. A differentiation is here 
constituted by the legal exemption of a Member State from a treaty article and lasts for as long as this exemption is valid uninterruptedly. I furthermore count differentiations that belong to the same policy area, affect the same country and start in the same year as only one single differentiation. As we will see, while the extent of DI does indeed increase over time, the story behind it is by no means straightforward. I furthermore differentiate between constitutional differentiation, which stems from new treaties or treaty revisions, and instrumental differentiation, which stems from the accession of new Member States (again see Schimmelfennig/Winzen 2014).

Chapter 2 expands on the existing literature in its discussion and analysis of the role of preference heterogeneity on DI in EU primary law. The role of preference heterogeneity is implicitly or explicitly present in numerous approaches to DI. To discuss this idea in more detail, I refer to the importance of system-level heterogeneity, group-level heterogeneity and unit-level heterogeneity and hypothesize that DI is more likely when preferences are highly heterogeneous in a group of states and unevenly distributed among groups of asymmetric size. I also propose that heterogeneity exerts its effects asymmetrically on the unit-level. Overall, I find that ideational considerations have a significant effect in treaty revisions, but not in enlargement treaties, whereas economic considerations have a significant effect in enlargement treaties, but not in treaty reforms. In short, it is the countries with the most eurosceptical constituencies that realize constitutional DI and the poorest new Member States that realize instrumental DI. I also find that the chances of countries to realize differentiation opportunities increase with the size of EU membership, although that finding remains somewhat fragile. I thus find that while the width of European integration plays an important role in DI in EU primary law, the attributes of the individual states more robustly explain the phenomenon.

\section{Delegation and EU secondary law differentiation}

In chapter 3, I examine the importance of delegation to the development of DI in EU secondary law. The basic question that I ask in this chapter is whether or not supranational institutions deserve the status of independent variables. I already touched upon this argument in this introductory chapter when I referred to the idea that DI is a means to foster European integration in that once integration is set in motion, it creates secondary effects that reinforce that movement, which I referred to as the processes of institutionalization and socialization. To shed light on this important 
question, I propose that the extent of DI in EU secondary law should decrease with the extent of the supranationalization of legislative procedures as well as the increasing age of a policy area. I refer to historical institutionalism and constructivist institutionalism in this regard, which I relate to supranationalism and post-functionalism as introduced in the above. If integration really does have secondary effects, I conjecture, what better place to observe them than in EU secondary law and with direct reference to the supranationality of legislative policy making and the age of a policy area?

Chapter 3 expands on the existing literature in its analysis of the effects of supranationalization and policy area age on DI in EU secondary law. I operationalize these variables straightforwardly in that I measure the involvement of the European Parliament in EU legislative procedures and the age of a policy area. I also test for the influence of the saliency of a policy area by controlling for the effects of legislative activity on DI. I find no effects from the supranationality of decision-making, the age of a policy area or legislative activity - with one exception. I find that the supranationality of decision making has a statistically significant negative effect on DI in EU market policies. With this, I find another liberal intergovernmentalist conjecture supported by the EUDIFF dataset. In general, liberal intergovernmentalism expects little effects from delegation, but rather suggests that the principals keep control over their agents at all times. And yet, based on the idea of incomplete contracting, liberal intergovernmentalism can be read to allow for exceptions exactly with regard to the delegation of competencies in market policies, where the potential gains from doing so are substantial, the political costs are low and the uncertainties about future contingencies are high.

\section{Differentiation in EU monetary policy}

In chapter 4, I examine the degree and causes of DI in EU monetary policy. To do so, I investigate the varied character of the process of European monetary integration along the lines of the concept of the unholy trinity, that is, the idea that states are unable to combine monetary policy autonomy with fixed exchange rates and the free movement of capital. I relate my arguments to a simple political economy framework based on liberal intergovernmentalist conjectures, in which the benefits of monetary cooperation stem from the benefits of a monetary union on scale economies, whereas the costs of monetary policy cooperation reflect the inability of 
state actors to target their monetary policies at domestic preferences when exchange rates are fixed and capital is mobile. In this framework, I suggest, we must expect the costs of monetary policy cooperation to exceed its benefits for growth-targeting countries, whereas inflation-targeting countries can profit from the benefits of monetary cooperation at little or no cost. I also propose, however, that this changes with an increasing convergence towards macroeconomic discipline over time and that, under the conditions of macroeconomic congruence, it is public opinion that national decision makers must increasingly give their attention to. In essence, I thus propose that DI in EU monetary policy is the result of the iterative re-formulation of national preferences under the impression of increasing economic interdependence and the increasing depth and politicization of European integration.

Chapter 4 expands on the existing literature in its definition of DI in EU monetary policy. Along the lines of the concept of the unholy trinity, I code countries' participation in the currency snake and the EMS; whether they abolished or protected capital controls; and whether or not they participate in EMU. In this vein, EMU becomes merely one iteration of monetary policy cooperation, for while some states combined fixed exchange rates with the free movement of capital only under EMU, others have already done so in the 1970s. This dependent variable thus allows me to research the topic of DI in EU monetary policy in a longitudinal fashion, capturing factors from both prior and after the Maastricht Treaty. It is in this vein that my measurement allows me to come to insightful conclusions about the driving forces of DI in EU monetary policy. In fact, here more than anywhere else, I find broad and substantial support for the general theoretical framework I employ in this thesis. 



\section{Chapter 2}

\section{Preference Heterogeneity and EU Primary Law Differentiation}

The official motto of European integration, united in diversity, certainly has some tangible truth to it. While the EU's competencies have evolved to encompass more policy areas at a higher level of centralization than any other regional or international organization, its membership has become wider and more diverse in successive enlargement rounds. The European experience seems to belie the intuition that centralization and functional expansion should become more difficult as cooperation becomes more heterogeneous. In this sense, united in diversity is not only a slogan, but also a description of the process of European integration.

In light of the above, scholars and practitioners have discussed why progress towards deeper and wider cooperation has been possible. One increasingly popular answer proposes that the EU has paid for widening and deepening with growing internal differentiation. As diversity has grown, proponents of centralization and policy expansion have often been unable to gain unanimous support for their initiatives and, so the argument goes, have instead devised schemes of differentiated integration. They have argued that there should be a common membership and institutional core, yet also that the substantive obligations of membership should not necessarily apply to everyone at all times (e.g. Tindemans 1975, Fischer 2000). Thus, while the EU successfully squares the circle of widening and deepening at face value, on closer look it may have internalized the seeming tension between the two processes, resulting in more but differentiated integration.

In what follows, I examine this story in greater detail. To begin with, I shed 
light on the existing literature on DI in EU primary law by discussing the development of DI on the basis of the EUDIFF dataset. I measure realized differentiation opportunities by taking into account both the number of policy areas as well as the number of EU Member States and show that while differentiation does in fact and hence in line with the common narrative - increase over time, the story behind that development is much more complicated than one might suspect on first sight. I also discuss the substance of differentiation and ask whether it is mainly the diversity of economic situations that causes conflict and drives integration outcomes or whether ideational diversity counts more than economic considerations. In fact, relying on the existing literature (Schimmelfennig/Winzen 2014), I propose that we ought to explain different instances of DI differently. More specifically, I expect constitutional differentiation, which stems from treaty revisions or the incorporation of new treaties into the acquis communautaire, to be best explained with ideational heterogeneity, while I propose that instrumental differentiation, which stems from enlargement rounds, is best explained with reference to economic heterogeneity.

I then expand the existing literature by discussing the notion of preference heterogeneity. The idea that DI is at least in part explained by some kind of preference heterogeneity is a widespread one. It is, at the same time, rarely discussed in more detail. And yet, although the link between heterogeneity and DI is intuitively convincing, it leaves important questions on the table. Does heterogeneity, for instance, capture the plurality of distinct views or rather the fact that some Member States deviate strongly from the rest? For, while heterogeneity is a system-level concept that says little about the preferences of individual Member States, it is always the individual Member States that ultimately realize differentiations. Furthermore, what characteristics of heterogeneity do we expect to influence DI? The relationship between heterogeneity, uniform integration and DI is an intricate one. We could easily imagine that high levels of heterogeneity spoil any attempt to integrate, even in a differentiated manner, with the consequence that a weaker level of uniform integration prevails. Similarly, every Member State except a few might sometimes have highly aligned preferences, leading to low levels of heterogeneity, yet the differentiated treatment of outliers. Simply speaking, we need to look closer into the structure of heterogeneity. In the following, I propose that DI is more likely when preferences are highly heterogeneous in a group of states (system-level heterogeneity) and unevenly distributed among groups of asymmetric size (group-level 
heterogeneity). I also propose that on the unit-level, heterogeneity exerts its effects asymmetrically.

I test my arguments in the last section of this study and find that ideational considerations have a significant effect in treaty revisions, but not in enlargement treaties, whereas economic considerations have a significant effect in enlargement treaties, but not in treaty reforms. In short, it is the countries with the most exclusive national identities that realize constitutional DI and the poorest new Member States that realize instrumental DI. I also find that system-level heterogeneity exerts its effects as expected, that is, I find that the chances of countries to realize differentiation opportunities increase with the width of the EU and thus its degree of heterogeneity. And yet, this result remains more fragile than the role of unit-level heterogeneity. I thus find that while the widening of the EU plays an important role for DI in EU primary law, the attributes of the acceding states more robustly explain the phenomenon.

\subsection{DI in EU Primary Law}

The literature on DI recognizes at least two common narratives on the phenomenon, namely the idea that the existing theories of European integration are unable to explain DI and the notion that DI is, in response to the widening and deepening of the EU, constantly on the rise. In the following, I contrast these common narratives with an empirical one, based on the EUDIFF dataset on DI in EU primary law. I also offer a first leeway into explaining the de-facto development of DI in EU primary law by referring it to the distinction between constitutional and instrumental DI in an essentially liberal intergovernmentalist logic. As we will see, the development of DI is not as straightforward as the general narrative might suggest and liberal intergovernmentalism does a robust job in explaining the phenomenon.

\section{Measuring DI}

In the remainder, I follow the definition of DI as captured by the EUDIFF dataset. DI here refers to the differential validity of EU rules across territories. In principle, the unit of analysis is the legal rule, that is, a statement in a legally binding and generally applicable act that makes a behavioral prescription towards the ad- 
dressees of this act. To identify such legal rules, the EUDIFF dataset focuses on treaty articles of legally binding sections of EU treaties. In EU primary law, the unit of observation thus is the article-year. However, in the remainder of this study, I refer to the definition of DI as refined by Schimmelfennig and Winzen (2014) who measure differentiations instead, which are constituted by the legal exemption of a Member State from a treaty article and last for as long as this exemption is valid uninterruptedly. Schimmelfennig and Winzen furthermore count differentiations that belong to the same policy area, affect the same country and start in the same year as one single differentiation. The idea behind doing so is that, first, such differentiations usually result from one single decision and therefore cannot be treated as independent observations and that, second, one would otherwise give an inappropriate weight to differentiations in policy areas covering many articles. A good case in point is that an exemption from the Schengen rules usually results in a large number of differentiations given the sheer scope of the respective treaty, although states have taken only one substantive decision. 1

\section{Development of DI}

The common argument on DI proposes that differentiated integration is an institutional response to the increasing diversity and divisiveness of the EU which results from both the widening and deepening of European integration. Here, the argument in full (Schimmelfennig/Winzen 2014, 360):

The more countries the EU integrates, the more likely it is to have a membership with heterogeneous preferences and capabilities. The more policy sectors it integrates, the more likely they will include valueladen or redistributive policies that provoke conflict and are difficult to manage or settle. Finally, the more supranationally centralized European integration becomes, the more it reduces state autonomy and the more likely it provokes nationalist backlash. Increased heterogeneity and conflict, in turn, threaten to create deadlock in an organization based to a large extent on intergovernmental consensus - particularly in the case of treaty negotiations that require unanimous agreement. DI then helps

\footnotetext{
${ }^{1}$ I thank Frank Schimmelfennig and Thomas Winzen for sharing their dataset on EU primary law differentiations.
} 
to overcome deadlock by allowing the Member States to co-operate at different levels of integration that fit their preferences and capabilities.

How, then, does this common narrative correspond to the de-facto development of DI in EU primary law? As figure 2.1 shows, growth in DI is neither linear nor irreversible. Generally, DI increases with each enlargement round, with new treaties and with treaty revisions. And yet, we also find a number of developments that contradict the common narrative. To begin with, enlargement rounds usually have only temporary effects on DI. Currently, for instance, the EU is still recovering from the differentiation shock of Eastern enlargement, but half of it has already been absorbed. Furthermore, and contrary to popular belief, DI has not seen its highest numbers after the Eastern Enlargement, but after the 1973 enlargement round. This suggests that heterogeneity does not simply increase with the number of EU Member States, but rather that the degree of that increase is dependent on the attributes of the states that join the EU. Also, DI stemming from the integration of new policy areas is not necessarily extraordinary in number or even permanent in applicability. For instance, although differentiation increases with the Schengen Treaty and the Treaty of Maastricht, this leads to an only modest and largely temporary rise of DI. Again, this suggests that it is not just the number of policy competencies integrated into the EU that explains its degree of differentiation, but rather that DI varies with the specific characteristics of these policy areas. Overall, looking again at figure 2.1. we can still conclude that DI is on the rise. But the story behind this development is much less intuitive than the common argument might suggest.

\section{Instrumental and constitutional DI}

The development of DI in the year 1995 neatly illustrates a core deficiency of figure 2.1. In 1995, Austria, Finland and Sweden joined the EU, bringing the number of its Member States from 12 to 15 . While joining the EU, all of these states acquired a number of differentiations, most notably in the areas of the free movement of goods, the free movement of capital and the acquis on competition. Also in 1995, the existing Member States implemented the Schengen acquis, from which five countries (Denmark, Greece, Ireland, Italy and the UK) acquired a differentiation. All of these differentiations - from both the accession of new Member States and hence the widening of the EU as well as from the integration of the Schengen 


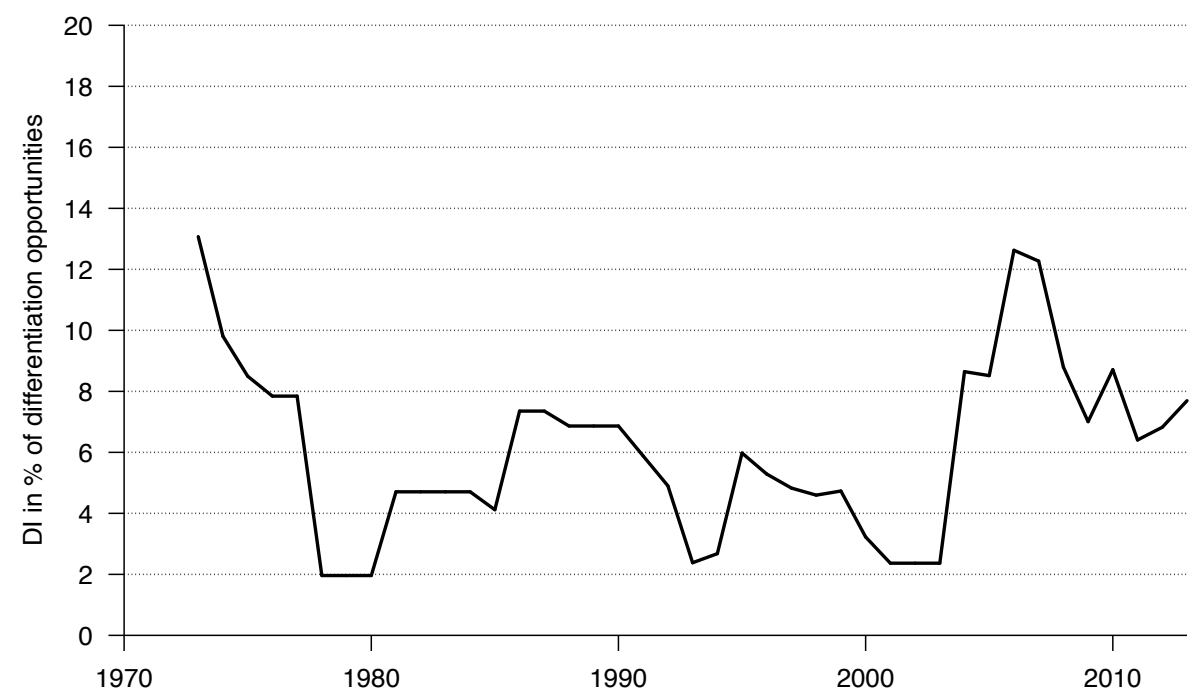

Figure 2.1: Development of DI in EU primary law

acquis and hence the deepening of the EU - equally feed into figure 2.1. As is immediately clear, however, they differ significantly in nature and as such ought to be explained differently. In the remainder, I thus disentangle constitutional DI, which stems from existing Member States and treaty revisions, and instrumental DI, which stems from the accession of new Member States. This distinction between instrumental and constitutional differentiation follows the arguments of Schimmelfennig and Winzen (2014).

Instrumental differentiation refers to DI that results from accession negotiations between the EU and membership candidates (Schimmelfennig/Winzen 2014, 361362): The EU requires candidates to adopt the entire body of EU rules, the acquis communautaire, and it normally expects them to follow these rules from the first day of membership. The EU and the candidate may, however, agree on transitional arrangements. They may determine a period of time during which particular rules do not apply, that is, in which the new Member States either do not enjoy certain rights of membership or are exempted from certain obligations. Such transitional arrangements are used as an instrument to overcome deadlock in accession negotiations deriving from conflicting preferences in lieu of the distribution of economic gains and losses from the accession of new Member States (Plümper/Schneider 2007; Schneider 2009). Old Member States can credibly threaten to veto enlargement unless the new Member States agree to forgo those rights and entitlements that cause 
net losses for the old members, while they have always granted new Member States temporary exemptions from the obligations of membership to facilitate their adaptation to market pressures and regulatory obligations.

Constitutional differentiation, on the other hand, is the outcome of intergovernmental negotiations on treaty revisions that strengthen the supranational policy competencies and capacities of the EU (Schimmelfennig/Winzen 2014, 362-364): These negotiations may reveal heterogeneous preferences regarding the scope of policy competencies or the adequate level of supranational integration. Because treaty revision require unanimous agreement, such conflict about the distribution of authority may generate deadlock and lead to the failure of further integration. In such circumstances, DI provides a way out of deadlock because it allows countries to opt-out from a policy and to remain at a lower level of integration or, respectively, to move ahead with an integration project. Integration-friendly states can grant the veto player an opt-out and thus secure agreement within the Community or Union framework or they can move out of the EU framework and conclude a separate intergovernmental treaty, as was the case with the Schengen regime or, more recently, the Fiscal Compact. Different from instrumental differentiation, where the distribution of economic gains and losses was assumed to be the driving force of DI, differentiation originating from treaty revisions predominantly reflects concerns over identity, sovereignty and the nature and powers of the EU.

Schimmelfennig and Winzen have have already shown the plausibility of their typology. Instrumental and constitutional differentiation are latent concepts that cannot be observed directly. Yet they can be expected to manifest themselves in distinctive and observable patterns of origin, duration, affected policies and affected countries. More specifically, Schimmelfennig and Winzen (2014, 362-364) hypothesize that whereas instrumental DI is likely to be temporary and short-term, constitutional DI is likely to be longer-term or even permanent; that whereas DI originating from enlargement is likely to cluster in market-related and (re-)distributive policy areas, DI originating from treaty revisions is likely to cluster in policies affecting core state powers; and finally that where instrumental DI is likely to be more prominent in enlargement rounds with poorer candidates and to affect comparatively poor new Member States more strongly, constitutional DI is likely to be driven by and focused on eurosceptic countries. And indeed, the authors' expectations are met (Schimmelfennig/Winzen 2014, 364-368): Instrumental differentiations are in 
general shorter and temporary, show a focus on market and distributive policies and a prominence of poorer countries. By contrast, constitutional differentiations are on average longer-term or even permanent, show a focus on core state powers and a prominence of countries with strong national identities. All these considerations allow me to formulate the following hypotheses:

$H_{1}$ : Whereas (i) instrumental differentiation varies with economic heterogeneity, (ii) constitutional differentiation varies with ideational heterogeneity.

\subsection{Preferences and Heterogeneity}

While the plausibility of distinguishing between instrumental and constitutional DI has already been asserted, it has not yet been extensively tested whether or not the probability of a country realizing a differentiation opportunity really varies with the heterogeneity of economic and ideational preferences. To answer this question, we must first elaborate on the nature of these proposed relationships. For, while the existing literature on DI often implies the notion of preference heterogeneity, it remains generally vague on the topic. In the following, I present an explicit notion of heterogeneity applicable to this study.

\section{The notion of preference heterogeneity}

The idea that DI is the result of some sort of preference heterogeneity is one of the most widespread notions on the topic. While sketching a research agenda for the study of DI, Holzinger and Schimmelfennig (2012) acknowledge the importance of heterogeneity when they propose that the heterogeneity of preferences has been established as a core ingredient to a theory of differentiated integration - but ask for precisely what kind of heterogeneity matters most without offering an answer or pointing to any in the existing literature. Similarly, Leuffen et al. $(2013,55)$ propose the importance of heterogeneity when they conjecture that, in a liberal intergovernmentalist framework, we should expect the likelihood of integration to increase with the homogeneity of national interests and the extent of differentiation to increase when interests diverge. Again, however, they refrain from offering definitions of either preference homogeneity or heterogeneity or what exactly they mean 
with the divergence of interests. In the same vein, in one of the most systematic approaches to DI in the literature, Kölliker (2001) proposes that DI is the result of the initial willingness of actors, the flexibility of institutions and the character of a policy area in terms of public goods theory. Again, however, he abstains from offering more insightful comments on the nature of the relationship between preference heterogeneity and DI.

The Oxford dictionary defines something as heterogeneous if it is diverse in character or content. But this opens just as many questions as it does answers. To begin with, the term heterogeneity is often used to refer to a whole being composed of units of a different nature (e.g. Lewin 2014; Page 2011). Here, an example would be an international organization that is composed of not just states, but also societal actors. For our purposes, however, heterogeneity is about variation in the attributes of units of the same nature, that is, the characteristics of EU Member States. To proceed, studying heterogeneity means differentiating between different levels of analysis. For, something that is diverse in character or content can be about the attributes of a group, on the one hand, or about what happens on the unit-level, on the other hand. For instance, negotiations over further integration are more likely to be controversial in a group of states with great variation in some attribute. At the same time, it may be a single state with a certain manifestation of an attribute that demands a special treatment. Finally, even in light of these clarifications, the concept of heterogeneity still allows for numerous manifestations. To name just a few, we may ask for how far the preferences of the most extreme actors lie apart, for whether there are identifiable clusters of countries or for the number of distinct positions that countries take. In the following, I define an explicit notion of heterogeneity applicable to this study and hopefully to the topic of DI more generally.

\section{Heterogeneity and DI}

In the following, I distinguish between system-level heterogeneity, group-level heterogeneity and unit-level heterogeneity. I hypothesize system-level heterogeneity to have effects on DI for two reasons: To begin with, countries are more likely to clash over substantive matters in a heterogenous group of states than in a homogeneous one. When I speak of heterogeneous preferences on the system-level, I do not mean issue-specific integration preferences such as whether Member States clash over the 
incorporation of the Schengen-acquis into EU law or over the introduction of the common currency. Instead, heterogeneity here is a state of affairs in which disputes over a wide range of possible issues are more likely because Member States differ in broad terms and, therefore, generally (though not necessarily all the time) develop conflicting issue-specific positions. General state properties, in other words, when meeting a specific proposal for integration, constitute the basis for the formation of issue-specific preferences. For instance, when countries generally disagree as to whether they support European integration, they need not necessarily have conflicting views on cooperation in employment policy. Yet dispute is still more likely in this case than if all countries favor or oppose integration. In a heterogeneous group of states, in other words, countries are less likely to find a set of substantive matters to agree on.

I further hypothesize that system-level heterogeneity increases the chances of not just substantive, but also general conflict among a group of countries. In other words, in a heterogeneous group of states, states are not just more likely to clash over substantive matters, but also less likely to create an environment promoting compromises and hence uniform integration. To name just one potential mechanism at play here, a heterogeneous group of states that faces more conflict over substantive matters may also hinder or prolong processes of socialization (e.g. Checkel 2005; 2007). If policy makers share only a small set of predispositions, thus the argument, processes of socialization are less likely or more cumbersome to materialize than if that same group of state representatives shares a larger set of predispositions in the very first place. In consequence, we would expect the finding of compromises to be complicated even beyond what we would expect from a purely substantive point of view, additionally fostering the realization of differentiation opportunities.

To proceed, I propose that differentiation is most likely to solve bargaining situations characterized by the uneven distribution of preferences and asymmetric group size and hence that group-level heterogeneity has an influence on DI. In the literature on DI, DI is often considered an institutional instrument to deal with gridlock in international cooperation (e.g. Plümper/Schneider 2007). Thereby, cooperation gridlock can be the result of either bargaining problems, that is, of countries being unable to reach a substantive agreement, or of commitment problems, that is, the problem that states agree substantively but cannot make their agreement work 
(e.g. Fearon 1998). Commitment problems arise if actors cannot credibly claim that they will comply with their obligations. Differentiation does not address this type of problem because it actually exempts some states from (parts of) a substantive agreement and renders the question of credible commitments unnecessary. One could even argue that DI is in fact a compliance tool, as it reduces the risk that the exempted country would fail to fulfill its obligations and stimulate a spiral of noncompliance in the very first place (Zhelyazkova 2014). But the more immediate point is really that differentiation excludes an actor before thought is given to making the agreement work among the remaining participants. Thus, DI is primarily a solution to bargaining problems.

Some of the better known bargaining problems revolve around information deficits or high transaction costs. What kind of bargaining problem, however, leads to demand for DI? I propose that such problems must revolve around separating the paths of two groups with deviating preferences. DI is likely to be the result of a process in which some states want to implement changes others dislike; some states want to move ahead; or two groups want to move into different directions. In essence, DI only makes sense if somebody gains from exclusion. Be it the laggards or those who move ahead: If nobody wins from the exclusion of some states, nobody will demand DI. With the term uneven distribution of preferences, I thus describe that DI has no relevance when everyone agrees or disagrees, but that it also does not really help when countries' preferences are more or less evenly spread across the entire range of possible positions. Who should be excluded in that case? There would be no obvious candidate that blocks the majority from progressing and any country singled out for exclusion would have a range of potential allies to avoid this. Preference heterogeneity is hence potentially more likely to lead to DI when some actors may gain from excluding others with distant views instead of incurring the costs of compromise or, alternatively, when one group wants to stay behind because the others' conceptions of integration are too distant.

For the notion of asymmetric group size, I see two potential manifestations. First, one may argue that DI is more likely if few actors with deviant preferences constitute an outsider group opposed to a mainstream. A small outsider group is easier to exclude against its will or to compensate for potential costs of being left behind. In turn, if a small group refuses to integrate it is less costly to let them have their way even if the gains from integration increase with group size. Finally, 
a smaller group that wants to move ahead independently has good chances of having a consensus on substantive matters to do so, whereas the laggards must not fear dramatic missed benefits from the cooperation of a small group. On the other hand, however, states may have better chances of realizing differentiation opportunities when a large group of states shares their general predispositions. Consider that the existence of similar predispositions does not imply that all of these states seek to realize differentiation opportunities at a given point in time or in relation to a given substantive matter. The existence of similar predispositions may imply, however, increasing chances of countries who want to realize differentiation opportunities, as the states that seek a differentiation find a larger number of states with an understanding of their situation among their bargaining partners. In other words, while I would still conjecture that it is usually small groups of states that realize differentiation opportunities, it may be that their chances increase if their broad predispositions are in line with those of a large group of states. In this vein, the role of group size remains theoretically ambivalent.

I also propose that unit-level heterogeneity has its effect on DI. While the idea that a more heterogeneous group of states is more prone to DI makes immediate sense, it is still individual states that realize exemptions. Heterogeneity must thus not least be studied at the unit-level. To be sure, even as a unit-level concept, heterogeneity remains a state of affairs and does not qualify as an issue-specific position. It is still general state properties that constitute the basis for the formation of issuespecific preferences when meeting a specific proposal for integration. Contrary to the system-level, however, disputes are now more likely not because a group of states entails a certain degree of heterogeneity, but because of the attributes of individual Member States. Here, I propose that heterogeneity has asymmetrical effects. This is an argument with great consequences. In one possible understanding of DI, we would hypothesize that the chances of a country to realize a differentiation opportunity increase with its degree of peculiarity, for instance with the degree of exclusiveness of its national identity from the average degree of that variable. Arguing in this way, however, would propose that differentiation can be the result of either particularly integration-friendly or particularly integration-sceptic preferences. Regardless of its substantial meaning, in other words, it would be the deviation of preferences that makes all the difference.

Despite its theoretical appeal, it makes little sense to expect symmetrical effects 
from unit-level heterogeneity. Consider the potential effects of identity-based euroscepticism on constitutional differentiation. Here, it is always the states with the highest values of euroscepticism that we must expect to realize a constitutional differentiation. Because the less integration-friendly state is closer to the status quo and a veto player, it wields superior bargaining power and can credibly threaten to block treaty reform. Similarly, as poorer membership candidates are more dependent on the EU and less competitive than wealthier Member Sates, the EU is both more capable of discriminating against them and more willing to accommodate them by granting exemptions. It is thus the poorer membership candidates that are prone to having a higher number of (instrumental) differentiations (for the entire argument see Schimmelfennig/Winzen 2014, 362). Heterogeneity does, in other words, exert its effects only in one direction (or asymmetrically).

To better understand the role of symmetry in unit-level heterogeneity, consider the realization of differentiation opportunities in the Amsterdam treaty. From the five countries that realized a differentiation opportunity (Denmark, Greece, Ireland, Sweden and the United Kingdom), the United Kingdom and Sweden rank among those countries with the most exclusive national identities, while Greece, Denmark and Ireland follow not far behind. If we would hypothesize that the chances of a country to realize a differentiation opportunity increase with the exclusiveness of its national identity, we would in fact achieve a remarkably good predictive quality. Would we hypothesize about the dispersion of national identity, however, that predictive quality would deteriorate markedly. For, assuming symmetrical effects from heterogeneity would force us to expect countries such as Luxembourg and Italy, which show the lowest values of identity-based euroscepticism, also to acquire a differentiation, which they have not. In other words, while we are in theory able to formulate our hypotheses simply in respect to the peculiarity of a country's predispositions, our existing empirical and narrative knowledge about DI prohibits us from doing so, thus making it futile to investigate unit-level heterogeneity as if it were a symmetrical concept. From all of the above, I can now formulate the following hypotheses:

$\mathrm{H}_{2}$ : The extent of DI varies with (i) the degree of system-level heterogeneity, (ii) the degree of group-level heterogeneity and (iii) the degree of unit-level heterogeneity. 


\subsection{Analysis}

In the following, I follow and expand on a memo by Winzen and Schimmelfennig (2014) to inquire the impact of unit-level and system-level heterogeneity on countries' chances of realizing differentiation opportunities. In line with Winzen and Schimmelfennig (2014), I find that the exclusiveness of national identity has a significant effect in treaty revisions, but not in enlargement treaties, whereas wealth has a significant effect in enlargement treaties, but not in treaty reforms. I also find that system-level heterogeneity increases the chances of countries realizing differentiation opportunities, but not with the same robustness as unit-level heterogeneity.

\section{Differentiation opportunities}

Throughout this study, I define DI as the number of independent differentiations as a share of all differentiation opportunities. Table 2.1 shows the differentiation opportunities that this paper covers: all major reforms of the founding treaties and enlargements since the Maastricht Treaty on European Union (TEU) as well as the Schengen Treaty (entry into force: 1995), the Treaty of Prum (2006), the ESM treaty (2012) and the Fiscal Compact (TSCG, 2013). These treaties cover varying numbers of policy areas and entail differentiation opportunities for varying numbers of countries. The Treaty on European Union, for instance, covers all policy areas from which all of the 12 Member States could acquire a differentiation. The Treaty of Prum, on the other hand, covers just one policy area, from which each of the 25 Member States at the time could acquire a differentiation. The 1995 enlargement treaty, to give one last example, covers again all policy areas, but only the three accession countries actually had the chance to acquire differentiations from it. As such, table 2.1 reflects the dataset I use to test my propositions and explains the number of cases the respective results refer to. ${ }^{2}$ How, then, did states make use of these differentiation opportunities? As table 2.1 shows, Member States realized almost no differentiation opportunities with comprehensive treaty revisions (Maastricht 1993, Amsterdam 1999, Nice 2003 and Lisbon 2010). Differentiations are, on the other hand, very common in revisions of individual policy areas (Schengen 1995, Prum 2006, ESM 2012 and TSCG 2013). In enlargement negotiations, the share of used

\footnotetext{
${ }^{2}$ I work with a list of 39 policy areas that I derived from the main treaties' chapter titles as well as the titles of additional treaties such as the Schengen agreements.
} 
differentiation opportunities increases from roughly $11 \%$ in the case of the 1995 enlargement round to $18 \%$ in the case of the 2004 and 2007 enlargement rounds and roughly $20 \%$ in the 2013 enlargement round.

\begin{tabular}{lllll}
\hline & $\begin{array}{l}\text { Number of } \\
\text { countries }\end{array}$ & $\begin{array}{l}\text { Number of } \\
\text { policy areas }\end{array}$ & $\begin{array}{l}\text { Realized DI } \\
\text { (rounded) }\end{array}$ \\
$\begin{array}{llll}\text { TEU 1993 } \\
\text { Amsterdam 1999 }\end{array}$ & 15 & 31 & $1.2 \%$ \\
Nice 2003 & 15 & 31 & $0 \%$ \\
Lisbon 2010 & 27 & 37 & $1.0 \%$ \\
\cline { 1 - 1 } Schengen 1995 & 12 & 1 & $41 \%$ \\
Prum 2006 & 25 & 1 & $88 \%$ \\
ESM 2012 & 27 & 1 & $37 \%$ \\
TSCG 2013 & 28 & 1 & $35 \%$ \\
\cline { 1 - 1 } ENL 1995 & 3 & 29 & $11 \%$ \\
ENL 2004 & 10 & 31 & $18 \%$ \\
ENL 2007 & 2 & 32 & $18 \%$ \\
ENL 2013 & 1 & 39 & $20 \%$ \\
\hline
\end{tabular}

Table 2.1: Differentiation opportunities in EU primary law

\section{Independent variables}

In the remainder, I compute economic and ideational preferences for all EU Member States since 1993. To cope with economic preferences, I collect the gross domestic product (GDP) per capita of the respective countries in 2005 constant US-Dollar from the World Bank. To cope with ideational preferences, I collect the degree of exclusive national identities, which is based on the percentage of citizens that state in Eurobarometer surveys that they feel exclusively national as opposed to national and European, European and national or European only. Measuring identity-based euroscepticism eschews some of the difficulties with the most common indicator for euroscepticism, which is usually derived from the Eurobarometer question whether citizens find the participation of their country in the EU a good thing, a bad thing or neither good nor bad. For this latter indicator suffers from the problem that it has not been surveyed after the year 2011 and must be suspected to be more dependent on economic or other short-term developments than identity-based euroscepticism. 
As such, measuring identity-based euroscepticism is better suited to offer meaningful results 3

I measure two of the three variants of heterogeneity from hypothesis 2 in the following, namely system-level heterogeneity and unit-level heterogeneity. I do so to investigate the relationship between the role of the attributes of individual states and the role of the size of EU membership, a topic I touched upon repeatedly in the above. To measure the role of unit-level heterogeneity, I follow the arguments of Schimmelfennig and Winzen (2014) and measure GDP per capita and exclusive national identities as is, that is, with no further computations. Here, I hypothesize that states with more exclusive national identities and lower values of wealth are more likely to realize differentiation opportunities than wealthier states and such with constituents that identify more with the EU. Given the distinction in constitutional DI and instrumental DI, I expect a positive correlation between identity and DI in treaty revisions as well as a negative correlation between wealth and DI in enlargement rounds. I also expect that identity is unable to explain DI in enlargement rounds and that wealth is unable to explain DI in treaty revisions. To measure system-level heterogeneity, I measure the number of EU Member States and thus assume that system-level heterogeneity increases with EU membership. I expect a positive relationship between system-level heterogeneity and DI in both instrumental and constitutional DI. Later, I also introduce an indicator for system-level heterogeneity based on the substantive heterogeneity among EU Member States.

\section{Empirical analysis}

I find two very different narratives when looking at unit-level heterogeneity. With regard to exclusive national identity, the UK, Ireland and Denmark drive heterogeneity in 1993. In 1995, Sweden, the UK and Austria show the most exclusive national identities. In 2003, the UK, Finland and Sweden take these places. With

\footnotetext{
${ }^{3}$ I measure the degree of exclusive national identity using a number of Eurobarometer surveys immediately prior to treaty revisions or, in the case of enlargements, because states are usually only surveyed once they are EU Member States, immediately after accession. Overall, I evaluate 16 Eurobarometer surveys between the years 1992 and 2013. More specifically, I use the following surveys: TEU 1993/94: 37 (1992); Schengen 1995: 40 (1993), 42 (1994); Enlargement 1995: 43 (1995); Amsterdam 1999: 49 (1998), 50.0 (1998); Nice 2003: 57.1 (2002), 58.1 (2002); Enlargement 2004: 62.0 (2004); Prum 2006: 64.2 (2005); Enlargement 2007: 64.2 (2005); Lissabon 2010: 64.2 (2005), 73.4 (2010); ESM 2012: 76.4 (2011); TSCG 2013: 77.3 (2012), 79.3 (2013); Enlargement 2013: 79.3 (2013).
} 
Analysis

the Eastern Enlargement, Hungary, Greece and the Czech Republic immediately show the most exclusive national identities among all EU Member States. In general, however, the new Member States' degree of exclusive national identities shows a downward-tendency after EU accession. With regard to wealth, economic heterogeneity is largely driven by Portugal, Spain and Greece (the 1981 and 1986 enlargement rounds) in 1993. Finland only joins the middle ranks upon accession, whereas Austria and Sweden rank among the more wealthy countries. In 2004, however, from the ten Member States with the lowest GDP, nine are new Member States (the other one being Portugal, the exception Cyprus). Upon accession, Bulgaria and Romania are the poorest Member States. Croatia does only little better when it joins in 2013. In sum, economic and ideational heterogeneity are driven by very different countries, both over time and across variables.

Figure 2.2 strongly supports the idea that the chances of countries to realize differentiation opportunities decrease with wealth in instrumental DI and increase with the exclusiveness of a country's national identity in constitutional DI. For instance, I find that the comparatively poor 2004 enlargement round realized a relatively high number of differentiation opportunities, whereas the comparatively wealthy 1995enlargement round realized only a few differentiation opportunities. With treaty revisions, I find that the exceptionally eurosceptical Denmark and United Kingdom realized 11 differentiation opportunities each, whereas the rather euro-friendly Luxembourg or Germany realized only one or even zero differentiation opportunities since 1993, respectively. Conversely, although not shown here, wealth does not appear to affect constitutional DI, while identity does not appear to affect instrumental DI.

From table 2.2, I observe the result of the logistic regression models for both instrumental and constitutional differentiation. I introduce year-dummy variables into both models to make sure that I really capture the effects of my independent variables at the respective differentiation opportunities and work with robust, country-clustered standard errors. I observe that exclusive national identity has a significant effect in treaty revisions and not in enlargement treaties, whereas wealth has a significant effect in enlargement treaties, but not in treaty reforms. With regard to the direction of these results, I observe a positive relationship between exclusive national identity and constitutional DI as well as a negative relationship between wealth and instrumental DI. It is, in other words, those countries with the most 

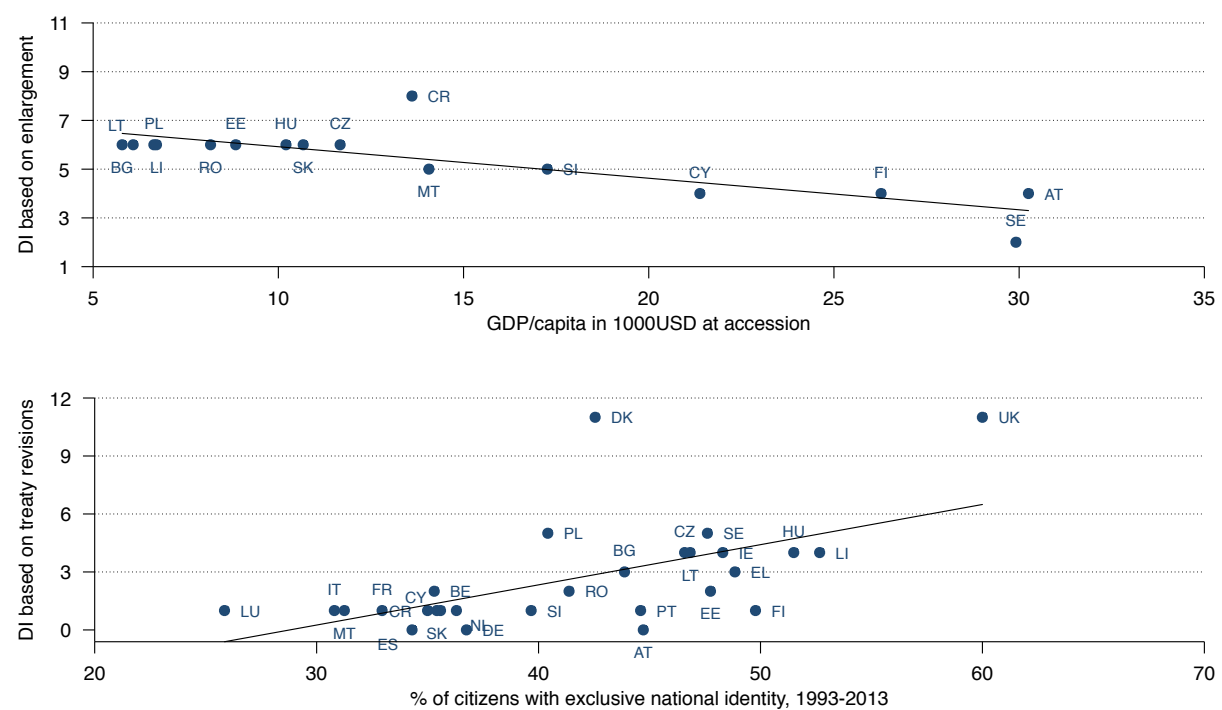

Figure 2.2: Descriptive bivariate relationships, identity and wealth

exclusive national identities that acquire differentiations in treaty revisions and the poorest new Member States that realize DI in enlargement negotiations. As already noted, this makes immediate sense. As poorer membership candidates are more dependent on the EU and less competitive than wealthier Member Sates, the EU is both more capable of discriminating against them and more willing to accommodate them by granting exemptions. Poorer membership candidates are thus prone to having a higher number of instrumental differentiations than wealthier membership candidates. On the other hand, because the less integration-friendly state is closer to the status quo and a veto player, it wields superior bargaining power and can credibly threaten to block treaty reform, as such making it more likely to being granted legal exemptions. More eurosceptical countries are thus prone to having a higher number of constitutional differentiations than their more euro-friendly counterparts.

We cannot directly interpret the size of the effects reported in table 2.2. However, based on the model estimates, I can simulate the predicted probability that a country realizes a differentiation opportunity with enlargement treaties or treaty revisions. Figure 2.3 shows the substantive effects of exclusive national identity and wealth on the probability that a country obtains a differentiation from enlargement treaties or treaty revisions; the simulations are based on the estimates reported in table 2.2. The $95 \%$ confidence interval indicates that the probability of the poorest countries to realize a differentiation opportunity with enlargement treaties 


\begin{tabular}{|c|c|c|c|c|}
\hline & \multicolumn{2}{|c|}{ Treaty revisions } & \multicolumn{2}{|c|}{ Enlargement } \\
\hline & Coeff. & SE & Coeff. & $\mathrm{SE}$ \\
\hline Identity & $0.10 * * *$ & 0.01 & 0.00 & 0.00 \\
\hline Wealth & -0.00 & 0.01 & $-0.02 * * *$ & 0.00 \\
\hline 1993 & (baseline) & & & \\
\hline 1995 & $4.34 * * *$ & 0.80 & & \\
\hline 1999 & -0.97 & 0.61 & & \\
\hline 2003 & (no DI) & & & \\
\hline 2006 & $6.88 * * *$ & 0.98 & & \\
\hline 2010 & 0.29 & 0.53 & & \\
\hline 2012 & $3.90 * * *$ & 0.62 & & \\
\hline 2013 & $4.10 * * *$ & 0.82 & & \\
\hline 1995 & & & (baseline) & \\
\hline 2004 & & & 0.02 & 0.16 \\
\hline 2007 & & & -0.03 & 0.17 \\
\hline 2013 & & & $0.27 *$ & 0.15 \\
\hline Constant & $-8.65 * * *$ & & $-1.27 * * *$ & \\
\hline $\mathrm{N}$ & 1864 & & 500 & \\
\hline $\begin{array}{l}\text { Log } \\
\text { pseudolikelihood }\end{array}$ & -178.44 & & -227.68 & \\
\hline
\end{tabular}

Note: Logistic regression models with year-dummy variables and robust country-clustered standard errors.

$* * *=\mathrm{p}<0.01, * *=\mathrm{p}<0.05, *=\mathrm{p}<0.1$

Table 2.2: Logit models of probability that country realizes DI 
is between $19 \%-22 \%$, whereas the wealthiest new Member States have about an $8 \%-13 \%$ chance of doing so. At the same time, Member States with highly exclusive national identity have about a $11 \%-25 \%$ chance to acquire a differentiation in treaty revisions, whereas the most inclusive countries have about a $0.0 \%-0.2 \%$ chance of doing so.
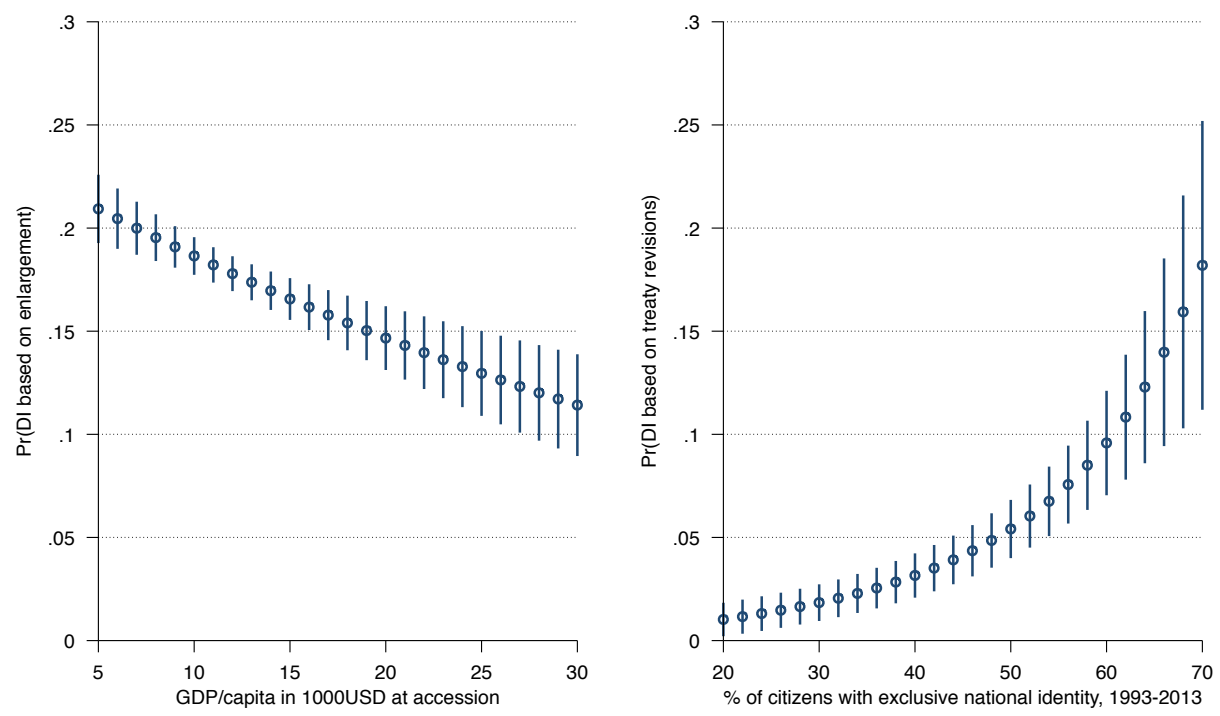

Figure 2.3: Effects of national identity and wealth on DI

Turning to system-level heterogeneity, figure 2.4 shows that the role of the number of EU Member States is as expected, as higher values of EU membership go hand-in-hand with higher values of realized differentiation opportunities. I find this conjecture to be intact in both instrumental and constitutional DI, although the relationship appears to be more robust in instrumental DI. I here measure the average number of realized differentiation opportunities per country to reflect the conjecture that the degree of system-level heterogeneity increases the chances of individual countries to realize differentiation opportunities. This finding is more insightful than one might acknowledge on first sight, for while it may be considered obvious that more EU Member States mean a higher absolute number of realized differentiation opportunities, the fact that an increase in EU Membership influences the share of realized differentiation opportunities per country is not as intuitive. While I cannot really substantiate why the number of EU Member States influences the use of differentiation opportunities with my statistical analysis, I gave hints at the connection between system-level heterogeneity and DI in the above, hypothesizing that 
it becomes less likely for countries to find substantive common grounds and more likely for them to engage in political conflict with increasing system-level heterogeneity, thus leading to a decreasing ability of countries to find compromises and hence an increasing chance for the realization of differentiation opportunities.
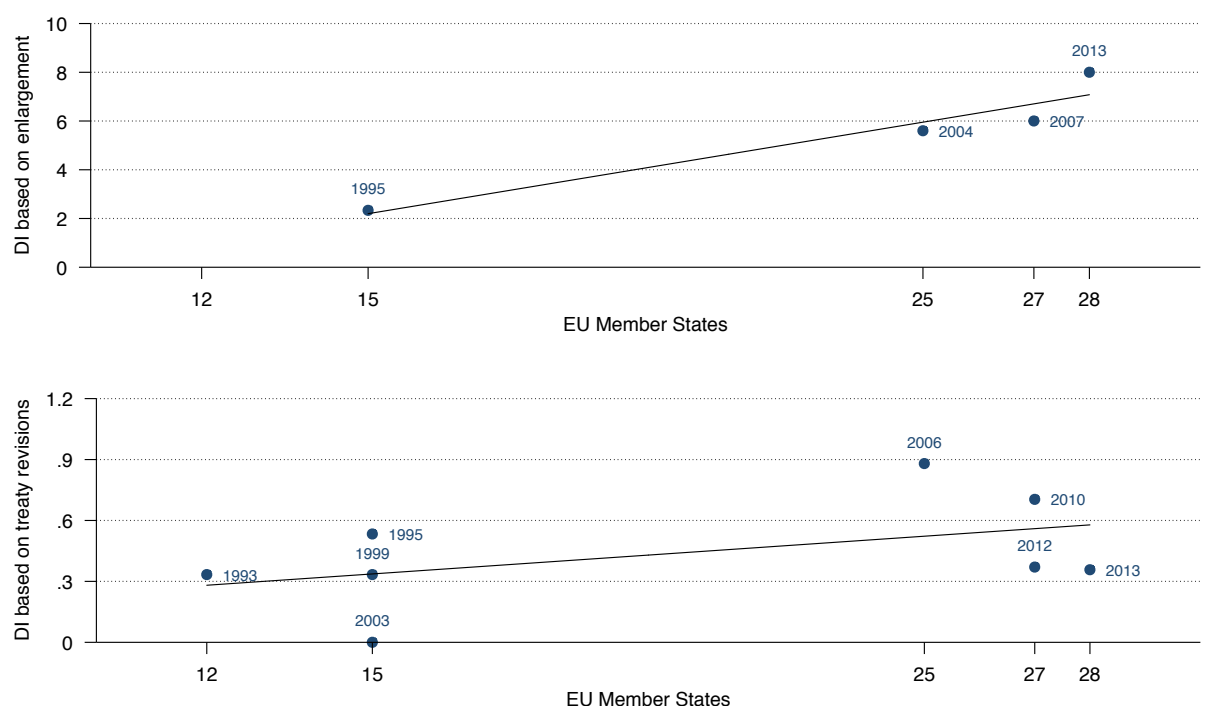

Figure 2.4: Descriptive bivariate relationships, EU membership

From table 2.3, I observe the result of the logistic regression models for the effect of EU membership on both instrumental and constitutional DI. I here introduce country-dummy variables and work with robust, year-clustered standard errors. I thus investigate the effect of the number of EU Member States on the chances of individual countries to realize differentiation opportunities, as conjectured in the above. I observe that the number of EU Member States increases the chances of countries to realize differentiation opportunities, albeit it only exerts a statistically significant effect in enlargement negotiations. This largely corresponds to the visual examination of figure 2.4 .

The number of EU Member States is not necessarily equal to the degree of heterogeneity in the EU. An acceding Member State may, for instance, have a degree of national exclusive identity that is exactly the average degree of the existing Member States, thus not adding to overall heterogeneity. On the other hand, an acceding Member State may be an outlier on some preference dimension and thus add substantially more to heterogeneity than what its accession would mean simply in terms of Member States. To capture such considerations, I create an alternative indicator 
for system-level heterogeneity by calculating the sum of all standardized distances from the yearly mean values across both identity and wealth. I standardize these distances in order to allow for a meaningful interpretation of the summed values. Before summing up, I convert all negative numbers into positive values to guarantee that larger values mean more heterogeneity.

I find that my proxy for substantive heterogeneity explains the use of differentiation opportunities on a statistically significant level in both treaty revisions and enlargement negotiations, although it only passes the $\mathrm{p}<0.1$-level with treaty revisions. To be sure, the number of EU Member States and my proxy for heterogeneity are strongly correlated. The number of EU Member States explains heterogeneity on the $\mathrm{p}<0.01$-level and with an $\mathrm{R}^{2}$ of 0.99 . And yet, the remaining variance between these two indicators leads to different results. I find, for instance, an increase in heterogeneity with every enlargement round, most substantially so with the 2004 enlargement round. This corresponds to the idea that more EU Member States mean more system-level heterogeneity. I also find, however, that heterogeneity fluctuates without any changes in EU membership, including a decrease in heterogeneity between some of the years in our sample - something that the common narrative would not have expected. As such, the indicator offers the potential to really substantiate the effect of heterogeneity on DI and to go beyond the mere notion that more EU Member States mean more heterogeneity.

I conjecture that we should take the explanatory power of my proxy on substantive system-level heterogeneity with a grain of salt. The role of EU Member States and heterogeneity is similar in enlargement negotiations, validating the explanatory power of system-level heterogeneity in this regard. Overall, however, the role of system-level heterogeneity for DI in EU primary law remains more ambiguous than the role of unit-level heterogeneity. Whereas economic and ideational attributes of EU Member States robustly explain the realization of differentiation opportunities in EU primary law, the role of system-level heterogeneity remains more uncertain.

\subsection{Conclusion}

To conclude, I would like to return to the two common narratives that I touched upon at the beginning of this study. To begin with, I stated that the literature on DI conjectures that the existing approaches to European integration are unable to 


\begin{tabular}{|c|c|c|c|c|c|c|c|c|}
\hline & \multicolumn{2}{|c|}{ Treaty revisions } & \multicolumn{2}{|c|}{ Enlargement } & \multicolumn{2}{|c|}{ Treaty revisions } & \multicolumn{2}{|c|}{ Enlargement } \\
\hline & Coeff. & SE & Coeff. & SE & Coeff. & SE & Coeff. & $\mathrm{SE}$ \\
\hline $\begin{array}{l}\text { Member } \\
\text { States }\end{array}$ & 0.09 & 0.06 & $0.03 * * *$ & 0.00 & & & & \\
\hline $\begin{array}{l}\text { Hetero- } \\
\text { geneity }\end{array}$ & & & & & $0.08^{*}$ & 0.04 & $0.02 * * *$ & 0.00 \\
\hline Belgium & (baseline & & & & (baselin & & & \\
\hline Germany & (no DI) & & & & (no DI) & & & \\
\hline Italy & 0.00 & 0.77 & & & 0.00 & 0.77 & & \\
\hline France & -0.70 & 0.76 & & & -0.70 & 0.76 & & \\
\hline Netherlands & -0.70 & 0.76 & & & -0.70 & 0.76 & & \\
\hline Luxembourg & -0.70 & 0.76 & & & -0.70 & 0.76 & & \\
\hline Denmark & $1.69 * *$ & 0.85 & & & $1.72 * *$ & 0.83 & & \\
\hline UK & $1.80 * *$ & 0.76 & & & $1.83 * *$ & 0.73 & & \\
\hline Ireland & 0.71 & 0.76 & & & 0.72 & 0.76 & & \\
\hline Greece & 0.41 & 0.77 & & & 0.41 & 0.77 & & \\
\hline Portugal & -0.70 & 0.76 & & & -0.70 & 0.76 & & \\
\hline Spain & (no DI) & & & & (no DI) & & & \\
\hline Austria & (no DI) & & (baseline) & & (no DI) & & (baseline) & \\
\hline Finland & -0.59 & 0.77 & 0.00 & 0.00 & -0.62 & 0.76 & 0.00 & 0.00 \\
\hline Sweden & $1.07 *$ & 0.59 & $-0.77 * * *$ & 0.00 & $1.05 *$ & 0.59 & $-0.88 * * *$ & 0.00 \\
\hline Cyprus & -0.18 & 0.83 & $-0.44 * * *$ & 0.00 & -0.34 & 0.78 & $-0.49 * * *$ & 0.00 \\
\hline Czech Rep. & $1.27 * *$ & 0.56 & $0.03 * * *$ & 0.00 & $1.11 *$ & 0.59 & $-0.01 * * *$ & 0.00 \\
\hline Estonia & 0.53 & 0.76 & $0.03 * * *$ & 0.00 & 0.36 & 0.79 & $-0.01 * * *$ & 0.00 \\
\hline Hungary & $1.27 * *$ & 0.56 & $0.03 * * *$ & 0.00 & $1.11 *$ & 0.59 & $-0.01 * * *$ & 0.00 \\
\hline Latvia & $1.27 * *$ & 0.56 & $0.03 * * *$ & 0.00 & $1.11 *$ & 0.59 & $-0.01 * * *$ & 0.00 \\
\hline Lithuania & $1.27 * *$ & 0.56 & $0.03 * * *$ & 0.00 & $1.11 *$ & 0.59 & $-0.01 * * *$ & 0.00 \\
\hline Malta & -0.18 & 0.83 & $-0.18 * * *$ & 0.00 & -0.34 & 0.78 & $-0.23 * * *$ & 0.00 \\
\hline Poland & $1.53 * *$ & 0.63 & $0.03 * * *$ & 0.00 & $1.36^{* *}$ & 0.69 & $-0.01 * * *$ & 0.00 \\
\hline Slovakia & -0.18 & 0.83 & $0.03 * * *$ & 0.00 & -0.34 & 0.78 & $-0.01 * * *$ & 0.00 \\
\hline Slovenia & -0.18 & 0.83 & $-0.18 * * *$ & 0.00 & -0.34 & 0.78 & $-0.01 * * *$ & 0.00 \\
\hline Bulgaria & 0.98 & 0.76 & $-0.07 * * *$ & 0.00 & 0.82 & 0.81 & $-0.08 * * *$ & 0.00 \\
\hline Romania & 0.55 & 1.08 & $-0.07 * * *$ & 0.00 & 0.39 & 1.12 & $-0.08 * * *$ & 0.00 \\
\hline Croatia & (no DI) & & (omitted) & & (no DI) & & (omitted) & \\
\hline Constant & $-5.03 * *$ & & $-2.38 * * *$ & & $-6.66 * *$ & & $-2.36 * * *$ & \\
\hline $\mathrm{N}$ & 1992 & & 500 & & 1992 & & 500 & \\
\hline $\begin{array}{l}\text { Log } \\
\text { pseudolikelihood }\end{array}$ & -279.73 & & -227.15 & & -273.71 & & -227.15 & \\
\hline
\end{tabular}

Note: Logistic regression models with country-dummy variables and robust year-clustered standard errors.

$* * *=\mathrm{p}<0.01, * *=\mathrm{p}<0.05, *=\mathrm{p}<0.1$

Table 2.3: Logit models of probability that country realizes DI 
explain DI. As we have seen, however, the approach employed in this study, which is largely based in a liberal intergovernmentalist framework, is able to convincingly explain the role of preference heterogeneity for the realization of differentiation opportunities in EU primary law. While this certainly is no encompassing explanation of the phenomenon, it still highlights that the literature on DI has prematurely written off the existing approaches to European integration, especially in light of the fact the literature entails only few studies relating to an established database on the extent and development of DI.

Furthermore, I proposed that the existing literature conjectures that DI is steadily on the rise due to the increasing width and depth of the EU. In this regard, while I found that the number of EU Member States only partially explains DI in EU primary law, substantive heterogeneity, which is closely linked to the number of EU Member States, more extensively explains the use of differentiation opportunities. I also found that the attributes of states robustly explain the use of differentiation opportunities in both instrumental and constitutional DI. DI is thus not just about the heterogeneity among a group of states, but also about the attributes of individual states. In other words, while the idea that DI is the result of an increasing width of the EU is not per se wrong, it remains somewhat ambiguous and masks quite a bit of the complexity behind the relationship between EU membership, countries' attributes, preference heterogeneity and DI in EU primary law.

Throughout this paper, I came across puzzles worthy of their own studies. To begin with, I expect my hypotheses on the causes of DI to also apply to the differences in the use of differentiation opportunities as reported in table 2.1. For instance, I expect enlargement rounds to result in relatively high rates of realized differentiation opportunities because they usually go hand in hand with the integration of a rather small group of states largely differing in their general predispositions, such as the integration of comparatively poor new Member States in the enlargement rounds with and after the year 2004. I would also hypothesize that revisions in individual policy areas result in more DI than comprehensive treaty revisions because we are more likely to witness uneven distributions of preferences and asymmetric group sizes in single-issue bargaining situations than in multi-issue bargaining environments, where issue-linkages in essence render such thoughts impenetrable. In any case, I find the differences in the use of differentiation opportunities to be an important and potentially insightful topic for further research on differentiated integration 
in the EU.

I also found measuring system-level heterogeneity to be much more demanding than originally expected. The indicators for system-level heterogeneity that I employed in this study are highly correlated. At the same time, the number of EU Member States and any measure of heterogeneity based on the substantive characteristics of these same Member States must necessarily be correlated. As such, while I was able to show that heterogeneity does a good job in explaining the chances of individual countries to realize differentiation opportunities and that it does so beyond the mere notion that more EU Member States mean more heterogeneity, I remain somewhat insecure about the robustness of this indicator. Establishing a robust explanatory power of substantive heterogeneity beyond the explanatory power of the number of EU Member States would be an important and insightful addition to the literature on DI, especially in EU primary law.

This study leaves a number of further questions for investigation. To begin with, although it already clarifies a number of dimensions of heterogeneity, it still remains shy of an encompassing theoretical or empirical treatment of the topic. Most importantly, I entirely omitted the study of other determinants of European primary law differentiation than Member States' preferences, including the role of bargaining power and domestic constraints (e.g. Moravcsik 1993). Neither did I touch upon the role of policy area characteristics, which figure prominently in existing studies to DI (e.g. Schimmelfennig/Winzen 2014). I also entirely omitted the role of group-level heterogeneity and did not combine different explanatory factors into a more elaborate, encompassing empirical model at this point. Future research should surely give more attention to these consideration. Finally, the analysis at hand offers no insights into the drivers of EU secondary law differentiation. It remains to be clarified whether the extent and development of EU secondary law differentiation corresponds to the patterns described in the above. While this may indeed be the case, ideational and institutional effects may be of more importance in secondary law legislation, as the creation of EU secondary law is defined by denser social interaction and more substantial delegation to the European level. 



\section{Chapter 3}

\section{Delegation and EU Secondary Law Differentiation}

One of the core questions of European integration research is whether or not institutions do matter. Do supranational institutions, in other words, deserve the status of an independent variable? Or is the EU continuously dominated by Member States preferences? The most intuitive way to refer to the debate about the importance of European institutions is with reference to the concept of delegation and the three main theories of institutionalism (e.g. Hall/Taylor 1996; Pollack 1997). According to rational institutionalism, states establish international institutions to deal with functional problems of international cooperation. The degree to which states are ready to delegate competencies to institutions depends on the contestation of these competencies and the benefits states ascribe to handling a given policy area on the supranational level. States thus delegate competencies selectively, and no independent effects develop beyond their choices. According to the logic of historical institutionalism, supranational institutions almost necessarily develop actor qualities on their own. Once set in place, they start to exert independent effects on international cooperation beyond the powers and control of the states that established them in the first place. Here, contrary to functional institutionalism, institutions indeed are independent variables on their own. This is also true in sociological institutionalism, although the effects here stem from the role of identities and ideas and materialize through the processes of socialization rather than institutionalization. Where supranationalism and liberal intergovernmentalism thus disagree over the precise nature of their explanatory variables in an essentially similar framework, sociological in- 
stitutionalism offers a true alternative and supplement to these approaches.

In this study, I test the ideas of delegation against the EUDIFF dataset on the differentiated character of EU secondary law. EU Member States have delegated an increasing amount of competencies to the EU level over time, while the EU has become increasingly supranationalized. At the same time, European institutions are directly involved in the legislation of EU secondary law. I thus find everything necessary to investigate the role of delegation in this set-up. In the perspective of rational institutionalism, which I relate to liberal intergovernmentalism in the remainder, I expect to find independent effects from delegation only very selectively, namely in market policies. In the perspective of historical institutionalism, which I relate to supranationalism in the following, I expect to find broad and substantial effects from the increasing supranationalization of legislative decision making on DI. With regard to sociological institutionalism, which I relate to post-functionalism, I expect the degree of differentiation to be negatively correlated to the age of a policy area.

I find only one statistically significant effect in my data, namely a negative effect of the supranationality of decision making on the extent of DI in market policies. This bodes well with my liberal intergovernmentalist conjecture, in which I propose that states only delegate competencies in line with the logic of incomplete contracting, which is at the core of the liberal intergovernmentalist reasoning about European integration (e.g. Moravcsik 1993). Combining these theoretical and empirical insights, I conjecture that states are willing to delegate sovereignty to the supranational level and to allow supranational institutions to exert their effects in market policies more than in any other policy area because of their comparatively low levels of contestation, the large potential gains from cooperation and the high level of uncertainty regarding the details of specific delegated decisions. I also find, however, my results to remain somewhat ambiguous and contradictory.

\subsection{DI in EU Secondary Law}

In the following, I define my dependent variable and show its development over both time and policy areas. I also introduce the common narrative on differentiated integration, according to which DI is the result of an increasing heterogeneity and contestation of European integration, a conjecture that I will use as a backdrop to 
my arguments and hypotheses throughout the remainder of this study.

\section{Measuring DI}

This study is interested in the differentiated character of EU secondary law across policy areas. The explanatory variables of this study must be expected to influence legislative activity, not the legislative body. Hence I consider only the production of EU secondary law, not its cumulative body. I thus count each legislative act only once, in the year it is put into force. On this basis, I investigate a simple dependent variable in this study, namely the share of differentiated acts as compared to all legal acts legislated in a given year. I also code policy areas. Policy area coding is reflected in table 3.1. It is based on primary law references, which are coded throughout the EUDIFF dataset. In a first step, primary law articles have been assigned to policy areas according to their heading in the treaty structure. This has been done for every treaty article and every primary law treaty, resulting in an extensive reference table. Subsequently, every legislative act has been checked for its primary law reference and then linked to this reference table based on the year it was put into force. Where more than one primary law reference is given, I restrict my analysis to the first of these. Table 3.1 shows the individual policy areas. I also aggregated four policy fields, however: market policies, agriculture, regulatory policies and core state powers.

\section{Development of DI}

The literature on DI knows a common narrative, according to which DI is the result of the increasing scope and depth of European integration and thus in tendency increasing over time. In the remainder of this study, I assess the applicability of this argument to EU secondary law. Here, the respective argument in full (Schimmelfennig/Winzen 2014, 360):

The more countries the EU integrates, the more likely it is to have a membership with heterogeneous preferences and capabilities. The more policy sectors it integrates, the more likely they will include valueladen or redistributive policies that provoke conflict and are difficult to manage or settle. Finally, the more supranationally centralized European integration becomes, the more it reduces state autonomy and the more 


\begin{tabular}{|c|c|}
\hline Policy field & Policy area \\
\hline Market policies & $\begin{array}{l}\text { Free movement of goods, workers, services, capital } \\
\text { Freedom of establishment } \\
\text { Competition } \\
\text { Taxation } \\
\text { Industry } \\
\text { Tourism } \\
\text { Research and technology }\end{array}$ \\
\hline Agricultural policies & Agriculture \\
\hline Regulatory policies & $\begin{array}{l}\text { Consumer protection } \\
\text { Public health } \\
\text { Social policy } \\
\text { Employment policy } \\
\text { Economic and social cohesion } \\
\text { Environment } \\
\text { Energy } \\
\text { EURATOM } \\
\text { Transport } \\
\text { Trans-European networks }\end{array}$ \\
\hline Core state powers & $\begin{array}{l}\text { CFSP } \\
\text { Development cooperation } \\
\text { Justice } \\
\text { JHA } \\
\text { Culture } \\
\text { Monetary policy } \\
\text { Economic policy }\end{array}$ \\
\hline Institutional policies & $\begin{array}{l}\text { Principles } \\
\text { Institutional provisions } \\
\text { General and final provisions } \\
\text { Protocol on privileges and immunities and the EIB } \\
\text { Administrative cooperation } \\
\text { Overseas territories } \\
\text { Financial provisions }\end{array}$ \\
\hline
\end{tabular}

Table 3.1: Coding of policy areas 
likely it provokes nationalist backlash. Increased heterogeneity and conflict, in turn, threaten to create deadlock in an organization based to a large extent on intergovernmental consensus - particularly in the case of treaty negotiations that require unanimous agreement. DI then helps to overcome deadlock by allowing the Member States to co-operate at different levels of integration that fit their preferences and capabilities.

Figure 3.1 shows the development of DI in EU secondary law over time. We see that differentiation in EU secondary law is most substantial in the late 1950s and in the 1960s. In 1958, for instance, more than $30 \%$ of the (few) legislated secondary acts were differentiated. Then, this figure drops to roughly $10 \%$ to $20 \%$ in the 1970s. In the 1980s and 1990s, the numbers mostly fluctuate between $5 \%$ and $10 \%$. They increase again in the 2000s and remain at around $10 \%$ into the year 2009. Overall, we see a rather stable development of DI in EU secondary, although the 1960s and 1970s are defined by much more volatility than the periods thereafter. I thus find that the common narrative on the development of DI in EU secondary law must be questioned. To begin with, secondary law differentiation is anything but linear, but develops, as we have just seen, in tendency sideways. Also, while some enlargement rounds appear to have a substantial impact on the development of DI, especially the 1973 and 2004 enlargement rounds, others do not, especially the 1981 and 1995 enlargement rounds. Similarly, while some treaty revisions have a rather substantial impact on DI, for instance the 1999 Treaty of Amsterdam, others remain largely absent, such as the 1986 Single European Act. Overall, I find that the development of DI in EU secondary law is much less intuitive than the common argument suggests.

\section{Development of DI over policy areas}

Table 3.2 shows the development of our dependent variable over time and policy areas.1. As we can see, market policies and agricultural policies are the most differentiated ones, followed by core state powers and regulatory policies. Market policies start from a relatively high share of $12.0 \%$ of differentiated acts in the

\footnotetext{
${ }^{1}$ Please note that I only aggregated this data to decades to make it easier to read; my data analysis will be conducted on the level of the year. Please also note that I will not further inquire institutional policies, for these not only contain no secondary law differentiation, but also remain largely outside the political logic we are trying to assess in this study.
} 


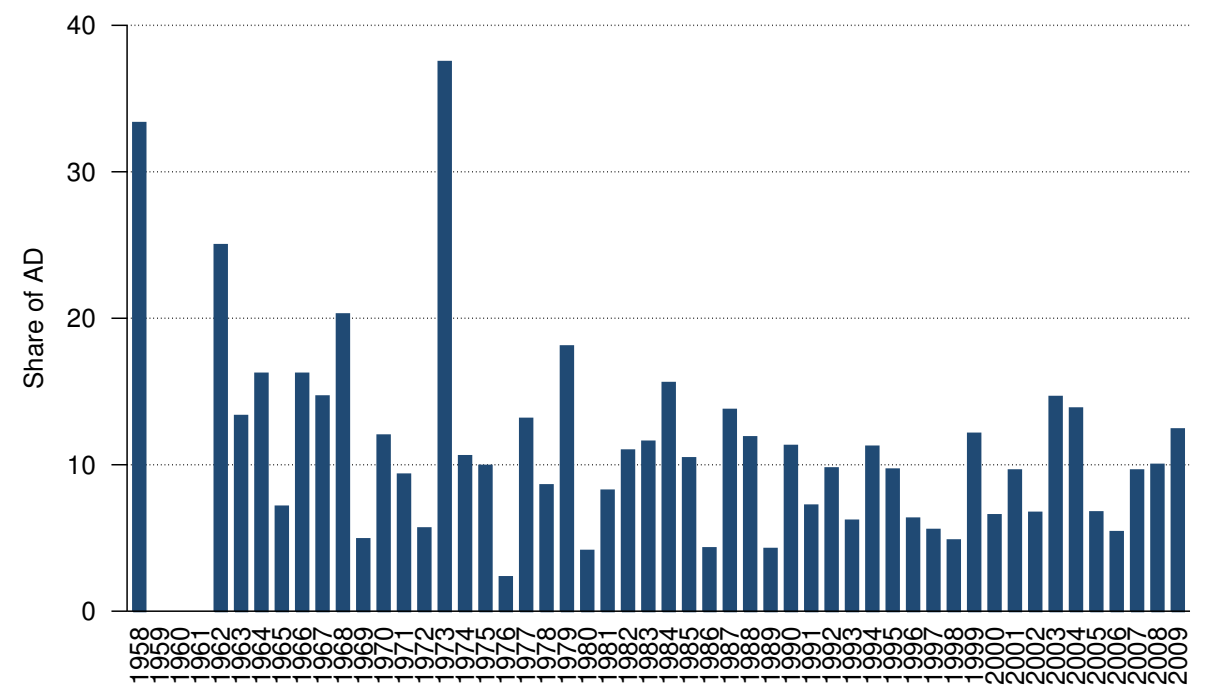

Figure 3.1: Development of DI in EU secondary law

1960s and reach their peak in the 1970s. They tend sideways into the 1980s, only to lose strongly in differentiated character thereafter. The differentiated character of agricultural policies also peaks in the 1970s. It tends sideways throughout the 1980 s and 1990s, but loses strongly in the 2000s. Regulatory policies remain at a lower level of differentiation than both market policies and agricultural policies, but start on the highest level of all policy areas in the 1960s. Differentiation rebounds somewhat in the 1990s, after it decreased substantially between the 1960s and the 1970s. The differentiation in core states powers remains on a low level and even reaches the lowest overall numbers in the 1990s. It then, however, and perhaps unsurprisingly, significantly increases in the 2000s. Over all policy areas, we witness an increase in DI from the 1960 s to the 1970s, followed by a gradual decrease into the 1990s and a strong rebound of DI in the 2000s, the latter being largely driven by the increasing DI in core state powers. Making sense of these developments lies at the core of the remainder of this study.

\subsection{Theories and Hypotheses}

In Duttle et al. (2013), we investigated the role of a number of system-level variables on the extent of DI in EU secondary law. We found a statistically significant 
Theories and Hypotheses

\begin{tabular}{|c|c|c|c|c|c|c|}
\hline & $1960 s$ & $1970 \mathrm{~s}$ & $1980 \mathrm{~s}$ & 1990s & $2000 s$ & Overall \\
\hline Market policies & 12.0 & 21.2 & 20.9 & 15.1 & 7.8 & 16.7 \\
\hline Agriculture & 13.1 & 13.6 & 9.5 & 10.0 & 6.0 & 10.1 \\
\hline Regulatory policies & 13.6 & 5.2 & 6.3 & 8.6 & 3.8 & 7.2 \\
\hline Core state powers & 6.2 & 7.7 & 7.2 & 4.7 & 15.2 & 8.5 \\
\hline Overall & 11.7 & 12.7 & 9.5 & 8.4 & 9.5 & 10.6 \\
\hline
\end{tabular}

Table 3.2: Development of DI over policy areas

explanatory power of trade interdependence, parliamentary preferences and the novelty of Member States and policy areas on DI in EU secondary law. We did not find any results for our hypotheses about the role of legislative procedures. As we only looked at our dependent variable on the systemic level, however, we did not seek to explain differentiation across policy areas or Member States. Ultimately, we did not pursue our analysis any further because we found our dependent variable to be too abstract to offer any meaningful results. More specifically, we feared that the high level of abstraction of our dependent variable enabled us to capture mainly temporal effects and to miss more fine-grained and relevant results. In this vein, I re-investigate the role of supranationality and policy area age in this study. To be sure, I do not seek to engage in competitive theory testing in the following, but to explore the explanatory power of a number of plausible explanatory variables derived from the main theories on European integration.

\section{Liberal intergovernmentalism}

Liberal intergovernmentalism explains European integration as a result of international interdependence, state preferences and intergovernmental bargaining (Moravcsik 1993; 1998). Crucially, the liberal intergovernmentalist framework pictures state preferences to be defined by key societal actors; groups articulate preferences, governments aggregate them. With regard to European integration, liberal intergovernmentalism proposes that demand for integration stems from the incentives created by economic interdependence and the international policy externalities among nations. More specifically, cooperation becomes an option when interdependence creates negative policy externalities on states that they are unable to avoid unilaterally (Moravcsik 1993, 485). In this perspective, cooperation through international insti- 
tutions is a purely functional choice. At the core of liberal intergovernmentalism thus lies a functional theory of international institutions.

Functional theories of institutions start from the assumption that states establish international institutions to efficiently deal with problems of international cooperation. In this understanding, institutions allow for greater cooperation by providing information and reducing uncertainty where transaction costs are high. Institutions thus serve as passive structures to identify issues, negotiate bargains as well as as to codify, monitor and enforce agreements. They thus allow for a contractual environment enabling efficient intergovernmental bargaining (Moravcsik 1993, 508; also see Keohane 1984; Hasenclever et al. 1997). This certainly explains the role of EU institutions as a framework for negotiating major decisions at intergovernmental conferences. The EU's acquis communautaire stabilizes a set of rules that can only be changed by unanimous consent. The institutions promote cooperation by providing information, determining a fora for intergovernmental bargaining and enabling the codification, monitoring and enforcement of agreements (e.g. Moravcsik 1993, 508).

The above mainly captures the role of European institutions in intergovernmental conferences and thus with regard to primary law developments. With regard to DI in EU secondary law, two conjectures best characterize the liberal intergovernmentalist approach. The first conjecture is straightforward, namely that states retain control over European integration also in EU secondary law. Neither the supranationality of decision-making nor the age of a policy area can thus be expected to have an influence on DI. Where supranationalism and post-functionalism essentially expect different or additional explanatory factors to be at play for the extent and development of DI in EU primary and secondary law, liberal intergovernmentalism conjectures that such effects do not exist. Institutions are nothing more than a functional solution to problems of interdependence and cooperation and a reflection of national preferences; the liberal intergovernmentalist perspective can thus be understood as the null-hypothesis to supranational and post-functional conjectures. Another way to put this is that in liberal intergovernmentalism, the national governments, as principals, always keep control over their agents, the European institutions (e.g. Pollack 1997; 2004).

The above must be qualified, however. For, the second liberal intergovernmentalist conjecture to DI in EU secondary law is that under certain conditions, states 
indeed delegate powers to the European institutions. In essence, liberal intergovernmentalism proposes that states only delegate competencies as a response to the problem of incomplete contracting (Garrett/Weingast 1991). Where Member States have shared goals, but are unable or unwilling to foresee all future contingencies involved in the realization of these goals, they may have an incentive to establish decision-making procedures or to empower neutral agents to propose, mediate, implement, interpret and enforce agreements (Moravcsik 1993, 509). Thereby, states only delegate competencies when the potential gains from cooperation are substantial, the level of uncertainty regarding the details of specific delegated decisions is high and the level of political risk for individual governments is low (Moravcsik 1993, 510-511).

The most immediate case where the conditions of incomplete contracting are met is with market policies. Here, the potential gains from cooperation are certainly substantial. Market policies are at the core of the EU and designed to allow for the elimination of negative policy externalities and the realization of market- and thus growth-potentials. Furthermore, the level of uncertainty with regard to future decisions is high. Market developments are highly dynamic and, especially where they hinge on technological developments, impossible to foresee. At the same time, due to the largely beneficial effects from market cooperation, the level of political risk involved for individual governments is low. In sum, I expect supranational forces of delegation to be at play even in a liberal intergovernmentalist framework, but only so in market policies:

$H_{1}$ : The extent of DI decreases as the supranationality of decisionmaking increases, but only in market policies.

\section{Supranationalism}

In the supranationalist framework employed in this study, European integration is the result of transnational preferences and institutional dynamics of delegation. Similar to liberal intergovernmentalism, supranationalism conceptualizes the preferences of states to emanate from society. Where liberal intergovernmentalism focuses on the effects of economic interdependence, however, supranationalism investigates the importance of transnational activity, that is, it focuses on those societal actors that engage in transactions and communications across national bor- 
ders. More importantly, however, where liberal intergovernmentalism conceptualizes national governments to be the key actors of European integration, supranationalism conjectures that governments are only reactive elements, constantly adjusting to the integration that is going on all around them. While the grand bargains are thus by definition intergovernmental, they are nothing but the arenas to reconcile the demands of a nascent, always developing, transnational society (Stone Sweet/Sandholtz 1997, 306-307).

Where supranationalism departs most substantially from liberal intergovernmentalism is in its theory of international institutions. Supranationalism argues for the relevance of supranational developments in influencing integration outcomes and the endogenous dynamics that increase integration beyond the control and interests of Member States (e.g. Haas 1968). Once movement towards the supranational pole begins, in other words, European rules generate a dynamic of their own. The supranational content of the EU does not fluctuate up and down in reflection of daily interstate bargaining, but generates stable movement towards the supranational pole (Stone Sweet/Sandholtz 1997, 310). Supranationalism thus questions the functional institutionalist perspective that states can design institutions to perform efficiently and reliably according to their preferences (Leuffen et al. 2013, 65; also see Pierson 1996; 2000; 2004). In this variant of historical institutionalism, the principals thus increasingly lose control over their agents. Despite numerous attempts to hold their agents at bay, these will seek to use the powers ascribed to them and especially to increase their autonomy (Pierson 1998, 35).

Given the above, supranational actors can be assumed to have a preference towards uniform integration. Differentiation makes European governance more complicated, as decision-making and monitoring becomes more cumbersome. DI limits the reach of supranational institutions and thus the powers attributed to them by state actors, while institutional actors tend to believe that supranational regulations are more efficient than national regulations. Hence supranational actors can be assumed to work towards overcoming exemptions and derogations. Furthermore, they can be assumed do so the more successfully the more capable they are. In other words, the capacity of supranational actors to shift policy outcomes in line with their preferences increases with their degree of discretion (for the entire argument, see Leuffen et al. 2013, 77-81). In this vein, uniform integration can be understood as another way of supranational institutions to foster supranationalization, or 
at least to not compromise on it, for by maximizing their reach, supranational institutions make sure to make use of all the supranational competencies they have been assigned. In consequence,

$\mathrm{H}_{2}$ : The extent of DI decreases as the supranationality of decisionmaking increases.

\section{Postfunctionalism}

Post-functionalism is a comparatively recent branch of EU theorizing that has its roots in IR theory, where it had established itself a couple of years earlier as the counterpart to the rationalist mainstream (e.g. Checkel 1998, Wendt 1992; 1999). In fact, not only did post-functionalism broaden the theoretical scope of EU studies; the study of the EU also helped advance the theory of post-functionalism (or constructivism) more generally (e.g. Christiansen et al. 2001; Checkel/Moravcsik 2001). Most simply put, post-functionalism stresses the importance of ideas and discourses for political behavior (Leuffen et al. 2013, 85). With regard to European integration, more specifically, post-functionalism focuses on ideational factors such as norms and identities that either facilitate integration via socialization (e.g. Checkel 2005) or constrain it via politicization (e.g. Hooghe/Marks 2008). That is, while liberal intergovernmentalism and supranationalism differ in their exact identification of the driving forces of European integration, they both find their answers in an essentially similar, functional logic. To post-functionalism, in contrast, European integration is the result of transnational community, that is, the strength of collective, common or compatible ideas and identities (Leuffen et al. 2013, 84-85).

Post-functionalism offers a theory of international institutions that is substantially different from those of both supranationalism and liberal intergovernmentalism. It is so on two accounts: First, sociological institutionalism assumes the primacy of ideational rather than material structures. In this perspective, instrumental (knowledge) and principled ideas (values and norms) as well as identities shape social preferences, interactions and outcomes in ways that cannot be reduced to material structures and interests (Leuffen et al. 2013, 85-87). Second, rather than behaving strategically or instrumentally and thus according to the logic of consequences, actors follow the logic of appropriateness. They thus do not judge behavioral alternatives according to their costs and benefits and hence considerations of 
utility, but by their conformity to values, norms and identities (March/Olsen 1999).

In sociological institutionalism, governmental preferences are endogenous rather than exogenously given. The identities, ideas and preferences of states can thus be modified or changed, say during negotiation periods or as a result of the participation in international institutions. In the case at hand, governmental preferences are thought to change with the involvement of national governments in the EU. This refers to the idea of socialization. In this perspective, institutions are not only the reflection of preferences, but also community building agencies and thus sites for the socialization of state representatives (Leuffen et al. 2013, 89). In this regard, we must distinguish between type I and type II socialization. Type I socialization refers to the adoption of new roles by state elites, whereas type II socialization refers to the changes in values and interests of state representatives. With regard to DI in EU secondary law, it is type II socialization that is of core interest. According to the principles of type II socialization, post-functionalism expects policy makers to converge on shared preferences with their exposure to one another and the legitimacy of ideas to them. Socialization in the EU is thus more likely to be successful the more frequent and intense the interaction of actors is, but it also also requires the actors to find these ideas legitimate (for the entire argument, see Leuffen et al. 2013, 95). In line with more general ideas about the role of preference heterogeneity and preference homogeneity for DI in both EU primary and secondary law, I conjecture that the extent of DI decreases as the interests of decision makers converge. In its most general formulation, I thus expect a reduction of DI with the age of a policy area. Thus,

$H_{3}:$ The extent of DI decreases as the age of a policy area increases.

\section{Saliency}

In yet another understanding, DI is the result of the saliency of a topic. This understanding largely derives from what I called the common narrative on DI in EU secondary law in the above. In this common perspective, DI is the result of increased heterogeneity and conflict and the subsequent danger of deadlock in European integration. I do not measure the role of preference heterogeneity in this study, but suggest that the role of political conflict can be subsumed under the term of saliency. I thus assume that topics become more contested the more salient they are. Impli- 
citly, I here also refer to the notion that specific periods of European integration have been defined by an increasing saliency of specific policy areas. For instance, while the 1980s are often seen as defined by the advancement of the single market, as reflected in the Single European Act, the 1990s are usually understood as being defined by the integration of core state powers such as monetary policy with the Treaty of Maastricht. With the increasing saliency of a topic, I thus also expect to witness increasing chances of differentiation opportunities being realized. I thus hypothesize:

$H_{4}$ : The extent of DI increases as the saliency of a policy area increases.

\subsection{Analysis}

In the following, I conceptualize and investigate my variables and conjectures. I find that my data largely correspond to the above hypotheses, especially the liberal intergovernmentalist hypothesis.

\section{Independent variables}

I measure the supranationality of a given policy area by investigating the involvement of the European Parliament (EP) in the relevant legal activity. In this regard, the EU knows of five different legislative procedures. In the codecision procedure, the Parliament and the Council jointly adopt EU legislation. Under the assent procedure, the Council must obtain Parliament's assent before certain decisions, which can accept or reject a proposal, but not amend it. If the Parliament does not give its assent to a proposal, the act cannot be adopted. Under the cooperation procedure, the Council can adopt a procedure by a qualified majority when it has the support of the Parliament, but needs to adopt a proposal unanimously if Parliament rejects it. In the consultation procedure, the Council must take note of the opinion of Parliament, but the Parliament has no means to reject a proposal, while the Council is not required to include the Parliament's opinion in the final legislation. Finally, in some decisions, the Parliament is not involved at all. I categorize these legislative procedures first and foremost according to the degree to which the European Parliament has veto powers in them and secondly, to distinguish the co-decision 
procedure from the assent procedure, in the degree to which the EP can influence legislation. I thus code EP involvement as reflected in table 3.3. I then determine these procedures on the level of the legislative act and aggregate these numbers for all legal acts put into force in a given policy field and year.

\begin{tabular}{|c|c|c|}
\hline & Legislative procedure & Characteristics \\
\hline 5 & Co-decision & EP has full veto-power \\
\hline 4 & Assent & EP has full veto-power \\
\hline 3 & Cooperation & EP has partial veto-power \\
\hline 2 & Consultation & EP has no veto-power \\
\hline 1 & no EP involvement & $\mathrm{EP}$ is not involved in legislative process \\
\hline
\end{tabular}

Table 3.3: Coding of legislative procedures

To proceed, I calculate the age of a policy area by subtracting the first year in which a legal act has been legislated in a policy field from the year in that the respective legal act has been put into force. First years have been coded with reference to the EUDIFF dataset, that is, they do not refer to the first years in which a policy area appears in EU primary law, but to the first year in which a legal act has defacto been legislated in the respective policy field. Finally, I capture the saliency of a topic by measuring the number of legal acts legislated in a given year and policy field from the dataset. Table 3.4 offers some first descriptive insights into our data. Please note that I only look at the years 1958-2009, which results in a total of 52 observations.

\begin{tabular}{|c|c|c|c|c|c|}
\hline & Obs & Mean & SD & Min & $\operatorname{Max}$ \\
\hline Supranationality & 52 & 1.8 & 0.6 & 1 & 3.9 \\
\hline Age of policy area & 52 & 24.8 & 14.4 & 1 & 50.6 \\
\hline Saliency & 52 & 82.9 & 39.3 & 3 & 172 \\
\hline
\end{tabular}

Table 3.4: Descriptive statistics

\section{Development of supranationality}

Table 3.5 allows us to inquire the development of the supranationality of decision making over time. Overall, table 3.5 refers to the common knowledge on the topic. To begin with, I find an increasing supranationalization of decision making over 
time that intensifies rather dramatically in the 1990s and the 2000s. I also find the expectable differences in supranationality between policy areas. More specifically, I find two different levels of supranationalization, as market policies and regulatory policies are substantially more supranational than agricultural policies and core state powers. As all policy areas start from roughly the same levels, this also implies that market policies and regulatory policies develop much more rapidly over time. Interestingly, while regulatory policies lag behind market policies in the 1990s, they become vastly more supranationalized in the 2000s. At the same time, agricultural policies and core state powers remain substantively behind, although agricultural policies become somewhat more supranationalized in the 2000s. I find that these developments largely support the liberal intergovernmental argument about the special role of market policies and the exceptional willingness of governments to delegate competencies to the European institutions in this policy area. I also find, however, that these arguments are contested by the fact that regulatory policies are similarly and ultimately, in the 2000s, even substantially more supranationalized than market policies.

\begin{tabular}{|c|c|c|c|c|c|c|}
\hline & $1960 \mathrm{~s}$ & 1970s & $1980 s$ & $1990 s$ & $2000 s$ & Overall \\
\hline Market policies & 1.7 & 1.7 & 1.9 & 3.1 & 3.4 & 2.3 \\
\hline Agriculture & 1.4 & 1.4 & 1.4 & 1.7 & 2.4 & 1.6 \\
\hline Regulatory policies & 1.5 & 1.8 & 1.9 & 3.0 & 4.8 & 2.5 \\
\hline Core state powers & 1.3 & 1.1 & 1.1 & 1.5 & 1.7 & 1.4 \\
\hline Overall & 1.5 & 1.5 & 1.5 & 2.0 & 2.9 & 1.8 \\
\hline
\end{tabular}

Table 3.5: Development of supranationality over policy areas and decades

\section{Development of saliency}

I also find some interesting insights with regard to legislative activity, which again largely follows my expectations. To begin with, as shown in table 3.6, I find that the legislative activity in agricultural policies overshadows the legislative activity in other policy areas in every decade except for the 2000s, where they are overtaken by both regulatory policies and core state powers. In terms of overall legislative activity, agricultural policies are followed by core state powers and regulatory policies. Whereas the legislative activity in market policies, regulatory policies and core state 
powers peaks in the 2000s, the legislative activity in agricultural policies peaks in the 1970s. Earlier, I proposed that legislative activity is a good indicator for the saliency of a topic and thus the degree to which it is contested. I thus find it fitting that agricultural policies reveal the highest numbers of legislative activity and that the numbers with core state powers increase so substantially over time. In this vein, I also find it fitting, and again largely to be in line with my liberal intergovernmental conjectures, that market policies reveal the smallest numbers of legislative activity. This again lends credibility to the argument that market policies occupy a special territory in EU secondary law in that they reflect not just an unusually great willingness to concede state sovereignty in their regard, but also shelter an unusually low amount of contestation.

\begin{tabular}{|c|c|c|c|c|c|c|}
\hline & $1960 \mathrm{~s}$ & 1970s & $1980 \mathrm{~s}$ & $1990 \mathrm{~s}$ & $2000 \mathrm{~s}$ & Overal \\
\hline Market policies & 7.8 & 12.4 & 9.5 & 10.7 & 15.3 & 10.7 \\
\hline Agriculture & 22.7 & 61.7 & 38.5 & 32.9 & 21.1 & 34.0 \\
\hline Regulatory policies & 3.2 & 12.5 & 13.6 & 20.1 & 29.7 & 15.2 \\
\hline Core state powers & 1.1 & 12.7 & 25.3 & 30.2 & 46.3 & 22.2 \\
\hline Overall & 34.9 & 99.7 & 87.1 & 95.1 & 114 & 82.9 \\
\hline
\end{tabular}

Table 3.6: Development of saliency over policy areas and decades

\section{Descriptive bivariate relationships}

Figure 3.2 shows the bivariate relationships between my independent variables and the share of DI across the four policy areas. As we can see, the relationship between supranationality as well as policy area age and DI is negative in all policy areas except for core state powers. This is in line with my hypotheses, except for the fact that I did not expect core state powers to reveal a different tendency. In general, I find that these relationships are rather weak, except in market policies. Turning to the bivariate relationship between legislative activity and the share of DI across policy areas, I find negative relationships between legislative activity and DI in all but the core state powers. This contradicts my hypothesis. I do find these relationships to be rather weak, however, and in tendency even weaker than those identified with regard to supranationalization and policy area age, so that their effects in a statistical model remain to be seen. In fact, as we will see, saliency exerts positive 

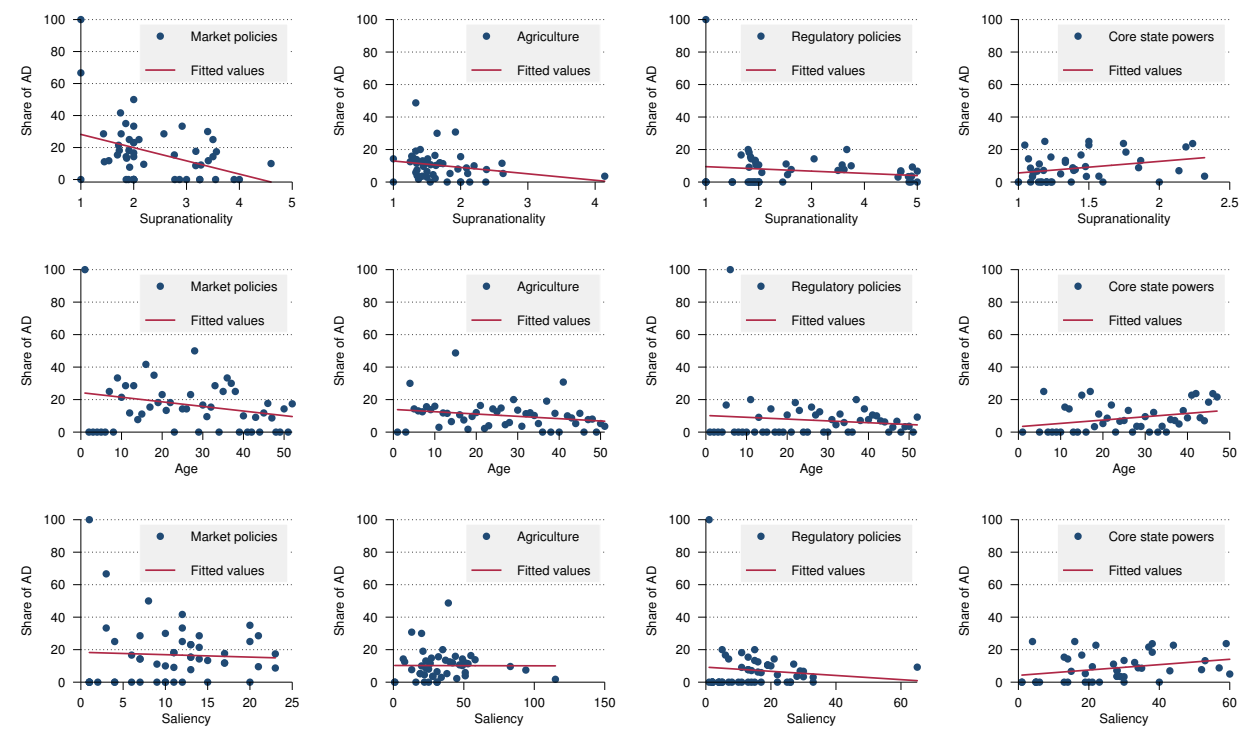

Figure 3.2: Descriptive bivariate relationships

effects on DI in my statistical analysis. At this point, the main finding to challenge my hypotheses is thus the positive relationship between supranationalization, age and DI in core state powers.

Looking again, however, this result is not that surprising. As we have seen in table 3.2. DI in core state powers is most substantial in the last decade of our dataset. Legislative activity is peaking in the 1990s and 2000s. Also, core state powers are the only policy area which reveal a positive relationship between legislative activity and DI. Finally, the supranationality of decision making only substantially increases in the 1990s and 2000s. I thus conjecture that the development of core state powers largely escapes my hypotheses for the fact that it goes through a structural break in the 1990s and with the Maastricht Treaty. Where market policies, regulatory policies and agricultural policies largely fit to the idea that DI decreases with the increasing empowerment of supranational actors and increasing dynamics of socialization, in other words, core state powers elude this logic in that their integration and politicization only peaks in the 1990s and thereafter.

\section{Empirical analysis}

Table 3.7 shows the results of a simple linear regression analysis in which I estimate the effects of supranationality, policy area age and saliency on DI. I here introduce 
dummys for my policy areas and work with robust, year-clustered standard errors. I find that only the supranationality of a policy area has a statistically significant effect on DI and that that effect is, as expected, negative. I thus find that the chances of countries to realize differentiation opportunities decrease with the extent of delegation. I also find that the role of saliency is as expected, as DI increases with the number of legal acts, but that this relationship is not statistically significant. Finally, I find that the age of a policy area exerts a positive effect on DI, which goes contrary to my hypotheses.

\begin{tabular}{|c|c|c|}
\hline & Coeff. & $\mathrm{SE}$ \\
\hline Supranationality & $-3.65^{* *}$ & 1.83 \\
\hline Age & 0.02 & 0.09 \\
\hline Saliency & 0.05 & 0.05 \\
\hline Market policies & (baseline) & \\
\hline Agricultural policies & $-10.34 * * *$ & 3.15 \\
\hline Regulatory policies & $-8.98 * *$ & 3.6 \\
\hline Core state powers & $-12.58 * * *$ & 3.39 \\
\hline Constant & $24.18 * * *$ & \\
\hline $\mathrm{R}^{2}$ & 0.11 & \\
\hline $\mathrm{N}$ & 198 & \\
\hline $\begin{array}{l}\text { Note: Linear regressio } \\
\text { area-dummy variables } \\
\text { clustered standard errc } \\
* * *=p<0.01, * *=p<0 .\end{array}$ & $\begin{array}{l}\text { model witl } \\
\text { nd robust y } \\
*=\mathrm{p}<0.1\end{array}$ & $\begin{array}{l}\text { policy- } \\
\text { ar- }\end{array}$ \\
\hline
\end{tabular}

Table 3.7: Results of linear regression analysis

Table 3.8 shows the results of a simple linear regression analysis in which I estimate the effects of supranationality, policy area age and saliency on DI in each individual policy area. I do so because I found in figure 3.2 that the relationship between supranationality and DI seems to be strongest in market policies and because I have theoretical reasons to expect supranationality to only exert effects in market policies. Indeed, now I find only one statistically significant effect, namely a negative effect of the supranationality of decision making on the extent of DI in market policies. Other than that, I must report a largely unsystematic picture. This essentially supports the liberal-intergovernmentalist hypothesis on DI in EU secondary law and largely reiterates my descriptive findings and theoretical conjec- 
tures from the previous sections. From a theoretical point of view, I argued that liberal intergovernmentalism expects effects of supranationality, but only in market policies. I conjectured that states delegate powers to the European institutions most substantially in market policies and that they do so according to the logic of incomplete contracting. In my descriptive analysis, I argued that these effects are indeed the ones most visible from the data. I found a high degree of supranationalization in market policies, combined with a low degree of contestation, and also found the descriptive bivariate relationship between supranationality and DI to appear rather strong with market policies. All of this supports the liberal intergovernmentalist argument about the special role of market integration and the respective willingness of states to delegate powers to the supranational institutions in this policy area. Combining my theoretical arguments and empirical insights, I thus conjecture that states are willing to delegate sovereignty to the supranational level and to allow supranational institutions to exert their effects in market policies more than in any other policy area because of their comparatively low levels of contestation, the large potential gains from cooperation and the high level of uncertainty regarding the details of specific delegated decisions.

\begin{tabular}{|c|c|c|c|c|c|c|c|c|}
\hline & \multicolumn{2}{|l|}{$\begin{array}{l}\text { Market } \\
\text { policies }\end{array}$} & \multicolumn{2}{|c|}{$\begin{array}{l}\text { Agricultural } \\
\text { policies }\end{array}$} & \multicolumn{2}{|c|}{$\begin{array}{l}\text { Regulatory } \\
\text { policies }\end{array}$} & \multicolumn{2}{|c|}{$\begin{array}{l}\text { Core state } \\
\text { powers }\end{array}$} \\
\hline & Coeff. & SE & Coeff. & SE & Coeff. & SE & Coeff. & SE \\
\hline Supranationality & $-12.48 * *$ & 6.32 & -2.63 & 2.40 & -1.04 & 1.64 & 5.11 & 5.04 \\
\hline Age & 0.28 & 0.33 & -0.08 & 0.12 & -0.00 & 0.20 & -0.00 & 0.20 \\
\hline Saliency & 0.01 & 0.48 & -0.02 & 0.05 & -0.03 & 0.14 & 0.12 & 0.12 \\
\hline Constant & $38.86^{* * *}$ & & $18.10 * * *$ & & 10.79 & & -1.84 & \\
\hline $\mathrm{R}^{2}$ & 0.15 & & 0.07 & & 0.01 & & 0.13 & \\
\hline $\mathrm{N}$ & 52 & & 50 & & 52 & & 44 & \\
\hline
\end{tabular}

Table 3.8: Results of linear regression analysis, individual policy areas

\subsection{Conclusion}

In this study, I looked at the development of DI in EU secondary law over time and inquired the explanatory power of three policy area-related explanatory variables. I found that the degree of DI in EU secondary law develops more or less sideways 
and thus does not systematically increase with the integration of new EU Member States or new policy areas. The common narrative on DI in EU secondary policy, according to which DI is constantly on the rise due to the increasing heterogeneity and contestation of European integration, must thus be contested. I also find that the development of supranationality and legislative activity is largely in line with our expectations, especially that market policies are among the most supranationalized and least contested of all policy areas. A simple lienar regression analysis shows that on the level of the individual policy area, the only statistically significant relationship in my data lies in the negative relationship between the supranationality of decision-making with DI in market policies. In other words, I find my data to be in line with my liberal intergovernmentalist conjectures.

This study leaves a number of questions unanswered. First, I largely neglected the role of decision making in the Council. Next to the role of the European Parliament, however, this is the main aspect of supranationality in EU legislative procedures that is usually labeled pooling as another form of supranationalization next to delegation. From the incorporation of decision-making procedures in the Council could indeed stem variance that puts our results into question, a topic that future studies should certainly take reference to. Second, I only inquired the applicability of my results on the level of the year. I could also aggregate my findings further, however, for instance to decades or qualitatively defined periods of time such as pre- and post-Maastricht years. Also, I could disaggregate my data to the level of the legal act. While I think that it is likely that these analyses will produce different results, I still consider my research design a worthwhile first inquiry into the topic. Third, I entirely neglected the interaction of country-level and policy area-level variables. It is entirely possible, for instance, that policy area characteristics influence the development of realized differentiation opportunities by Member States or that, the other way around, Member State preferences exert their effects only in certain policy areas. While I expect much explanatory power to lie in such approaches, they go beyond the scope of my analysis.

Finally, while this study largely supports my liberal intergovernmentalist conjectures, it is not without ambiguities and inconsistencies. Most importantly, the above does not fit with the fact that we cannot find any relationship between supranationality and DI for regulatory policies, although they are more supranationalized than market policies. The difference, I propose, lies in the higher degree of contest- 
ation in regulatory policies, as visible in its substantially larger degree of legislative activity. To be sure, compared to agricultural policies and core state powers, regulatory policies are still among the more uncontested policies. And yet, I find that they reflect a larger legislative activity in four of the five decades under consideration in this study and ultimately come up with an overall-degree of legislative activity that is at a $150 \%$ of market policies'. In this vein, contestation may explain why regulatory policies, although they are supranationalized to a similar degree than market policies, do not show the same effects from supranationalization. If this is the case, however, it implies two follow-up questions, namely why states would allow the supranationalization of regulatory policies in the first place and how they are able to control secondary law legislation beyond what is reflected in legislative procedures. I suggest that these are fascinating avenues for future research on DI in EU secondary law. 



\section{Chapter 4}

\section{Differentiation in EU Monetary Policy}

Monetary integration is one of the key aspects of European integration. The Member States of the European Union (EU) moved from autonomous monetary policymaking to the supranationalization of monetary policy in the Economic and Monetary Union (EMU) through the currency snake in the 1970s and the European Monetary System (EMS) in the 1980s. Over time, scholars came up with numerous explanations for this increasing supranationalization of monetary policymaking among EU Member States. In this study, I examine the variation in this integration, that is, horizontal differentiation (DI) in EU monetary policy.

A number of existing approaches to European monetary integration implicitly argue about the driving forces of horizontal DI in EU monetary policy. This is the case, for instance, with Sandholtz (1993), who stresses the role of the initial divergence and later convergence of macroeconomic policymaking. For, in the same vein in that he argues that differences in macroeconomic policymaking prohibit vertical integration, he also conjectures about which states refrain from monetary policy cooperation and which participate in it. And yet, Sandholtz is exemplary for the literature in that he does not give more consideration to such thoughts. On the other hand, the literature on differentiated integration offers broad theoretical inroads into the topic of European integration in general and EU monetary policy more specifically (e.g. Leuffen et al. 2013). And yet, this literature lacks an empirical approach to horizontal DI in EU monetary policy. In this study, I advance the literature on the differentiated character of the EU by engaging one of the main grand theories 
of European integration, liberal intergovernmentalism, to come up with an explanation of DI in EU monetary policy. I relate my findings to a simple political economy framework based on liberal intergovernmentalist conjectures, in which the benefits of monetary policy cooperation stem from the benefits of a monetary union on scale economics, whereas its costs stem from the inability of state actors to target their monetary policies at domestic preferences.

One of the key issues with studying EU monetary policy is to find a measurement that allows to study the phenomenon over time. In the remainder, I study the concepts of monetary policy autonomy and monetary policy cooperation by looking at the decision of states to fix their currencies or uphold flexible exchange rates and to protect or abandon capital controls during the currency snake, the EMS and EMU. In this vein, the fixing of currencies and the abolition of capital controls under EMU becomes merely one manifestation of monetary policy cooperation, for, countries have taken these same policy decisions ever since the 1970s. I thus argue that whenever an EU Member State refrains from combining fixed exchange rates with the free movement of capital, it realizes a differentiation opportunity from monetary policy cooperation in the EU. I suggest that while the costs of monetary policy cooperation exceed its benefits for growth-targeting countries, inflation-targeting countries can profit from the benefits of monetary cooperation at no or little costs. I also propose, however, that this changes with an increasing convergence towards macroeconomic discipline over time and that, under the conditions of macroeconomic congruence, it is public opinion that national decision makers must increasingly give their attention to. I test these arguments in the last section of this study and find that they largely apply to my data. In essence, I thus propose that DI in EU monetary policy is the result of the iterative re-formulation of national preferences under the influence of an increasing economic interdependence and an increasing depth and politicization of European integration.

\subsection{DI in EU Monetary Policy}

One of the key interests of the study of DI is to study variation in integration. This variation can be vertical, which refers to variation in the degree of supranationalization of two policy areas. It can also be horizontal, however, which refers to variation in Member States' participation in one individual policy area (e.g. Leuffen et al. 
2013, 12). In the remainder of this study, I investigate the extent and development of horizontal DI in EU monetary policy.

\section{Studying EU monetary policy}

The eventual success of vertical monetary policy integration obscures the fact that its history is defined by a substantial degree of horizontal variation. In fact, the literature on the vertical integration of EU monetary policy is so extensive that it makes most sense to refer to it only in general terms. To begin with, as McNamara (1998) shows, there is a distinction in material and ideational studies. Whereas some authors see European monetary integration as a reflection of functional cost-benefit analyses, in other words, others see it more as a reflection of ideational concerns. Frieden (2002), furthermore, distinguishes between approaches that focus on broad constituencies and the effects of economic efficiency and such that focus on the distributional effects of monetary policy. While the gains of scale economies are at the center of the first studies, the distributional effects of monetary integration are at the core of the latter. In his broad and encompassing paper, Sandholtz (1993) lists and indeed structures a number of major theories and arguments on monetary integration - the choice of which remains valid to the day - according to the distinction between sufficient and necessary explanatory factors. While he finds it fruitful to study the role of individual explanatory factors, in other words, he urges us not to forget the role of sequencing, timing and combination. Sadeh and Verdun (2009), finally, explicitly refer to the importance of different levels of analysis in their literature review. It is in this coordinate system that the numerous explanations on the topic find their place.

The study at hand adds in two key ways to the existing literature: First, it brings together the study of European monetary integration with the study of differentiated integration in the European Union in that it researches horizontal DI in EU monetary policy. The key aspect of European monetary integration is the development from monetary policy autonomy to monetary policy cooperation. In the remainder, I assess the variation in that development by measuring the de-jure and de-facto participation or non-participation of Member States in the currency snake, the EMS and EMU as well as by their protection or abolition of capital controls. I do so in parts with reference to the EUDIFF dataset on EU primary law and secondary law differentiation. By doing so, I measure and empirically investigate the 
horizontal differentiation of EU monetary policy in a way which allows me to extend the analysis of DI in EU monetary policy beyond the study of EMU to also encompass earlier attempts at monetary policy cooperation and thus to investigate the extent and development of DI in EU monetary policy over time. All of this is especially insightful because EU monetary policy is one of the EU's most horizontally differentiated policies. Second, the study at hand brings forth a simple political economy framework on the topic of DI in EU monetary policy. I conjecture that while the benefits of monetary cooperation stem from the benefits of a monetary union on scale economies and are distributed equally among all countries, its costs are distributed asymmetrically among our sample. I also conjecture that the costs of monetary cooperation are largely in line with a liberal intergovernmentalist framework, for, my explanation of DI in EU monetary policy heavily relies on the potential costs of monetary cooperation on incumbent governments as well as the effects from economic interdependence as well as the depth and politicization of European integration.

\section{Dependent variable}

To study the extent and development of DI in EU monetary policy, I refer to what is called the unholy trinity in the literature, that is, the inability of states to uphold monetary policy autonomy when exchange rates are fixed and capital is mobile (Mundell, 1961; 1963). Monetary policy autonomy describes states' ability to target their monetary instruments at domestically defined goals. Most importantly, central banks influence lead interest rates and the money supply to accommodate domestic economic situations. If an economy is in a recession, for instance, central banks might stimulate spending and investment by lowering lead interest rates and expanding the supply of money. As differences in interest rates generate differential rates of expected return, the pursuit of independent monetary policies on the basis of divergent economic situations generates inter-state capital flows. If exchange-rates are floating, such disequilibria simply shift demand and supply dynamics in the currency markets and move exchange-rate values. If they are fixed, however, central banks must offset any disequilibrium and change their interest rates and money supply decisions accordingly.

However, according to the unholy trinity, states do not lose their ability to target domestic goals simply when exchange rates are fixed, but only when exchange 
rates are fixed and capital is mobile (Mundell, 1961; 1963). With capital controls in place, states can indeed combine monetary policy autonomy and fixed exchange rates. Capital controls allow states to prevent the capital in- or outflows that force them to diverge from their preferred lead interest rates and money supply preferences when exchange-rates are fixed. Without capital mobility, the relationship between monetary policy autonomy and fixed exchange-rates is neither fully determined nor decisive 11 States thus have three monetary policy options - namely monetary policy autonomy, the free movement of capital and fixed exchange-rates - of which they must choose two. In other words, if states are interested in monetary policy autonomy, they must decide for either fixed exchange rates or capital mobility. If they are interested in monetary policy cooperation, they must combine fixed exchange rates with the free movement of capital. EMU is thus merely one manifestation of monetary policy cooperation. For while some states only opted for fixed exchange rates and the free movement of capital in the 1990s and with EMU, others had already done so in the 1970s and 1980s throughout the currency snakeand EMS-periods. It is in this vein that studying the unholy trinity allows me to come up with an understanding of DI in EU monetary policy over time.

In the remainder, I code the use of both de-jure and de-facto differentiation opportunities. With regard to the fixed-but-adjustable exchange rate systems under scrutiny here, I identify three distinct ways of opting-out, namely that states either do not participate in them in the first place; that they withdraw their participation in the process; or that they devaluate their currencies..$^{2}$ The EU's first attempt at a fixed-but-adjustable exchange rate system after the breakdown of the Bretton Woods system was the currency snake. Of the 9 EU Member States that could have taken part in it, all except Ireland did do so, while the United Kingdom, Denmark, Italy and France withdrew their participation at one point or another (Gros/Thygesen 1998, 17). While all EU Member States took part in the EMS, Belgium, Luxembourg, Denmark, France, the Netherlands, Ireland, Italy and the United Kingdom devaluated their currencies at one point or another or left the system altogether (Gros/Thygesen 1998, 68).

\footnotetext{
${ }^{1}$ We come back to the temporal applicability of this argument later in this study.

${ }^{2}$ I code the revaluations of Germany as devaluations of the respective EU Member States. Doing so does not influence my results, for separately coding revaluations only leads to a new category on my dependent variable in which the sign of the coefficients is reversed. It does not change anything with the remaining results. From a substantial point of view, this is legitimate because revaluations and devaluations are effects of the same underlying divergence.
} 
Let us now turn to the free movement of capital. The chapter on the free movement of capital was introduced into primary law in 1958 and with the Treaty of Rome. It is exclusively concerned with the free movement of capital as understood in the context of the unholy trinity as presented in the above. And just like an optout from the currency snake and the EMS was a possibility, so was the protection of capital controls. Over time, and according to the EUDIFF dataset on DI in EU primary law, 6 of the 12 potential states - Denmark, Greece, Spain, Ireland, Portugal and the United Kingdom - acquired a differentiation from the free movement of capital. However, although introduced along with the freedom of goods, persons and services to form the four fundamental freedoms of the European Economic Community, the freedom of capital movement remained at length unimplemented. This is true even after the transitory period for the removal of barriers to the other fundamental freedoms had expired in 1969 and mainly due to the interpretation of the European Court of Justice. Relying on the provision requiring the abolition of restrictions to the movement of capital between Member States only to the extent necessary to ensure the proper functioning of the common market, the Court denied direct effect of the obligation to allow capital to move freely, de-facto favoring the maintenance of existing Member State legislation on capital controls (Vardi 2011, 41-43).

The above implies that we cannot only look at the de-jure legal exemptions from the respective treaty article, but must also check for the de-facto handling of the free movement of capital. Member States were not, in other words, required to acquire a formal differentiation if they wanted to uphold capital controls, but could also do so without formally opting out from the respective obligation. To capture this dimension, I look at the Chinn-Ito index (Chinn/Ito 2008). The Chinn-Ito index is based on the International Monetary Fund's (IMF) Annual Report on Exchange Agreements and Exchange Restrictions and indicates the presence or absence of four pivotal aspects of capital mobility: the existence of multiple exchange rates, restrictions on current account transactions, restrictions on capital account transactions, as well as the requirement to surrender export proceeds. For the remainder, I code opt-outs from the free movement of capital whenever a country does not only fulfill all aspects of international capital mobility as indicated by the Chinn-Ito Index.

The protection of capital controls became legally impossible only with directive 
$88 / 361 /$ EEC. This directive signifies the full incorporation of the free movement of capital into the acquis communautaire, a process that only began in the late 1980s, when the Delors Commission drafted the 1985 Commission White Paper to exit the period of eurosclerosis that Europe had just gone through. As it did so, it had come to the conclusion that the 1992 program - as the plan of the revitalization of the internal market through a combination of further liberalizations of European trade and procedural reforms came to be known - also required capital liberalization. The free movement of capital, thus the idea, was essential to the functioning of the internal market. The Commission first tried to incorporate the free movement of capital into the 1986 Single European Act, but failed to do so. Only two years later, however, the European Council issued directive 88/361/EEC that obliged all member states to liberalize all capital movements by no later then the year 1990 (Abdelal 2007, 65-69). Only now had the free movement of capital became a mandatory part of EU monetary policy. To be sure, directive 88/361/EEC still retains some emergency clauses in which it shall not apply. Also, the council did allow for transition periods. However, by the very nature of the directive, it did not allow for any substantial differentiation. For the first time, the free movement of capital was now an undisputed part of European integration.

The last differentiation opportunity in EU monetary policy is EMU. The final stage of EMU started with 11 Member States in 1999: the original EC-6, Austria, Finland, Ireland, Spain and Portugal. Four countries hence potentially qualify as having an opt-out from EMU, namely Greece, the UK, Sweden and Denmark. We can easily dismiss that potentiality for Greece, whose temporal opt-out does not qualify as a differentiation in the understanding of this study. The two countries that clearly acquired a differentiation are the UK and Sweden. The UK was granted a formal opt-out of EMU with the Maastricht Treaty. Sweden, which joined the European Union in 1995 and would actually be obliged to join the euro by its accession treaty, has chosen not to join the ERM II mechanism and thus ultimately also to refrain from overtaking the euro. Both countries have thus kept their exchange rates flexible and have hence, in the understanding of the unholy trinity, protected their monetary policy autonomy. The case of Denmark is less clear. Denmark has optedout from EMU after a public referendum, but has nevertheless pegged its currency to the euro within the ERM mechanism. As such, it has fixed its exchange-rate against the euro and, combined with the free movement of capital and again in light of the 
unholy trinity, foregone its monetary policy autonomy. At the same time, however, as it can give up its exchange rate peg at any time unilaterally, Denmark has preserved a substantial degree of autonomy compared to those countries that have given up their national currencies in a conceptually irrevocable currency union. While I would thus count Denmark as having fixed its currency prior to EMU, I define the setting of Denmark under EMU as a differentiation and hence define Sweden, the UK and Denmark as having either a de-facto or de-jure differentiation under EMU.

Figure 4.1 shows the use of differentiation opportunities over time. I here measure, on the level of the year, the number of realized differentiation opportunities as a share of all potential differentiation opportunities. For instance, if 6 from $12 \mathrm{Mem}$ ber States fixed their currencies, but protected their capital flows in a given year, they would have realized $25 \%$ of all differentiation opportunities in that respective year. Figure 4.1 shows that the share of realized differentiation opportunities reaches a maximum of more than $80 \%$ in 1979 , which makes it fair to say that DI in EU monetary policy has at times been the norm rather than the exception. Figure 4.1 also shows a rapid decrease of the use of differentiation opportunities over time. Ultimately, only $10.3 \%$ of all differentiation opportunities are realized, namely the abstention of Sweden, Denmark and the UK from fixing their currencies to the euro.

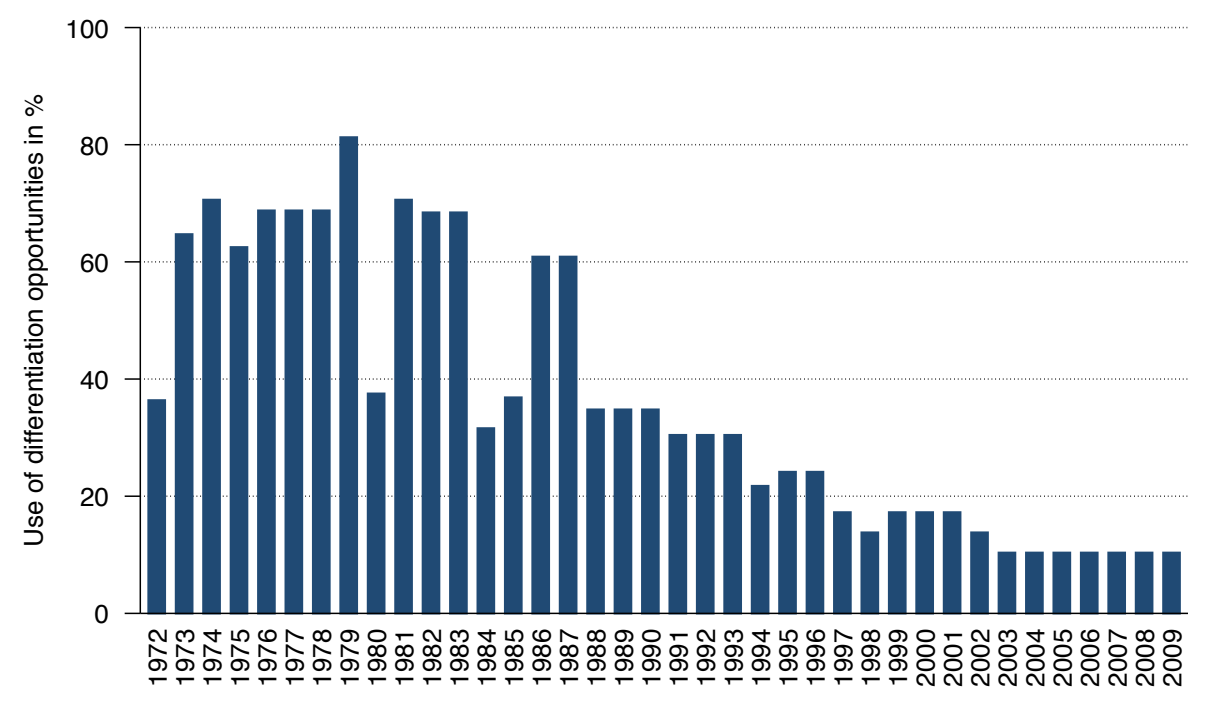

Figure 4.1: Development of DI in EU monetary policy 


\subsection{Explaining DI in EU Monetary Policy}

In the following, I propose two general approaches to explain horizontal DI in EU monetary policy. More specifically, I distinguish an approach based on macroeconomic discipline from a public-opinion approach. I derive these theories from a simple political economy framework, from which I also expect the character of differentiation to change over time and in line with increasing economic interdependence as well as the depth and politicization of European integration.

\section{The politics of DI in EU monetary policy}

I find it most appropriate to proceed with this study with reference to a simple political economy framework that tries to constructively bring forth an explanation of DI in EU monetary policy rather than just to demarcate my findings from other approaches - an undertaking that is ultimately always futile. In this vein, the basic argument of the approach adopted in this study is that the supranationalization of authority in the EU is associated with costs and benefits for the respective units. Thereby, the core trade-off of European integration is that centralization typically internalizes costs and takes advantage of scale economics, but is associated with the issue that, after pooling, the individual unit cannot legislate anymore according to the specific preferences of the people in their jurisdictions (Wasserfallen 2014, 426). Crucially, this implies unequal trade-offs on the unit-level, for while the benefits of centralization are usually available to all, the costs of giving up policy autonomy are distributed asymmetrically (e.g. Frieden 2004).

The benefits from monetary cooperation stem from the economic gains that are associated with it. Most importantly, monetary integration leads to a reduction in transaction costs and decreases the uncertainty about future exchange rates and hence leads to an increase in trade and investment (e.g. de Grauwe 2012, 5471). The costs of monetary integration stem from the inability of states to act, after pooling, according to the specific preferences of their electorate. This is in line with the liberal intergovernmentalist framework adopted in this study, which implies that governments care first and foremost about their re-election, but that they require the support of a broad coalition of domestic actors to reach that target (Moravcsik 1993, 483). From this follows that on the very fundamental level, monetary policy cooperation is only feasible where it incurs no or only modest costs on a domestic 
society or, in other words, where the fixing of one's national currency and the free movement of capital has limited adverse effects on the electorate of a country and hence does not threaten the survival of an incumbent government.

In line with the above, my primary approach to the phenomenon of differentiated integration in EU monetary policy focuses on the role of macroeconomic discipline and indiscipline. Its general idea is rather straightforward: As markets treat states differently according to their extent of macroeconomic discipline and indiscipline, states develop different monetary policy preferences. Thereby, the key decision of states is to either employ expansive macroeconomic policies to support their economies and accept the corresponding inflationary dynamics or try to avoid inflationary dynamics by disciplining their macroeconomic choices (e.g. Goodman 1992). Macroeconomic policymaking is crucial for monetary policy preferences because differences in macroeconomic discipline influence currency developments through markets' assessment of current and expected inflation and interest rates. While inflation-targeting goes hand in hand with lower rates of inflation and more moderate inflation expectations and helps traders to conjecture further interest rate developments, growth-targeting goes hand in hand with interest rate variability, higher rates of inflation and elevated inflation expectations (e.g. Taylor/Taylor 2004).

In other words, where inflation-targeting policies in general stabilize a currency, growth-targeting policies usually weaken a currency. Now, in fixed-but-adjustable exchange rate regimes, strengthening a weakening currency requires depletable foreign exchange reserves, which heightens the risk of devaluations - not only, but also due to the increasing risk of speculative attacks (e.g. Obstfeld 1986). In other words, macroeconomic indiscipline makes countries more likely to experience devaluations and currency crises and thus to experience the accompanying costs of these developments on their respective economies, the adverse effects of which, in turn, endanger the survival of the incumbent government (e.g. Walter 2013). With this, the free movement of capital also takes center stage. For countries in danger of currency crises have ample reason to control capital movements to regain some control over these processes or, before it comes to it, protect themselves from extensive capital outflows. In sum, where governments in inflation-targeting countries are free to profit from the benefits of currency stability and the free movement of capital, governments in growth-targeting countries are more likely to stay away from fixed exchange rates and to protect capital movements. 
My second approach to DI in EU monetary policy focuses on the role of public opinion. In this perspective, politicians are essentially guided by the preferences of the electorate in the sense that they must not necessarily take note of the more immediate effects from monetary policy cooperation, but the general preferences towards European integration in their electorate. In essence, thus, public opinion on European integration is assumed to be well structured, to affect national voting and to be connected to the basic dimensions that structure contestation in European societies (e.g. Hooghe/Marks 2008). Hence, governments that care about re-election must listen to the preferences expressed in their electorates and act accordingly. Just like financial instabilities can threaten the survival of governments in the macroeconomic discipline-approach, so does the neglect of public opinion constitute a threat to the future of an incumbent government in the public opinion-approach. Accordingly, I expect monetary policy preferences to be related to public opinion and hence differentiation in EU monetary policy to be the result of differences in the public reception of European (monetary) integration. All said, I formulate the following hypothesis:

\section{$\mathrm{H}_{1}$ : The probability of a country realizing DI in EU monetary policy (i) increases with macroeconomic expansiveness and (ii) increases with the degree of euroscepticism in an electorate.}

\section{Development over time}

While the asymmetrical distribution of the costs from monetary policy cooperation may influence the monetary policy preferences of states in a cross-sectional understanding, we must also expect countries to change their preferences over time. Liberal intergovernmentalism allows for the re-formulation of national preferences essentially in three cases, namely in response to changes in interdependence and the accompanying re-distribution of international policy externalities (e.g. Moravcsik 1993, 485), in reaction to the politicization of policy areas (e.g. Leuffen et al. 2013, 261) and as a result of the increasing effects from European integration (e.g. Sandholtz 1993). In other words, I conjecture that the development of DI in EU monetary policy is the result of the iterative re-formulation of national preferences under the influence of increasing economic interdependence, the increasing politicization of European (monetary) integration and the increasing depth of European integration. 
As such, my approach to DI in EU monetary policy is fully in line with a liberal intergovernmentalist reasoning and the importance it gives to national governments, domestic societies, interdependence and politicization.

One of the main reasons that countries re-consider their preferences in the liberal intergovernmentalist framework lies with changes in interdependence. The idea of the importance of transborder flows of goods, services, factors or pollutants lies at the very heart of liberal theories of interdependence. Liberal intergovernmentalism in essence expects economic interdependence to create incentives for policy cooperation when economic interdependence increases; the policies of two or more governments, due to these increases in economic interdependence, create ever more negative policy externalities for one another; and unilateral adjustment strategies in this environment become increasingly ineffective, inadequate or expensive (Moravcsik 1993, 485). More specifically, I expect interdependence to lead to an increasing convergence of macroeconomic policymaking and thus monetary policy preferences over time, hence leading to a decrease in DI in EU monetary policy.

I also conjecture that the increasing depth of European integration leads to a decrease in DI in EU monetary policy. Scholarly discussions about European integration often revolve around a distinction between intergovernmental and institutionalist perspectives, in which intergovernmentalists hold that European integration reflects the preferences and power of Member States, whereas institutionalists conjecture that supranational institutions exert independent effects on their own (e.g. Stone Sweet/Sandholtz 1997). What is often missed in this dichotomy is that even in liberal intergovernmentalism, national interests are increasingly defined by EU membership. As Sandholtz writes (1993, 3), community decisions are bargains that reflect state interests, but those interests are increasingly shaped by EU membership. EU membership becomes, in other words, part of the cost-benefit analysis of governments and societal groups. As such, I expect the extent of cooperation to increase among EU Member States and thus the extent of DI in EU monetary policy to decrease with the depth of European integration. I thus conjecture:

\section{$\mathrm{H}_{2}$ : The extent of DI in EU monetary policy $(i)$ decreases with economic interdependence and (ii) decreases with European integration.}

Finally, whereas interdependence and the depth of the EU facilitate integration, 
politicization creates obstacles. In simple terms, interdependence only promotes integration conditional on low politicization (Leuffen et al. 201, 261). In the case at hand, the role of interdependence increases substantially over time, as is reflected in the increasing amounts of cross-border capital transactions especially throughout the 1980s and thereafter (e.g. Solomon 1999). Furthermore, with these increases in capital flows, growth-targeting countries become increasingly vulnerable to policy externalities and unable to deal with market pressures unilaterally (e.g. Andrews 1994). Growth-targeting countries thus increasingly re-formulate their macroeconomic policies and monetary policy preferences and converge on strategies of macroeconomic discipline and monetary policy cooperation. At the same time, however, we witness an increasing politicization of European integration over time and no later than with the Treaty of Maastricht, thus creating obstacles for unitary integration in EU monetary policy and, at the same time, changing the character of DI in EU monetary policy. More specifically, while I expect macroeconomic policymaking to influence DI in EU monetary policy prior to the Maastricht Treaty, I expect public opinion to play that part thereafter:

$\mathrm{H}_{3}$ : The extent of DI in EU monetary policy varies with macroeconomic discipline prior to the Maastricht Treaty, but with euroscepticism thereafter.

\subsection{Analysis}

In the following, I test my conjectures. I find that whereas macroeconomic discipline explains the use of differentiation opportunities prior to EMU, euroscepticism does so thereafter. I also find that the extent of DI in EU monetary policy decreases with the extent of interdependence and the depth of European integration. I thus find empirical support for all of my conjectures.

\section{Development over time}

In the above, I proposed that increasing interdependence would lead to a convergence towards macroeconomic discipline and hence a convergence of monetary preferences and a decrease of DI in EU monetary policy over time. Key explanatory in this argument lies with the idea that increasing cross-border capital flows 
increase the exposure of growth-targeting countries to negative policy externalities, which they are also increasingly unable to tackle unilaterally. This argument is largely undisputed. To begin with, economic interdependence increased substantially throughout the 1980s and thereafter (e.g. Solomon 1999, 109; Eichengreen 2008, 228-232). The idea that certain states became increasingly unable to answer to the corresponding negative policy externalities unilaterally and thus converged on macroeconomic discipline is often told with reference to the convergence of inflation rates in the course of the 1970s and 1980s (e.g. Gros/Thygesen 1998, 71). On the narrative level, it is best exemplified with reference to France. In 1981, after the election of the Mitterrand government, and in fear of new expansive macroeconomic policies, capital started to flee France. The French government tightened its controls on capital outflows. And yet, as it was unable to halt the flight of capital, the franc had to be devalued three times in eighteen months. Consequently, France adopted a franc fort-strategy in the course of the 1980s (e.g. Abdelal 2007, 58-59; Loriaux 1991).

The idea that increasing interdependence, rising policy externalities and the increasing ineffectiveness of unilateral actions would lead to a convergence towards macroeconomic discipline is also known in the literature as the capital mobility hypothesis (e.g. Webb 1991; Goodman/Pauly 1993; Andrews 1994). While the capital mobility hypothesis is not undisputed (e.g. Lane 2006; Bearce 2007; 2009), it is largely accepted (e.g. Gros/Thygesen 1998; Eichengreen 2008). All of the elements of hypothesis 2 are thus in place. And indeed, accepting the notion of an ever-increasing economic interdependence before but especially with and after the 1980s, figure 4.1 makes apparent a strong relationship negative between international capital flows and DI in EU monetary policy. As interdependence increased, DI in EU monetary policy decreased over time.

What about, then, the role of European integration? Figure 4.2 shows that the share of realized differentiation opportunities decreases with the number of integrated policy areas in the EU and thus the depth of European integration. ${ }^{3}$ Figure 4.2 thus supports my argument about the role of European integration on states' calculation of costs and benefits. Consider that prior to the Maastricht Treaty, as the

\footnotetext{
${ }^{3}$ I work with a list of 39 policy areas that I derived from the main treaties' chapter titles as well as the titles of additional treaties such as the Schengen agreements. I only calculate values until the year 2009, however, which excludes the European Stability Mechanism and the Fiscal Compact from that list, resulting in a maximum of 37 integrated policy areas.
} 
above has shown, monetary policy cooperation was an explicitly voluntary choice. Also, it is no stretch to argue that immediately after the breakdown of the Bretton Woods regime, choosing flexible exchange rates over fixed ones or capital controls over the free movement of capital were considered equally legitimate and appropriate choices (e.g. Polanyi 1944; Ruggie 1982; Blyth 2002). This gradually changed, however. As the prospects of EMU became more explicit, monetary policy choices became more and more intertwined with the future of not just monetary policy cooperation, but European integration more generally. With the signing of the Maastricht Treaty, states were legally required to join EMU, dependent on their ability to fulfill a set of convergence criteria and without any legal exemptions. The effort behind acquiring a differentiation thus increased dramatically, and so must have done the uncertainties around doing so. At the same time, with the continuous deepening of European integration, the benefits of monetary policy cooperation included those entailed in membership in the EU more generally, for instance access to the Single Market. As such, I argue that the decline of DI in EU monetary policy in line with the depth of European integration validates my arguments about the role of European integration for the interest calculation of Member States.

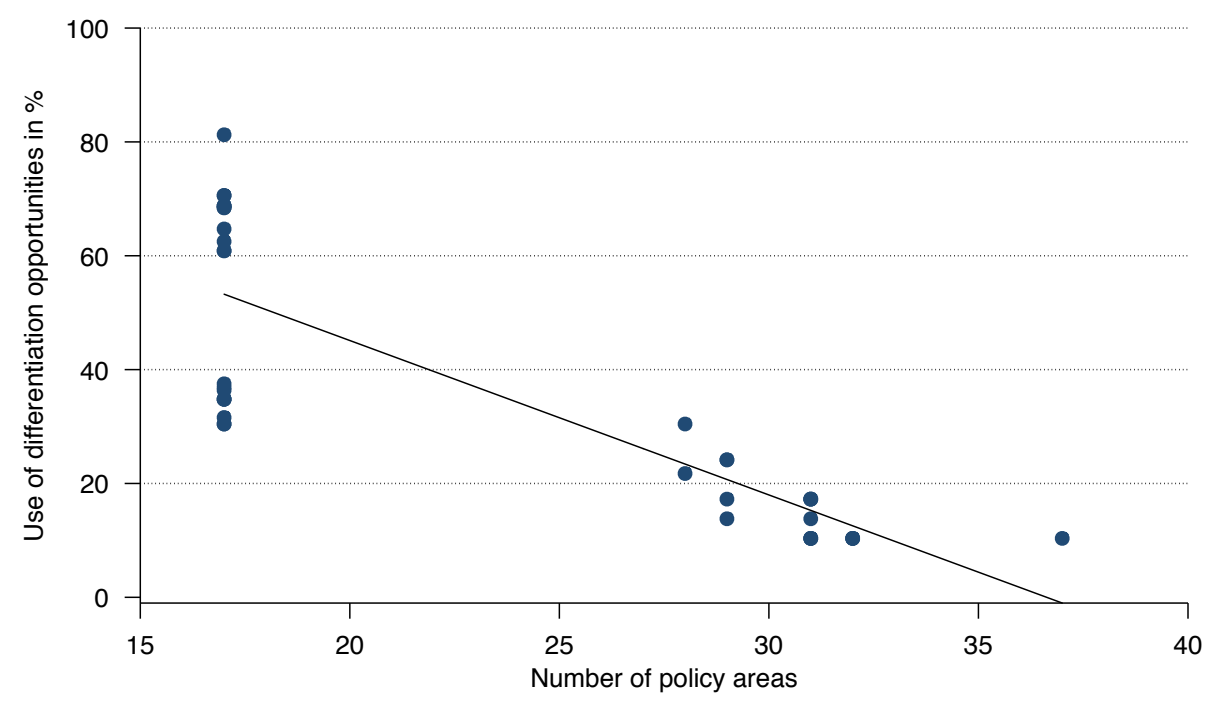

Figure 4.2: Depth of European integration and DI 


\section{The politics of DI}

What is left for us to investigate is whether or not macroeconomic discipline and public opinion have their expected effects at the respective points of time. To test my propositions, I investigate the development of monetary policy cooperation in light of two main variables. I measure the role of macroeconomic policymaking through inflation rates, which I collected from the World Bank. To get an understanding of the development of public opinion, I look at euroscepticism. I collected data on euroscepticism from the Eurobarometer surveys, in which the European Commission asks its citizens: Generally speaking, do you think that (your country's) membership of the European Community/Common Market/European Union is...? One can respond with a good thing, neither good nor bad or a bad thing. I define the level of euroscepticism as the share of people that respond with a bad thing in any given country and year ${ }^{4}$

Figure 4.3 shows the mean inflation rates and mean rates of euroscepticism in 1972-1991 and 1992-2009, respectively. All values are only computed for years in which the respective country has been a Member State of the EU. The dependent variable follows the definition as it is reflected in figure 4.1, that is, I show the number of realized differentiations as a share of all differentiation opportunities. Figure 4.3 shows a rather strong relationship between inflation rates and DI prior to EMU that almost completely falls apart thereafter. Note, for instance, how Germany, the country with the lowest inflation rates, has realized no differentiation opportunity, while Italy, the country with the highest rates of inflation, has realized more than $80 \%$ of differentiation opportunities prior to EMU but less than $10 \%$ thereafter. Also note the convergence of inflation rates between the two periods of time, which allures to the discussion about the convergence towards macroeconomic discipline that we have touched upon in the above. I also find a strong relationship between euroscepticism on DI, which is more consistent than the one between inflation and DI and appears to be stronger after EMU than before it. Especially, I here find that the three countries which do not participate in EMU (UK, Sweden and Denmark) are among the five countries with the highest rates of euroscepticism.

Interestingly, would we exclude Austria, Finland and Sweden and thus the 1995 enlargement round from our analysis, the two remaining countries with a differenti-

\footnotetext{
${ }^{4}$ For a more fine-grained discussion of how to operationalize national preferences towards DI, see Leruth (2015).
} 
ation from EMU would be the two countries with the strongest values of euroscepticism. Indeed, doing so would not be entirely implausible. Austria, Finland and Sweden only joined the EU in 1995 and thus after the Maastricht Treaty. As such, the obligation to enter EMU was one of their obligations when joining the EU altogether. Acquiring a differentiation would most certainly have meant for the accession process to stall or fail. Or, in other words, if opting-out from monetary policy cooperation comes with increasing potential costs with the deepening of European integration, as I argued before, we must expect opting-out from EMU for these three countries to come with substantial potential costs. Such an argument about the role of euroscepticism in an environment of vastly increased potential costs would explain why only one of these states ultimately acquired a differentiation, although all of them are among the countries with the highest rates of euroscepticism. It would also explain why it is Sweden that acquired such a differentiation, for the degree of euroscepticism in its population exceeds the degree of even Austria and Finland. Finally, it would explain the nature of Sweden's differentiation, for, Sweden never formally acquired a such, like the UK or Denmark, but unilaterally refrained from joining the last phase of EMU. In the remainder, however, I do not treat the enlargement round of 1995 any differently from the states that joined before it.
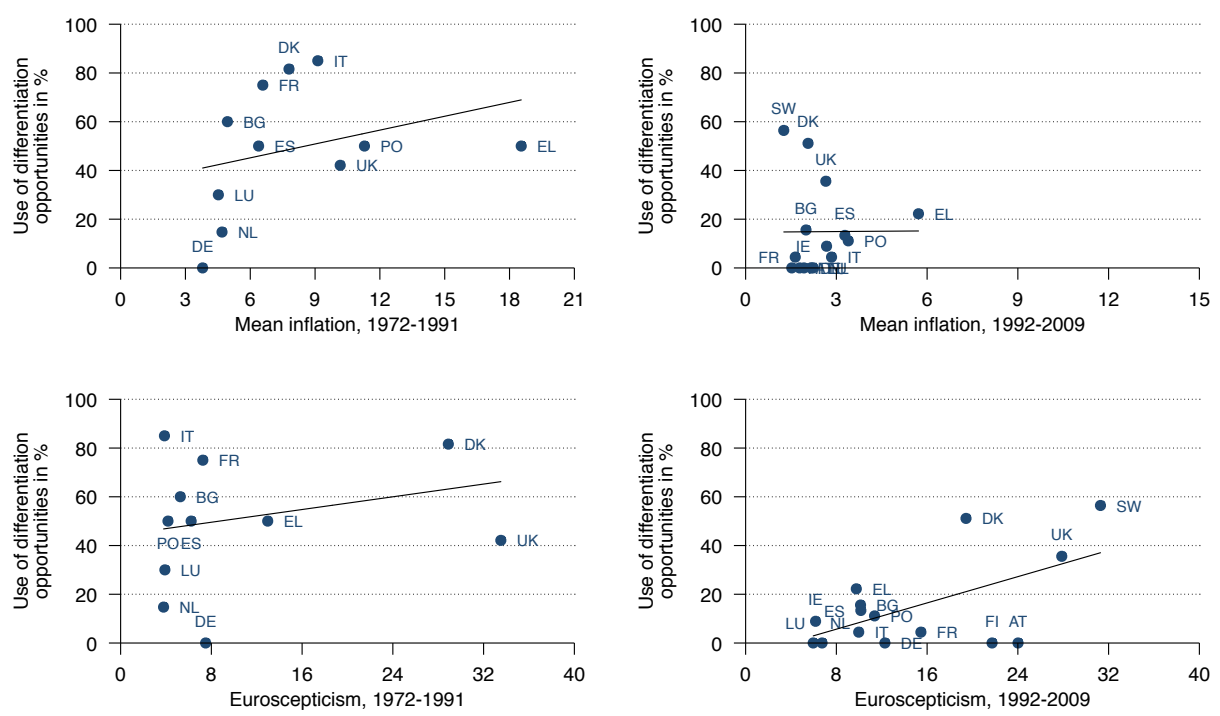

Figure 4.3: Descriptive bivariate relationships

Figure 4.3 comes with two major limitations: First, it treats the post-Maastricht period the same than the pre-Maastricht period when it comes to the possibility of 
realizing differentiation opportunities. However, while the realization of differentiation opportunities was a recurring decision prior to EMU, it was not thereafter. To begin with, capital controls remained a possibility into the early 2000 s, but only in a transitory understanding. In substance, except in some situations of emergency, capital controls were a thing of the past and not an instrument to deploy at wish. At the same time, fixing one's currency is not a recurring decision, but considered an irrevocable commitment under EMU. Consider that the acquis communautaire knows of no exit-clause to the euro. To be sure, the very nature of European integration makes it entirely possible that EU law will be changed to allow for an exit from the euro or that a country at one point in time leaves the common currency unilaterally. By today, however, as no country has ever left the currency union, we still must consider the euro to be irrevocable. As such, the nature of monetary policy cooperation under EMU is very different from monetary policy cooperation prior to EMU. In consequence, the variance in the dependent variable after the Maastricht Treaty, which stems from the role of capital mobility and capital controls and from the transitory arrangement with Greece, does not measure the same thing than it does prior to the Maastricht Treaty. Under EMU, the monetary trilemma has become a dilemma and changed from representing the continuous decision-making of states to representing one single substantive decision.

The second issue with figure 4.3 comes from the fact that it measures the realization of differentiation opportunities against countries' currency fixity as well as the question of whether they allow for the free movement of capital. In fact, however, the concept of monetary policy autonomy dictates that states need to realize only one of these differentiation opportunities to realize monetary policy autonomy. As I argued before, if states want to protect their monetary policy autonomy, they must either keep exchange rates flexible or protect capital movements. As such, while figure 4.3 allowed for an insightful visualization of the topic, it does not measure the dependent variable exactly as conceptualized.

In the following, I conduct a logistic regression analysis to inquire why states realize differentiation opportunities. I do so by taking note of the above reservations. Prior to 1991, I code DI on a yearly basis, coding the realization of a differentiation opportunity whenever a state either protects its currency flexibility or its capital movements or does both at the same time. Post-Maastricht, I code the existence of capital mobility for all states and measure a differentiation from the fixing of 
their exchange rates only for Sweden, Denmark and the UK. I measure this latter setting at only one point in time to reiterate the fact that states have taken only one substantive decision when it comes to EMU. Please note that the analysis for EMU thus comes with major limitations, most importantly a small sample size, which makes my findings more illustrative than conclusive.

As table 4.1 shows, I find that while inflation rates explain the use of differentiation opportunities prior to EMU, values of euroscepticism explain the use of differentiation opportunities thereafter. I also find that inflation rates are unable to explain DI in EU monetary policy under EMU, whereas euroscepticism is unable to do so prior to EMU. Finally, I find that higher values of inflation are correlated to higher values of DI prior to EMU, whereas higher values of euroscepticism are correlated to higher values of DI under EMU. In sum, I find that while macroeconomic discipline explains why states did or did not opt for monetary policy cooperation in the currency snake and the EMS, euroscepticism explains states' monetary policy preferences under EMU. I thus find my hypotheses to be supported.

\begin{tabular}{|c|c|c|c|c|}
\hline & \multicolumn{2}{|c|}{$1972-1991$} & \multicolumn{2}{|c|}{ 1992-2009 } \\
\hline & Coeff. & SE & Coeff. & SE \\
\hline Inflation & $0.25 * * *$ & 0.07 & 0.47 & 0.66 \\
\hline Euroscepticism & 0.02 & 0.05 & $0.35 * * *$ & 0.12 \\
\hline Constant & -1.11 & & $-9.41 * *$ & \\
\hline $\mathrm{N}$ & 194 & & 15 & \\
\hline Log pseudolikelihood & -94.58 & & -3.24 & \\
\hline
\end{tabular}

Table 4.1: Logit models of probability that country realizes DI

My findings remain robust with different model specifications. Most importantly, my main argument suggests that it makes sense to introduce year-dummy variables into my model. Doing so allows me to disentangle whether or not my independent variables really effect the dependent variable at the respective points in time. For the post-EMU period of time, this makes no difference, as I here measure only one point in time. For the pre-Maastricht period, doing so does not change anything with the direction or significance of my results, but leads to a substantially stronger coefficient for the effect of inflation on DI ( 0.55 as compared to 0.25 in the original model). The introduction of robust country-clustered standard errors does 
not change any significance levels. When I introduce country-dummy variables, both independent variables become statistically significant on the $\mathrm{p}<0.05$-level prior to EMU, whereas values of euroscepticism beyond $21.98 \%$ perfectly predict the realization of differentiation opportunities thereafter. This suggests that differences in inflation rates and euroscepticism do not just explain the cross-sectional logic of DI, but also their temporal ones. The fact that the temporal development of inflation rates is significantly correlated to the realization of DI of individual countries again broadly validates the framework I employ in this study.

I proposed that the increasing politicization of European monetary integration would change the determinants of DI in EU monetary policy over time. The results from table 4.1 largely support this argument. To be sure, this finding is strongly supported by our existing theoretical, empirical and narrative knowledge on the topic. As Sandholtz concludes $(1993,25)$, national political leaders did not undertake discussions of monetary union to satisfy the demands of pro-integrationist publics or, for that matter, conduct opinion surveys to establish the views of the electorates until the initiative towards EMU was well under way. Mass opinion was a permissive condition of EU monetary policy integration rather than a driving force; generally favorable public opinion granted national leaders wide leeway in which to work in the direction of EMU. This changed, however, with the Maastricht Treaty. As European integration grew in scope and depth, it proved ripe for politicization. Especially, the process of legitimating the Maastricht Treaty opened the previously isolated, complex elite bargain behind it to public scrutiny and alerted publics to the fact that European integration was increasingly contesting national sovereignty (for the entire argument, see Hooghe/Marks 2008). One indicator to support this argument can be found in the proportion of statements devoted to European issues in national electoral campaigns, which increased from $2.5 \%$ in the 1970 s to $7 \%$ in the 1990s (Kriesi 2007). A similar indicator can be found in those studies that suggest that the proportion of social movement protest oriented at the EU has increased from around $5 \%$ to $10 \%$ in the 1980 s to between $20 \%$ and $30 \%$ in the 1990 s (e.g. Imig 2004; Tarrow 2005). While this list is by no means exhaustive, it captures the general argument about the increasing politicization of European integration in the literature, which is generally uncontested. All said, I thus conclude that DI in EU monetary policy is the result of the iterative re-formulation of national preferences under the impression of increasing economic interdependence and an increasing 
depth and politicization of European integration.

Finally, while we cannot directly interpret the size of the effects reported in table 4.1. I can simulate the the predicted probability that a country realizes a differentiation opportunity in EU monetary policy based on the models reported in it. Figure 4.4 shows the substantive effect of inflation rates and euroscepticism on the probability that a country obtains a differentiation from EU monetary policy. The $95 \%$ confidence interval indicates that the probability of low-inflation countries to realize a differentiation opportunity prior to EMU was between $15 \%$ and $45 \%$, whereas the probability of high-inflation countries was close to $100 \%$. In fact, the lowest values of inflation have constantly been measured in Germany, which realized no differentiation opportunity at all, while the highest value of inflation prior to 1991 is 24\%, logged in by the UK in 1975 and Greece in 1981, respectively, who both realized a fair share of differentiation opportunities. At the same time, the probability of very euro-friendly countries to realize a differentiation opportunity was almost $0 \%$ under EMU, whereas the chances of very eurosceptical countries to realize a differentiation opportunity reached from $75 \%$ and $100 \%$. In fact, Sweden shows a value of euroscepticism of $31 \%$ under EMU and has realized its differentiation opportunity. We thus see that the effects of both inflation and euroscepticism are rather powerful and quite precisely predict the realization of differentiation opportunities in EU monetary policy.
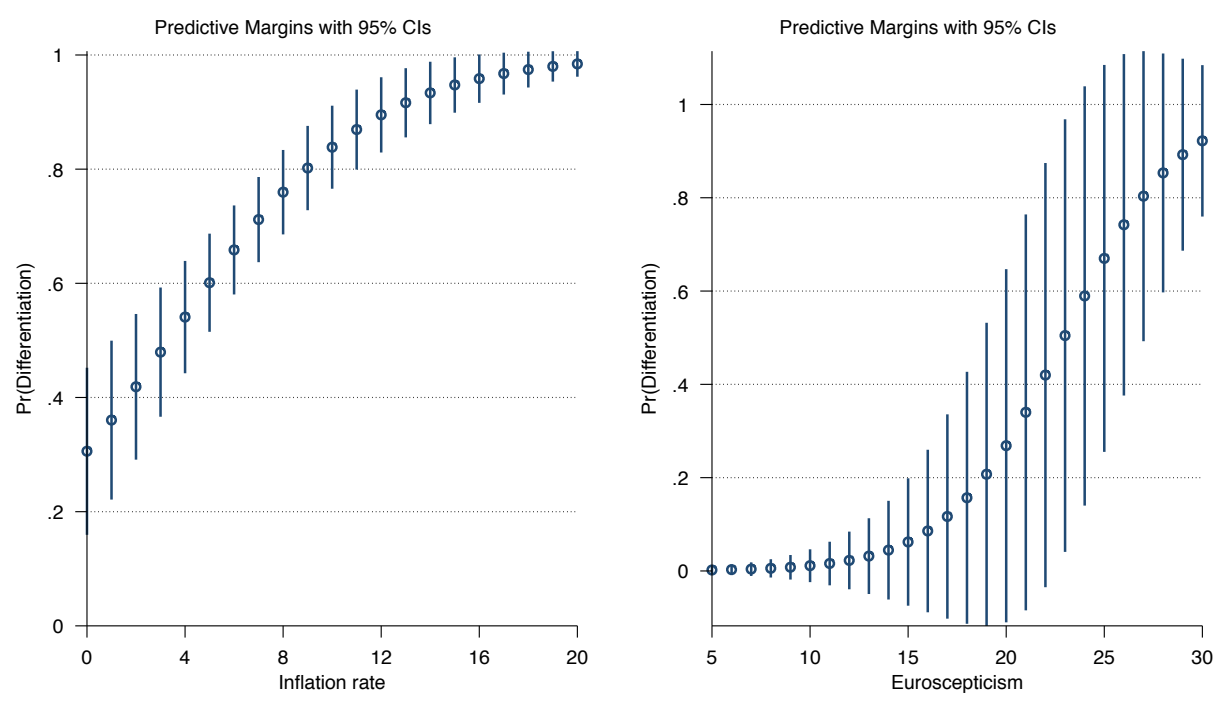

Figure 4.4: Effects of inflation rates and euroscepticism on DI 


\subsection{Conclusion}

This study offers an extensive investigation of differentiation in EU monetary policy. I propose in a simple political economy framework on the basis of liberal intergovernmentalist conjectures that the differentiated character of European monetary integration is the result of the iterative re-formulation of national preferences under the impression of an increasing convergence towards macroeconomic discipline and an increasing depth and politicization of European integration. I find support for these ideas in that I find that while it is macroeconomic discipline that explains monetary policy preferences prior to the Maastricht Treaty, it is public opinion that explains monetary policymaking thereafter. I also find that DI in EU monetary policy decreases with interdependence and the depth of European integration. As such, I argue that liberal intergovernmentalism is able to convincingly explain the extent and development of DI in EU monetary policy.

This study leaves a number of opportunities for further research. To begin with, while I tried to refer to the respective narratives whenever possible, I only tested the correlational applicability of my hypotheses, but not their causal attributes, and have left numerous causal links untouched. The causal chain I proposed with regard to macroeconomic discipline, inflation rates, market preferences and DI, for instance, is a rather complex one. It includes a number of statements - for instance, about how inflation rates are influenced by macroeconomic policymaking and how markets react to these inflation rates - which I was not able to study in more detail. This is not uncommon or necessarily problematic, but further inquiry into these questions would nevertheless be more than worthwhile. On a similar note, the statistical treatment of my hypotheses has remained rather basic. This is in part due to the nature of our dependent variable, but for the more methodologically inclined, my hypotheses may certainly offer more rewarding opportunities.

Furthermore, I find it interesting how steady DI in EU monetary policy declines, for it questions the centrality of state actors in European monetary integration. While not at the heart of this study, I here refer to the idea that less state-centric approaches might in fact expect the decline of DI in EU monetary policy to happen gradually due to processes of institutionalization and supranationalization. From an institutionalist perspective, we would expect the EU's broader institutional structure, once movement toward the supranational pole has begun, to become a dy- 
namic on its own and thus the respective actors to use the powers at their disposal to expand the scope of the EU and hence to decrease the degree of differentiation. Monetary integration is a particular case in point of these potential processes, for it was the Commission and other supranational bodies that were arguing - and indeed preparing - for EMU even at times when national governments were still opposed to the idea (e.g. Verdun 1999, James 2012). From a post-functionalist perspective, we would expect that once cooperation in a policy area has begun, the frequent exposure of state representatives to one another harmonizes their preferences, potentially again leading to a decrease of differentiation over time (e.g. Checkel 2005; 2007). Again, monetary integration may be a particular case in point here, for the cooperation in monetary policymaking is, as we have seen throughout this study, an intensive and longstanding one. These arguments find support by the fact that DI in EU monetary policy has decreased steadily over time and not rapidly with the Maastricht Treaty and highlight that the role of national actors as well as the dynamics of institutionalization and socialization ought to be researched more carefully.

Also, a conversion towards macroeconomic discipline might not just result from exogenous pressures, but may also be the result of ideational, endogenous processes. In the argument about a neoliberal revolution, structural conditions set the parameter under which governments decide, but do not tell us about what policy choices governments make when faced with these structural constraints (e.g. Helleiner 1994; Jabko 1999; Parsons 2003). After all, governments could choose to accept, or try to reduce, the costliness of their policy choices. And still, there are good arguments to also expect a development towards macroeconomic discipline from an ideational perspective, including the perceived failure of Keynesianism in the wake of the first oil crisis, an alternative policy paradigm (monetarism), as well as the German policy success (McNamara 1998; 1999; 2006). I am not able to pin down the sources of these development in the scope of this study. However, as I do not try to engage in competitive theory-testing in this study, but rather attempt to bring forth a liberal intergovernmentalist approach to DI in EU monetary policy, my treatment of alternative approaches must necessarily remain limited.

In the same vein, I left numerous explanatory approaches untouched in the very first place. As I already stated, the literature on European monetary integration is extensive. In this study, I only tried to investigate the explanatory power of liberal intergovernmentalism. At the same time, the explanatory approaches that I have 
chosen are abstract enough so that they allow for the subsumption of other explanatory approaches. The debate about the role of macroeconomic discipline includes, for instance, a debate about the preferences of states to tie their monetary policies to those of more credible counterparts (e.g. Giavazzi/Pagano 1988). On a similar note, debates about the role of left-right considerations are somewhat subsumed in the debate about the role of public opinion (e.g. Oatley 1999; 2012). While these are for themselves important approaches with their own logic and indicators, I propose that the study at hand covers a comparatively large space of such alternative explanatory approaches, although obviously only in a superficial fashion. Second, I propose that my explanation for DI in EU monetary policy is meaningful enough to defend its limited scope. It gives an explicit and empirical backing to a very widespread understanding of the process of European monetary integration in both academia and the general public. It is also in this sense that my dependent variable has proven to be worthwhile, for it has allowed me to study the role of macroeconomic policymaking and public opinion against one single dependent variable over time, thus allowing me to come to my conclusions altogether.

Finally, I find it notable that my analysis also adds to the literature on the vertical integration of EU monetary policy (see Leuffen et al. 2013, 143-155). This is especially true given my findings about the decreasing role of macroeconomic discipline and indiscipline. For, in that I find that macroeconomic policymaking looses in explanatory power over time, I lend further credibility to the perspective that the prospects of macroeconomic discipline were a necessary precondition for talks on monetary union. This refers to the arguments of Sandholtz (1993, 10), who proposes that the hard-currency countries were only willing to initiate further steps of monetary integration in light of this convergence of domestic political economies. Otherwise, they would have been unwilling to tie themselves to their inflationary partners and their partners would have been unwilling to sacrifice national economic strategies based on expansionary policies. Only now could the spillover effects from the common market project (e.g. Haas 1968), the perceived asymmetry in the EMS (e.g. Grieco 1995) or German interests (e.g. Kaltenthaler 2002) be turned into productive use and targeted at the build-up of a monetary union in Europe. In EU monetary policy, but perhaps in all of European integration, the relationship between the determinants of horizontal DI and the drivers of vertical integration is an intricate one that deserves to receive more attention. 


\section{Conclusion}

In chapter 1. I investigated the extent and development of DI, applied a liberal intergovernmentalist framework to the topic, proposed that the EU must be understood as a system of differentiated integration and discussed the normative value of DI. The subsequent chapters of this thesis touched upon all of these topics in greater detail. In the remainder, I take stock of what I learned from my substantive inquiries beyond the more specific lessons that already became apparent in each of the respective chapters. What, in other words, do my findings tell us about the idea of the EU as a system of differentiated integration, about the normative value of DI and about the validity of the liberal intergovernmentalist framework? And what do they tell us about the common narratives on DI, according to which DI is constantly on the rise due to the increasing width and depth of European integration and cannot be explained with the existing theories of European integration?

\section{The EU as a system of differentiated integration}

Throughout this study, I find support for the notion that the EU must be conceptualized as a system of differentiated integration. The EU started with only six Member States in the 1950s and set out to create a common market. Today, it consists of 28 Member States and touches upon a broad range of policy areas. While the defining features of European integration are thus on first sight those of deepening and widening, I showed in chapter 1 that a number of scholars propose that the EU must be understood as a system of differentiated integration. This thesis' findings largely validate that proposition. Measured as a share of legal acts or treaty articles in force, more than $30 \%$ of EU primary and secondary law has at times been of a differentiated character. Even when measuring individual differentiations in relation to differentiation opportunities, which is a rather conservative measurement of DI, up to $12 \%$ of differentiation opportunities in EU primary law have at times 
been realized. Also, almost $40 \%$ of all new legal acts have been of a differentiated character in EU secondary law in the early 1970s. Not least, I found that differentiation has been the norm rather than the exception in EU monetary policy, as Member States realized up to $80 \%$ of their differentiation opportunities in EU monetary policy in the late 1970s. These numbers make apparent that DI is an important feature of European integration. Although its development is not as straightforward as the common narrative on the topic suggests, differentiation is a core ingredient of European integration.

\section{Normative interpretations of DI}

In chapter 1, I proposed that differentiated integration is often discussed against the background of whether it fosters or compromises European integration or, in other words, of whether or not it threatens the authority of the EU's political order. I have shown that where the contra-differentiation group sees DI as an expression of national sovereignty and thus a danger to the idea of European integration, the pro-differentiation camp sees DI as part of an opportunity of allowing those who want to move ahead to do so, of overcoming gridlock in bargaining situations and of enabling secondary effects from integration. Where differentiation is essentially the beginning of the end of European integration for the skeptics, it is an enabling factor of European integration to those in favor of the concept. What, then, have we learned about these questions from the study at hand?

To begin with, we learned about the importance of distinguishing between constitutional and instrumental differentiation. To reiterate, I found in chapter 2 that we must distinguish between constitutional DI, which is concerned with opting-out from new treaties or with treaty revisions, and instrumental DI, which is concerned with the often transitory differentiations that acceding Member States are allowed to realize. As I have shown, in line with the contra-differentiation camp, constitutional DI is largely the result of concerns of sovereignty and national identity and has the character of preserving national competencies. It is opting-out in the more negative understanding of the term. On the other hand, instrumental DI is largely in line with the conjectures of the pro-differentiation camp, for here, DI is about allowing new and relatively poor Member States to join the EU and thus to advance the authority of the EU's political order. With instrumental DI, differentiation allows Member States to overcome gridlock in bargaining situations and thus ultimately 
enables rather than compromises European integration.

While à la carte-differentiation is rejected outright by the European institutions as well as many European policy makers and scholars of European integration, the existence of constitutional DI shows that it nonetheless plays a prominent part in European integration. At the same time, I argued in chapter 1 that by understanding DI in the logic of multi-speed DI, the idea of DI could indeed be combined with the Monnet method of European integration and leave the European idea intact. To be sure, we do not yet know whether or not constitutional differentiations, such as the opt-outs of the UK and Denmark from the common currency, are permanent or not. Even though the respective differentiations do not expire automatically, countries may still at any time decide to participate in the respective policy areas. If they were to do so, these supposedly permanent differentiations would just have been another iteration of multi-speed Europe. In the same vein, it is entirely possible that temporary differentiations become permanent at a later point in time and that hence instrumental differentiation serves to protect national autonomy at one point or another. But given our present knowledge, we must concede that both multispeed Europe and à la carte Europe are a reality of European integration. The same is also true for variable geometry DI, which remains, however, ambiguous in terms of its normative interpretation.

Authors such as Ruggie (1993) or Stubb (2002) argue that as differentiation allows for further integration, it also allows for secondary effects from that integration, which in turn brings forward the unity of the EU and thus the authority of the EU's political order. These authors essentially suggest that unity can only be achieved by allowing for differentiation first. This argument potentially applies to both EU primary and secondary law. In chapter 3, I studied its merits against the development of DI in EU secondary law and could show that it does only partially apply. I found no effects from delegation except in market policies, where states can expect the greatest potential gains, the least potential costs and the most uncertainty about future contingencies from incomplete contracting. This suggests that the principals of European integration keep tight control over their agents, only enabling secondary effects from institutionalization, but not socialization, and only in specific policy areas. As such, the idea that integration has broad and general effects on differentiation must be contested.

Chapter 4 offers yet another perspective on the relationship between integration 
and differentiation. Here, I find that differentiated integration can indeed lead to unitary integration over time. We saw that up to more than $80 \%$ of differentiation opportunities were used in EU monetary policy at some point in time. We also saw, however, that that number comes down to roughly $10 \%$ under EMU. Throughout this process, countries moved through different institutional settings. Initial steps of integration offered much flexibility and thus allowed states to experiment with their policy choices. Over time, states settled on a more rigid setting of monetary policy cooperation. The driving forces of that development are manifold, including the role of interdependence and politicization. I also conjectured, however, that the increasing depth of European integration affected the cost-benefit analyses of governments. In this vein, early and flexible steps of differentiated integration also contributed to the realization of more unitary and rigid forms of cooperation over time.

The above makes clear that the normative content of DI is rather intricate. From the perspectives that I looked at the topic in this study, it becomes apparent that the normative content of DI varies between different manifestations of the phenomenon and can thus not be judged on a general level. In normative terms, DI is not just good or bad, but can be either.

\section{Evaluating the liberal intergovernmentalist framework}

Throughout this thesis, I find that governments are indeed the key actors of European politics. In fact, the idea of a centrality of governmental preferences is a key ingredient in all of my substantive chapters. In chapters 2 and $4 \mathrm{I}$ argue that economic and ideational preferences such as wealth, macroeconomic discipline or euroscepticism convincingly explain the extent and development of DI. I do so with reference to the argument that the respective indicators reflect societal preferences, but that these societal preferences are pursued by governments in search for their re-election. As such, governments and governmental preferences are at the core of these chapters. Things are a bit more complicated with regard to chapter 3, but essentially the same. For in chapter 3 , in that I only find secondary effects from European integration in market policies, I find that governments, as principals, exert control over the European institutions, as their agents.

I also find the role of interdependence to be as conceptualized. I did not study the cross-sectional attributes of this argument, for which I would have had to conduct an 
analysis based on differences in interdependence between countries or policy areas. However, I find reference to the temporal applicability of this argument in chapter 4. Here, I hypothesize that increasing economic interdependence leads to increasing negative policy externalities for certain governments and hence ultimately to a convergence of monetary policy preferences. In that I find support for my hypothesis, I give great credibility to the idea of a centrality of interdependence, at least in EU monetary policy, and at least with reference to the effects of increasing economic interdependence over time.

In chapters 3 and 4 I find support for the argument about the centrality of politicization. In chapter 3, I find hints of an important qualitative difference between politicized and non-politicized policy areas. More specifically, I find that the level of delegation to supranational institutions exerts a statistically significant, negative effect on DI in the field of non-politicized market policies, whereas it does not do so in the similarly supranationalized, but substantially more politicized policy area of regulatory policies. In chapter 4, I find substantial support for the role of politicization in that I find that whereas macroeconomic discipline is able to explain DI in EU monetary policy prior to the 1980s, euroscepticism is able to do so thereafter and thus after the politicization of European integration. In both cases, I find support for the key argument behind the concept of politicization, namely that it plays a counter-part to interdependence in the sense that where interdependence facilitates unitary integration, politicization creates obstacles for that process.

Finally, I conjecture in chapter 1 that states only delegate powers to the EU where they can benefit from this incomplete contracting and thus where their potential benefits are high, the potential costs low and the future contingencies are largely unclear. I base my argument on the idea of incomplete contracting as proposed by Garret and Weingast (1991) and Andrew Moravcsik (1993). In chapter 3, I argue that these conditions are best given in market policies and thus hypothesize that I only expect effects from the supranationalization of competencies on DI in market policies. This is exactly what I find in my analysis. As such, I largely substantiate the rationalist institutionalist approach of liberal intergovernmentalism and hence another part of my general theoretical framework as introduced in chapter 1 . The above makes apparent that liberal intergovernmentalism offers a powerful starting point to analyze the extent and development of DI in EU primary and secondary law. 


\section{Extent and development of DI}

Now that I found that liberal intergovernmentalism does indeed offer fruitful approaches to DI, it is also time to come back to the idea that DI is constantly on the rise due to the increasing width and depth of European integration. I repeatedly highlighted the deficiency of this narrative. In chapter 1, I find that the extent and development of DI in EU primary and secondary law shows a sideways tendency and that DI varies substantially across Member States and policy areas. I thus conjectured that DI is not just about the development of the EU on the system-level, but also about the attributes of individual EU Member States and policy areas. I find general support for this conjecture. In chapter 2, I find that whereas system-level heterogeneity exerts rather ambiguous effects on DI in EU primary law, the economic and ideational attributes of individual EU Member States robustly explain the realization of differentiation opportunities. In chapter 4, I find that states are influenced asymmetrically by the costs of monetary policy cooperation and that the extent of DI in EU monetary policy decreases rather than increases with the amount of policy areas integrated into the EU. With regard to DI across policy areas, chapter 3 shows that policy areas are not equally susceptible to differentiation and that the driving forces of DI across policy areas differ substantially. My findings thus show that although the common narrative cannot be unequivocally rejected, it must at least be seriously questioned. The development of DI in EU primary and secondary law is substantially more complicated than the common narrative suggests, while the key role in this complexity goes to the relationship between what I have called system-level heterogeneity in chapter 2 and the attributes of individual Member States and policy areas.

\section{A new common narrative on DI}

It is time, then, to propose a new narrative on the extent and development of DI in EU primary and secondary law. To begin with, I find in this study that different forms of DI are influenced by different explanatory factors. More specifically, while the extent and development of DI to preserve national autonomy is found in ideational considerations, DI that corresponds to capabilities and overcoming gridlock in bargaining situations is defined by economic considerations. I also find, however, that the driving forces of DI must be expected to differ across time and 
following the logic of both interdependence and politicization. This basically results in an argument about both the cross-sectional and the time-series behavior of DI that alludes to a limited number of concepts, namely wealth, euroscepticism, interdependence and politicization. I thus propose that DI does not increase with the width and depth of European integration, but with the distribution of wealth and euroscepticism across countries, with the susceptibility of policy areas to economic and ideational considerations as well as with the development of interdependence and politicization over time. While this is certainly not as intuitive and clear-cut as the common narrative, it offers a wealth of interesting research questions and hypotheses to investigate in more detail.

\section{A note on current developments}

One of the most interesting questions this thesis touched upon is the one about the relationship between interdependence and politicization. I find it fitting that Leuffen et al. $(2013,268)$ also dedicate, as I am doing here, one of the very last paragraphs of their book to this topic. Whatever governments will do to resolve the problems of European integration, they write, is likely to increase politicization. Politicization, however, is likely to increase DI. Having gone through this thought-process, my faith in the notion of an ever closer union has certainly been tested. Consider that the last few years have witnessed intense conflict in the EU that was largely defined by exactly the interplay of interdependence and politicization. The outbreak of the eurozone crisis was largely influenced by interdependence in the form of the interconnectedness of the global financial system (e.g. Krugman 2008, Roubini 2010), while its regional contagion was largely due to the interdependence of European financial markets (e.g. de Grauwe/Ji 2012, Shambaugh 2012). Interdependence thus created negative policy externalities on states which they were increasingly unable to cope with unilaterally. In the past, as we have seen in chapter 4, this has led to steps of integration. But today, despite a very similar situation, we find few largescale, primary-law attempts at further integration. Despite the immense increase in interdependence, in other words, the politicization of European integration prohibits further steps of substantial integration. I thus find it likely that the idea of the EU as a system of differentiated integration is going to receive much more importance in the years to come.

And yet, we learned in the study at hand that the interplay of interdependence 
and politicization is highly complex. Scholars and practitioners alike proposed, at numerous instances, that now would be the time that the EU would only be able to progress if it would allow for more differentiation. This is true for Leo Tindemans in the 1970s just as it is true for Joschka Fischer in the year 2000. And yet, as we saw, DI in EU primary and secondary law develops, by most measurements, more or less sideways. In light of the recent eurozone crisis, it is rather compelling to declare yet another time that the era of differentiation is just around the corner (e.g. Leruth/Lord 2015, 756). If the study at hand taught us anything, however, then it is that we must differentiate between the potential for instrumental DI and constitutional DI and the susceptibility of policy areas and countries to the dynamics of wealth and euroscepticism. This finds reflection in the fact that DI has developed sideways in the last couple of years and that the countries that realized differentiation opportunities from new treaty obligations and treaty revisions were the existing champions of DI. In fact, from the old Member States, only Sweden, Denmark and the United Kingdom opted out from the ESM Treaty, while Sweden and the United Kingdom do not participate in the TSCG. The current developments thus largely correspond to my previous findings.

\section{Concluding remarks}

The EU is not a unitary entity in which states sometimes manage to opt-out from certain obligations, but a system of differentiated integration (also see Leruth/Lord 2015; Warleigh-Lack 2015). Understood like this, studying DI allows us to build on our narrative and theoretical understanding of European integration. The topic of DI almost naturally leads to the topics of preference heterogeneity and delegation, for instance, which I investigated in the above. An interest in DI also helps us to understand that the logic of European integration differ across policy areas, which motivated me to inquire the extent of DI in one particular policy area, namely EU monetary policy. But this list is by no means exhaustive. I only researched a certain amount of mainly liberal intergovernmentalist conjectures. I left an enormous amount of topics untouched even in a strictly liberal intergovernmentalist framework. I almost entirely ignored supranationalist and post-functionalist propositions and did not go into any more depth in any other policy area than in EU monetary policy. In other words, the study of DI still offers numerous opportunities for further inquiry. The scope of this potential advancement becomes apparent in the 
study of Leuffen et al. (2013), who offer an extensive treatment of potential research questions and hypotheses. Armed with a new common narrative on the topic, understanding the EU as a system of differentiated integration and the EUDIFF dataset offers a fruitful research agenda to students of the EU.

Throughout my thesis, I tried to elaborate on the explanatory power of liberal intergovernmentalism. At no point did I want to suggest that liberal intergovernmentalism is superior to its competitors. Neither does the fact that I found support for my hypotheses exclude the possibility that supranationalist or post-functionalist hypotheses may also be supported. In other words did I not try to engage in competitive theory testing, but in bringing forward and investigating plausible liberal intergovernmentalist conjectures with regard to the extent and development of DI in European integration. It certainly is true that no single theory of European integration is able to explain all instances of DI. Perhaps only a synthetic theoretical framework is able to conclusively shed light on DI in the European Union (Leuffen et al. 2013, 259-267). But this is obviously always true for any subject of social science research. Even more importantly, it is a bit premature. Before we may want to come up with a synthetic framework of DI in European integration, we might as well put more effort into the application of our existing theoretical toolbox.

Every now and then, the study of European integration is said to have reached its limits. With every major step of integration, some propose that the EU has reached its institutional boundaries. With every iteration of integration theory, others see these theories perfected - or outdated altogether. But just as the EU will not stop developing, integration theories will always be subject to change. With the eurozone crisis, new impetus has been given not just to the advancement of the EU, but also to integration theories. Already, the theory-carousel has started to spin again (e.g. Schimmelfennig 2014; Niemann 2015; Verdun 2015). With the EUDIFF dataset on differentiation in the EU, we now have an additional dependent variable to test our conjectures. As DI gives importance to supplementary developments and perspectives and is likely to remain a key feature of the EU, the topic will certainly remain with us for some time to come. While the results of my thesis will thus always be tentative, I hope that I helped to move the study of DI into the spheres of positive, cumulative and theory-oriented research. 



\section{Bibliography}

Abdelal, Rawi. 2007. Capital Rules. The Construction of Global Finance. Cambridge, Massachusetts and London: Harvard University Press.

Adler-Nissen, Rebecca. 2008. "The Diplomacy of Opting-Out: a Bourdieudian Approach to National Integration Strategies." Journal of Common Market Studies 46(3): 663-684.

Adler-Nissen, Rebecca. 2009. "Behind the Scenes of Differentiated Integration: Circumventing National Opt-Outs in Justice and Home Affairs." Journal of European Public Policy 16(1): 62-80.

Adler-Nissen, Rebecca. 2011. "Opting Out of an Ever Closer Union: The Integration Doca and the Management of Sovereignty." West European Politics 34(5): 1092-1113.

Adler-Nissen, Rebecca. 2014. Opting Out of the European Union: Diplomacy, Sovereignty and European Integration. Cambridge: Cambridge University Press.

Andrews, David M. 1994. "Capital Mobility and State Autonomy: Toward a Structural Theory of International Monetary Relations." International Studies Quarterly 38(2): 193-218.

Bearce, David H. 2007. Monetary Divergence. Domestic Policy Autonomy in the Post-Bretton Woods Era. Ann Arbor: The University of Michigan Press.

Bearce, David H. 2009. "EMU: The Last Stand for the Policy Convergence Hypothesis?" Journal of European Public Policy 16(4): 582-600.

Blyth, Mark. 2002. Great Transformations. Economic Ideas and Institutional Change in the Twentieth Century. Cambridge: Cambridge University Press.

Checkel, Jeffrey T. 1998. "The Constructivist Turn in International Relations Theory." World Politics 50(2): 324-348.

Checkel, Jeffrey T. 2005. "International Institutions and Socialization in Europe: Introduction and Framework." International Organization 59(4): 801-826. 
Checkel, Jeffrey T. 2007. International Institutions and Socialization in Europe. Cambridge: Cambridge University Press.

Checkel, Jeffrey T. and Andrew Moravcsik. 2001. "A Constructivist Research Program in EU Studies?” European Union Politics 2(2): 219-249.

Chinn, Menzie D. and Hiro Ito. 2008. "A New Measure of Financial Openness." Journal of Comparative Policy Analysis 10(3): 309-322.

Christiansen, Thomas, Knud Erik Jorgensen and Antje Wiener. 2001. The Social Construction of Europe. London: SAGE Publications.

de Búrca, Gráinne. 2000. Differentiation within the Core: The Case of the Common Market. In Constitutional Change in the EU: From Uniformity of Flexibility?, ed. Gráinne de Búrca and Joanne Scott. Hart Publishing pp. 133-172.

de Grauwe, Paul and Yuemei Ji. 2012. "Mispricing of Sovereign Risk and Macroeconomic Stability in the Eurozone." Journal of Common Market Studies 50(6): 866-880.

de Neve, Jan-Emmanuel. 2007. "The European Onion? How Differentiated Integration is Reshaping the EU." Journal of European Integration 29(4): 503-521.

Downs, George W., David M. Rocke and Peter N. Barsoom. 1998. "Managing the Evolution of Multilateralism.” International Organization 52(2): 397-419.

Duttle, Thomas, Katharina Holzinger, Thomas Schäubli, Frank Schimmelfennig and Thomas Winzen. 2013. "The Dynamics of Secondary-Law Differentiation in the European Union.” Presented at EPSA Barcelona.

Dyson, Kenneth and Martin Marcussen. 2010. "Transverse Integration in European Economic Governance: Between Unitary and Differentiated Integration." European Integration 32(1): 17-39.

Eichengreen, Barry. 2008. Globalizing Capital. A History of the International Monetary System. Princeton: Princeton University Press.

Fearon, James D. 1998. "Bargaining, Enforcement, and International Cooperation." International Organization 52(2): 269-305.

Fischer, Joschka. 2000. From Confederacy to Federation: Thoughts on the Finality of European Integration, Speech by Joschka Fischer at the Humboldt University in Berlin, 12 May 2000. In What Kind of Constitution for What Kind of Polity?, ed. C Joerges, Y Méni and JHH Weiler. Florence: European University Institute. 
Fossum, John Erik. 2015. "Democracy and Differentiation in Europe." Journal of European Public Policy 22(6): 799-815.

Frey, Bruno S. and Reiner Eichenberger. 1996. "FOCJ: Competitive Governments for Europe." International Review of Law and Economics 16: 315-327.

Frieden, Jeffry A. 2002. "Real Sources of European Currency Policy: Sectoral Interests and European Monetary Integration." International Organization 56(4): 831-860.

Frieden, Jeffry A. 2004. "One Europe, One Vote? The Political Economy of European Union Representation in International Organizations." European Union Politics 5(2): 261-276.

Garrett, Geoffrey and Barry R. Weingast. 1991. Ideas, Interests and Institutions: Constructing the EC's Internal Market. Berkeley: University of California Press.

Gehring, Thomas. 1998. "Die Politik des koordinierten Alleingangs. Schengen und die Abschaffung der Personenkontrollen an den Binnengrenzen der Europäischen Union.” Zeitschrift für Internationale Beziehungen 5(1): 43-78.

George, Stephen. 1998. An Awkward Partner. Britain in the European Community. Oxford: Oxford University Press.

Giavazzi, Francesco and Marco Pagano. 1988. "The Advantage of Tying One's Hands. EMS Discipline and Central Bank Credibility." European Economic Review 32: 1055-1082.

Glaser, Charles L. 2010. Rational Theory of International Politics. The Logic of Competition and Cooperation. Princeton: Princeton University Press.

Goodman, John B. 1992. Monetary Sovereignty. The Politics of Central Banking in Western Europe. Ithaca and London: Cornell University Press.

Goodman, John B. and Louis W. Pauly. 1993. "The Obsolescence of Capital Controls? Economic Managment in an Age of Global Markets." World Politics 46(1): 50-82.

Grabitz, Eberhard. 1984. Abgestufte Integration: Eine Altermative zum herkömmlichen Integrationskonzept? Kehl am Rhein: N. P. Engel.

Grieco, Joseph M. 1995. "The Maastricht Treaty, Economic and Monetary Union, and the Neo-Realist Research Programme." Review of International Studies 21(1): 21-40. 
Gros, Daniel and Niels Thygesen. 1998. European Monetary Integration. From the European Monetary System to Economic and Monetary Union. New York: Longman.

Gstöhl, Sieglinde. 2015. "Models of External Differentiation in the EU's Neighbourhood: an Expanding Economic Community?" Journal of European Public Policy 22(6): 854-870.

Haas, Ernst B. 1968. The Uniting of Europe: Political, Social and Economic Forces. Stanford: Stanford University Press.

Hall, Peter A. and Rosemary C. R. Taylor. 1996. "Political Science and the Three New Institutionalisms.” Political Studies 44: 936-957.

Hartlapp, Miriam and Gerda Falkner. 2009. "Problems of Operationalization and Data in EU Compliance Research.” European Union Politics 10(2): 281-304.

Hasenclever, Andreas, Peter Mayer and Volker Rittberger. 1997. Theories of International Regimes. Cambridge: Cambridge University Press.

Helleiner, Eric. 1994. States and the Reemergence of Global Finance. From Bretton Woods to the 1990s. Ithaca and London: Cornell University Press.

Hobolt, Sara B. and Patrick Leblond. 2009. "Is My Crown Better than Your Euro? Exchange Rates and Public Opinion on the European Single Currency." European Union Politics 10(2): 202-225.

Holzinger, Katharina and Frank Schimmelfennig. 2012. "Differentiated Integration in the European Union: Many Concepts, Sparse Theory, Few Data." Journal of European Public Policy 19(2): 292-305.

Hooghe, Liesbet and Gary Marks. 2008. "A Postfunctionalist Theory of European Integration: From Permissive Consensus to Constraining Dissensus." British Journal of Political Science 39(1): 1-23.

Hristova, Vassela. 2008. Exit Through the Backdoor? Differentiated Integration in EU Secondary Law. Paper presented at the Annual Meeting of the MPSA National Conference.

Imig, Doug. 2004. Contestation in the Streets: European Protest and The Emerging Europolity. In European Integration and Political Conflict, ed. Gary Marks and Marco Steenbergen. Cambridge: Cambridge University Press.

Jabko, Nicolas. 1999. "In the Name of the Market: How the European Commission Paved the Way for Monetary Union." Journal of European Public Policy 6(3): 475-495. 
Jachtenfuchs, Markus. 2001. "The Governance Approach to European Integration." Journal of Common Market Studies 39(2): 245-264.

James, Harold. 2012. Making the European Monetary Union. The Role of the Committee of Central Bank Governors and the Origins of the European Central Bank. Cambridge and London: Harvard University Press.

Jensen, Christian B. and Jonathan B. Slapin. 2012. "Institutional Hokey-Pokey: The Politics of Multispeed Integration in the European Union." Journal of European Public Policy 19(6): 779-795.

Kaltenthaler, Karl. 2002. "German Interests in European Monetary Integration." Journal of Common Market Studies 40(1): 69-87.

Keohane, Robert O. 1984. After Hegemony. Cooperation and Discord in the World Political Economy. Princeton: Princeton University Press.

Keohane, Robert O. and Joseph Nye. 1977. Power and Interdependence. New York: Longman.

Koenig-Archibugi, Mathias. 2004. "Explaining Government Preferences for Institutional Change in EU Foreign and Security Policy." International Organization 58(1): 137-174.

Kölliker, Alkuin. 2001. "Bringing Together or Driving Apart the Union? Towards a Theory of Differentiated Integration." West European Politics 24(4): 125-151.

Kölliker, Alkuin. 2006. Flexibility and European Unification: The Logic of Differentiated Integration. Lanham: Rowman and Littlefield.

Kriesi, Hanspeter. 2007. "How National Political Parties Mobilize the Political Potentials Linked to European Integration." European Union Politics 8: 83108.

Krugman, Paul. 2008. The Return of Depression Economics and the Crisis of 2008. London: Penguin Books.

Lane, Philip R. 2006. “The Real Effects of European Monetary Union.” The Journal of Economic Perspectives 20(4): 47-66.

Lavenex, Sandra. 2015. "The External Face of Differentiated Integration: Third Country Participation in EU Sectoral Bodies." Journal of European Public Policy 22(6): 836-853.

Lavenex, Sandra and Frank Schimmelfennig. 2009. "EU Rules beyond EU Borders: Theorizing External Governance in European Politics." Journal of European Public Policy 16(6): 791-812. 
Lenaerts, Koen and Piet Nuffel. 2005. Constitutional Law of the European Union. London: Sweet \& Maxwell.

Leruth, Benjamin. 2015. "Operationalizing National Preferences on Europe and Differentiated Integration." Journal of European Public Policy 22(6): 816835 .

Leruth, Benjamin and Christopher Lord. 2015. "Differentiated Integration in the European Union: a Concept, a Process, a System or a Theory?" Journal of European Public Policy 22(6): 754-763.

Leuffen, Dirk, Berthold Rittberger and Frank Schimmelfennig. 2013. Differentiated Integration: Explaining Variation in the European Union. Basingstoke: Palgrave Macmillan.

Lewin, Peter. 2014. "The Meaning and the Implications of Heterogeneity for Social Science Research." Studies in Emergent Order 7: 202-219.

Lord, Christopher. 2015. "Utopia or Dystopia? Towards a Normative Analysis of Differentiated Integration." Journal of European Public Policy 22(6): 783798.

Loriaux, Michael. 1991. France after Hegemony. Ithaca, N.Y.: Cornell University Press.

March, James G. and Johan P. Olsen. 1999. Rediscovering Institutions. The Organizational Basis of Politics. New York: Free Press.

McNamara, Kathleen. 1998. The Currency of Ideas. Ithaca and London: Cornell University Press.

McNamara, Kathleen. 1999. "Consensus and Constraint: Ideas and Capital Mobility in European Monetary Integration." Journal of Common Market Studies 37(3): 455-476.

McNamara, Kathleen. 2006. "Economic Governance, Ideas and EMU: What Currency Does Policy Consensus Have Today?" Journal of Common Market Studies 44(4): 803-821.

Miles, Lee. 2005. The North. In The Geopolitics of Euro-Atlantic Integration, ed. Hans Mouritzen and Anders Wivel. London: Routledge.

Milner, Helen V. 1997. Interests, Institutions, and Information. Domestic Politics and International Relations. Princeton: Princeton University Press.

Monnet, Jean. 1978. Memoirs. London: Collins. 
Moravcsik, Andrew. 1993. "Preferences and Power in the European Community. A Liberal Intergouvernmentalist Approach." Journal of Common Market Studies 31(4): 473-524.

Moravcsik, Andrew. 1998. The Choice for Europe. Social Purpose \& State Power from Messina to Maastricht. Ithaca, New York: Cornell University Press.

Mundell, Robert A. 1961. "A Theory of Optimum Currency Areas." The American Economic Review 51(4): 657-665.

Mundell, Robert A. 1963. "Capital Mobility and Stabilization Policy under Fixed and Flexible Exchange Rates." The Canadian Journal of Economics and Political Science 29(4): 475-485.

Naurin, Daniel and Rutger Lindahl. 2010. "Out in the Cold? Flexible Integration and the Political Status of Euro Opt-Outs." European Union Politics 11(4): 485-509.

Niemann, Arne and Demosthenes Ioannou. 2015. "European Economic Integration in Times of Crisis: a Case of Neofunctionalism?" Journal of European Public Policy 22(6): 196-218.

Oatley, Thomas. 1999. "How Constraining is Capital Mobility? The Partisan Hypothesis in an Open Economy.” American Journal of Political Science 43(4): 1003-1027.

Oatley, Thomas. 2012. International Political Economy. Boston: Pearson.

Obstfeld, Maurice. 1986. "Rational and Self-Fulfilling Balance-of-Payments Crises." The American Economic Review 76(1): 72-81.

Page, Scott E. 2011. Diversity and Complexity. Princeton and Oxford: Princeton University Press.

Parsons, Craig. 2003. A Certain Idea of Europe. Ithaca and London: Cornell University Press.

Pierson, Paul. 1996. "The Path to European Integration: A Historical Institutionalist Analysis." Comparative Political Studies 29(2): 123-163.

Pierson, Paul. 1998. The Path to European Integration: A Historical-Institutionalist Analysis. In European Integration and Supranational Governance, ed. Wayne Sandholtz and Alec Stone-Sweet. Oxford: Oxford University Press.

Pierson, Paul. 2000. "Increasing Returns, Path Dependence, and the Study of Politics." American Political Science Review 94(2): 251-267. 
Pierson, Paul. 2004. Politics in Time. History, Institutions, and Social Analysis. New Jersey: Princeton University Press.

Plümper, Thomas and Christina J. Schneider. 2007. "Discriminatory Membership and the Redistribution of Enlargement Gains." Journal of Conflict Resolution 51(4): 568-587.

Polanyi, Karl. 1944. The Great Transformation. The Political and Economic Origins of Our Time. Massachusetts: Beacon Press Books.

Pollack, Mark A. 1997. "Delegation, Agency, and Agenda Setting in the European Community." International Organization 51(1): 99-134.

Pollack, Mark. A. 2001. "International Relations Theory and European Integration." Journal of Common Market Studies 39(2): 221-244.

Pollack, Mark A. 2004. The New Institutionalisms and European Integration. In European Integration Theory, ed. Antje Wiener and Thomas Diez. Oxford: Oxford University Press.

Risse, Thomas, Daniela Engelmann-Martin, Hans-Joachim Knope and Klaus Roscher. 1999. "To Euro or Not to Euro? The EMU and Identity Politics in the European Union." European Journal of International Relations 5(2): $147-187$.

Roubini, Nouriel. 2010. Crisis Economics. A Crash Course in the Future of Finance. London: Penguin Books.

Ruggie, John G. 1982. "International Regimes, Transactions, and Change: Embedded Liberalism in the Postwar Economic Order." International Organization 36(2): 379-415.

Ruggie, John G. 1993. "Territoriality and Beyond: Problematizing Modernity in International Relations." International Organization 47(1): 139-174.

Sadeh, Tal and Amy Verdun. 2009. "Explaining Europe's Monetary Union: A Survey of the Literature." International Studies Review 11: 277-301.

Sandholtz, Wayne. 1993. "Choosing Union: Monetary Politics and Maastricht." International Organization 47(1): 1-39.

Sandholtz, Wayne and Alec Stone-Sweet, eds. 1998. European Integration and Supranational Governance. Oxford: Oxford University Press.

Schimmelfennig, Frank. 2014. "European Integration in the Euro Crisis: The Limits of Postfunctionalism." Journal of European Integration 36(3): 321-337. 
Schimmelfennig, Frank, Dirk Leuffen and Berthold Rittberger. 2015. "The European Union as a System of Differentiated Integration: Interdependence, Politicization and Differentiation." Journal of European Public Policy 22(6): 764-782.

Schimmelfennig, Frank and Thomas Winzen. 2014. "Instrumental and Constitutional Differentiation in the European Union." Journal of Common Market Studies 52(2): 354-370.

Schneider, Christina. 2009. Conflict, Negotiation and European Union Enlargement. Cambridge: Cambridge University Press.

Shambaugh, Jay C. 2012. “The Euro's Three Crises.” Brookings Papers on Economic Activity pp. 1-54.

Solomon, Robert. 1999. Money on the Move. The Revolution in International Finance since 1980. Princeton: Princeton University Press.

Stone-Sweet, Alec and Wayne Sandholtz. 1997. "European Integration and Supranational Governance." Journal of European Public Policy 4(3): 297-317.

Stubb, Alexander C. G. 1996. "A Categorization of Differentiated Integration." Journal of Common Market Studies 34(2): 283-295.

Stubb, Alexander C. G. 2002. Negotiation Flexibility in the European Union. Amsterdam, Nice and Beyond. Basingstoke: Palgrave Macmillan.

Tarrow, Sidney. 2005. The New Transnational Activism. Cambridge: Cambridge University Press.

Taylor, Alan M. and Mark P. Taylor. 2004. "The Purchasing Power Parity Debate." Journal of Economic Perspectives 18(4): 135-158.

Tindemans, Leo. 1975. "European Union: Report to the European Council.” Bulletin of the European Communities 76(1).

Toshkov, Dimiter. 2010. Taking Stock: A Review of Quantitative Studies of Transposition and Implementation of EU Law. Vienna: Institute for European Integration Research.

Tuytschaever, Filip. 1999. Differentiation in European Union Law. Oxford: Hart Publishing.

Vardi, Noah. 2011. The Integration of European Financial Markets. The Regulation of Monetary Obligations. London and New York: Routledge. 
Verdun, Amy. 1999. "The Role of the Delors Committee in the Creation of EMU: an Epistemic Community?" Journal of European Public Policy 6(2): 308-328.

Verdun, Amy. 2015. "A Historical Institutionalist Explanation of the EU's Response to the Euro Area Financial Crisis." Journal of European Public Policy 22(6): 219-237.

Walker, Neil. 1998. "Sovereignty and Differentiated Integration in the European Union." European Law Journal 4(4): 355-388.

Walter, Stefanie. 2013. Financial Crises and the Politics of Macroeconomic Adjustments. Cambridge: Cambridge University Press.

Warleigh-Lack, Alex. 2015. "Differentiated Integration in the European Union: Towards a Comparative Regionalism Perspective." Journal of European Public Policy 22(6): 871-887.

Wasserfallen, Fabio. 2014. "Political and Economic Integration in the EU: The Case of Failed Tax Harmonization.” Journal of Common Market Studies 52(2): 420435.

Webb, Michael C. 1991. "International Economic Structures, Government Interests, and International Coordination of Macroeconomic Adjustment Policies." International Organization 45: 309-342.

Wendt, Alexander. 1992. "Anarchy is What States Make of It: The Social Construction of Power Politics." International Organization 46(2): 391-425.

Wendt, Alexander. 1999. Social Theory of International Politics. Cambridge: Cambridge University Press.

Winzen, Thomas and Frank Schimmelfennig. 2014. "Constitutional and Instrumental Differentiation: Empirical Evidence on the Conditional Impact of Identity and Wealth on Differentiated European Integration." Prepared for the workshop Differentiated Integration at Konstanz University.

Zhelyazkova, Asya. 2014. "From Selective Integration Into Selective Implementation: The Link Between Differentiated Integration and Conformity with EU Laws." European Journal of Political Research 53: 727-746.

Zielonka, Jan. 2001. "How New Enlarged Borders Will Reshape the European Union." Journal of Common Market Studies 39(3): 507-536.

Zielonka, Jan. 2006. Europe as Empire. The Nature of the Enlarged European Union. Oxford: Oxford University Press. 